\title{
RESERVOIR CHARACTERIZATION OF THE LOWER GREEN RIVER FORMATION, SOUTHWEST UINTA BASIN, UTAH
}

\author{
Deliverable 3.1 \\ Report on the Petrophysics and Diagenesis of the Core Samples from \\ Southwest Uinta Basin, Utah \\ by \\ S. Robert Bereskin \\ Tesseract Corp. SLC, UT
}

Contract DE-AC26-98BC15103

C. D. Morgan, Program Manager

Utah Geological Survey

Virginia Weyland, Contract Manager
U.S. Department of Energy
National Petroleum Technology Office

Submitting Organization: Utah Geological Survey

1594 West North Temple, Suite 3110

P.O. Box 146100

Salt Lake City, Utah 84114

(801) 537-3300 
This report was prepared as an account of work sponsored by an agency of the United States Government. Neither the United States Government nor any agency thereof, nor any of their employees, makes any warranty, express or implied, or assumes any legal liability or responsibility for the accuracy, completeness, or usefulness of any information, apparatus, product, or process disclosed, or represents that its use would not infringe privately owned rights. Reference herein to any specific commercial product, process, or service by trade name, trademark, manufacturer, or otherwise, does not necessarily constitute or imply its endorsement, recommendation, or favoring by the United States Government or any agency thereof. The views and opinions of authors expressed herein do not necessarily state or reflect those of the United States Government or any agency thereof. 


\section{TABLE OF CONTENTS}

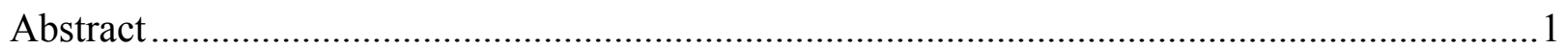

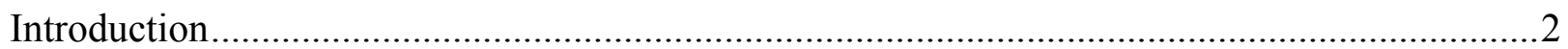

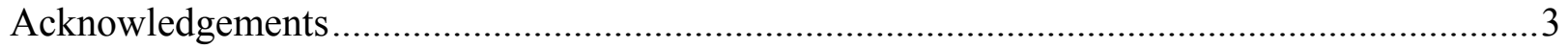

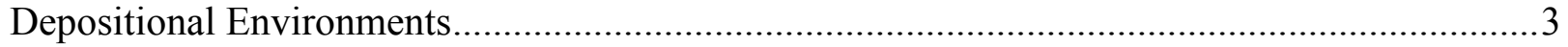

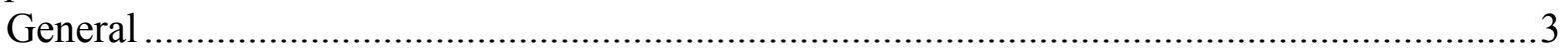

Alluvial Facies ....................................................................................................... 4

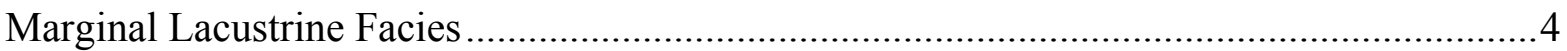

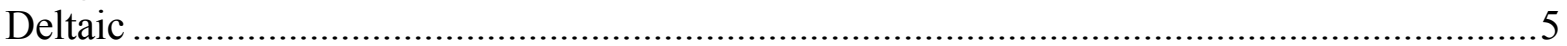

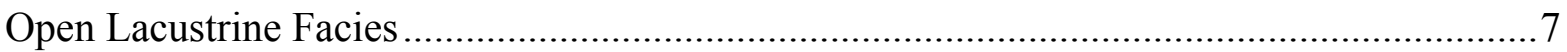

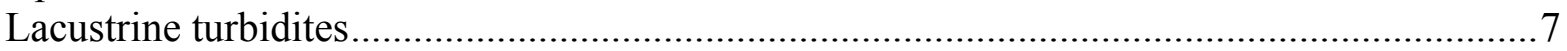

Depositional Environment Summary and Conclusions .............................................. 9

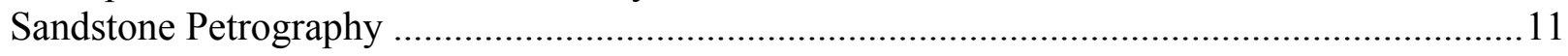

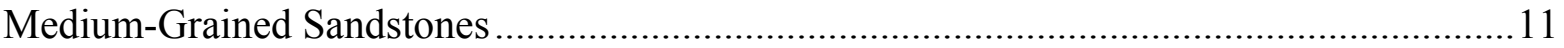

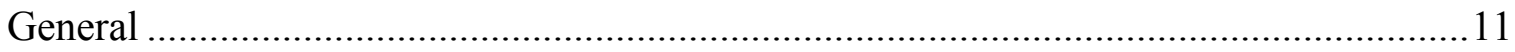

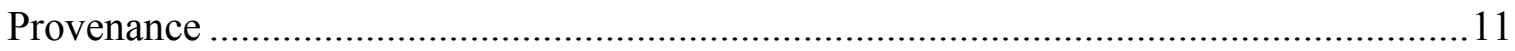

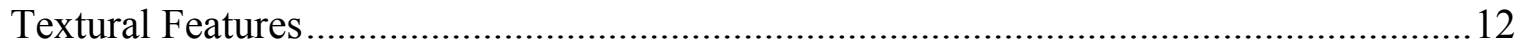

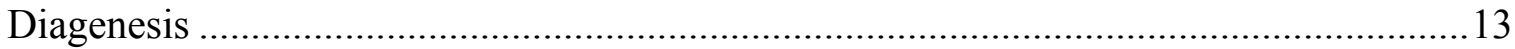

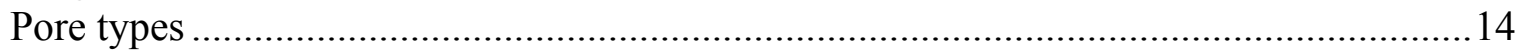

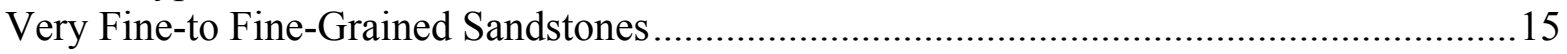

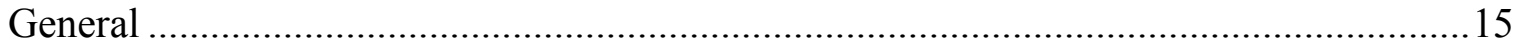

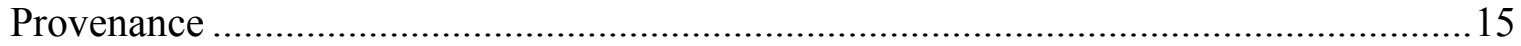

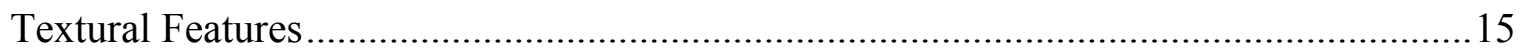

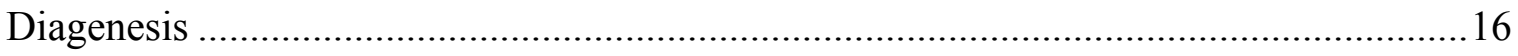

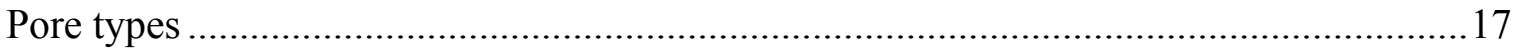

Ripple Drift Laminated Sandstones

(Variation of Very Fine- to Fine-Grained Sandstones)................................................... 18

Very Fine Sand/Coarse Silt of the Lower Douglas Creek Interval

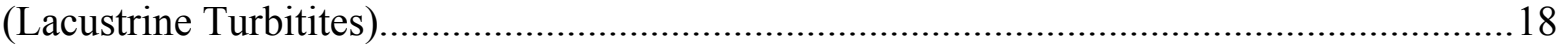

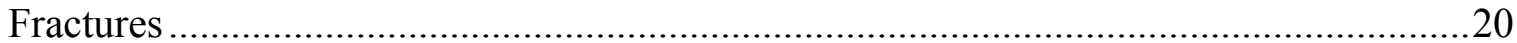

Sandstone Petrologic Summary and Conclusions...........................................................2 21

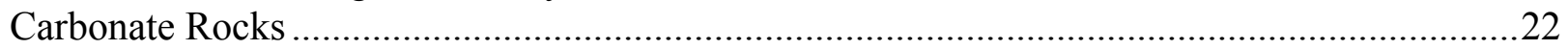

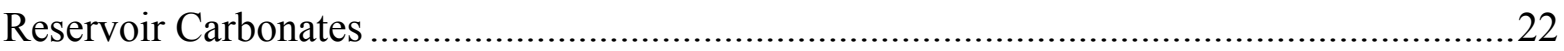

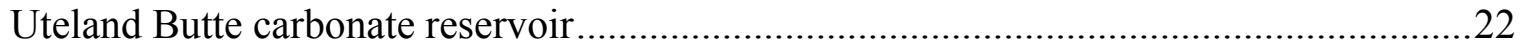

Castle Peak Limestone (carbonate marker, Ryder and others, 1976) ..............................25

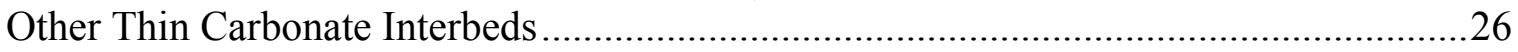

Nonreservoir Lithologies in "Carbonate" Settings .........................................................26

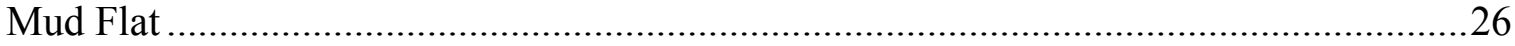

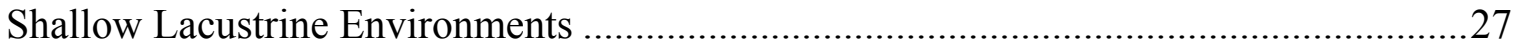

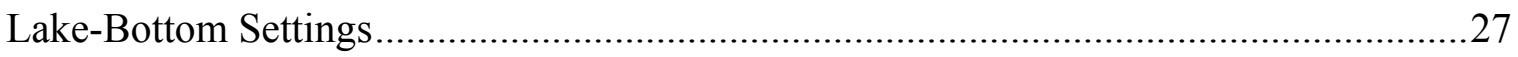

Carbonate Petrology Summary and Conclusions............................................................27

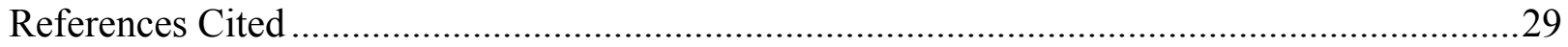

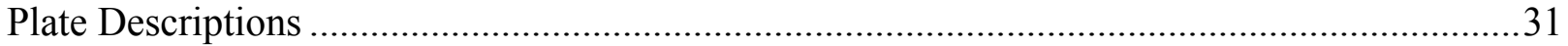

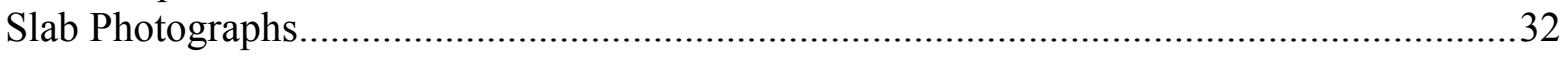




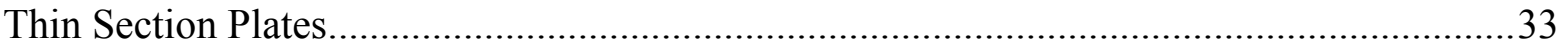

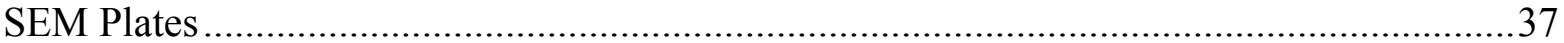

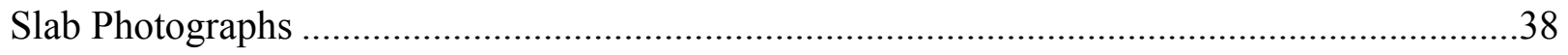

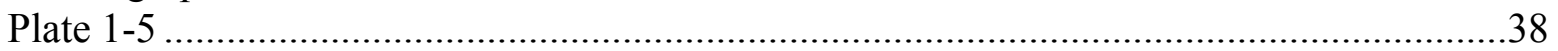

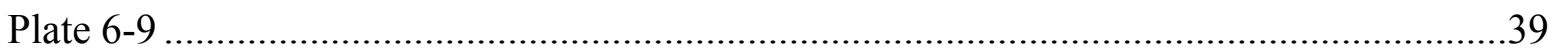

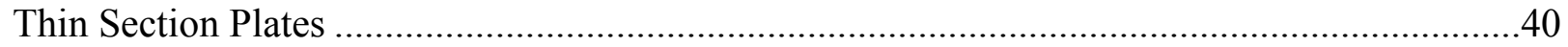

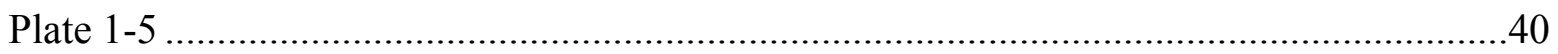

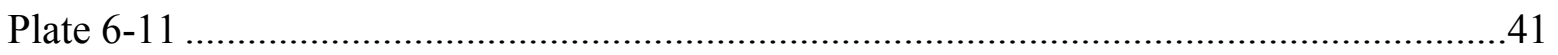

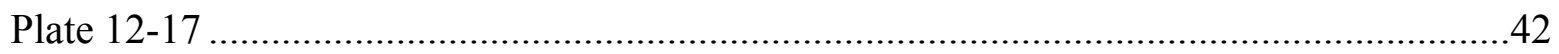

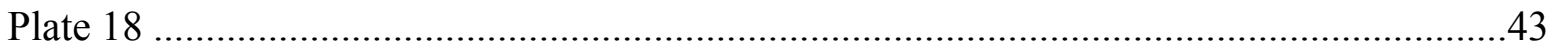

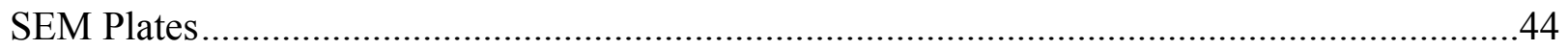

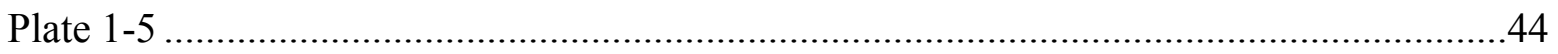

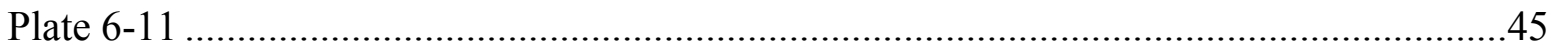

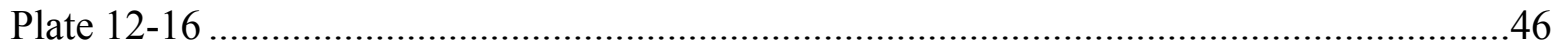

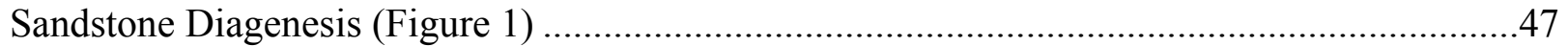

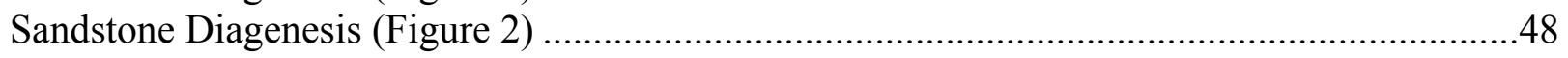

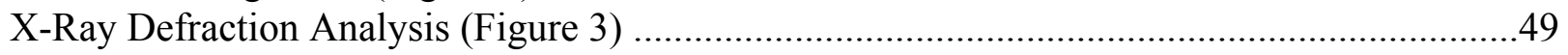

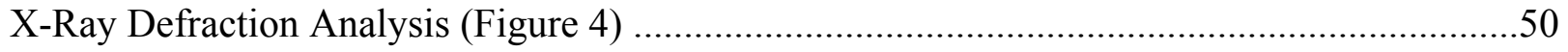

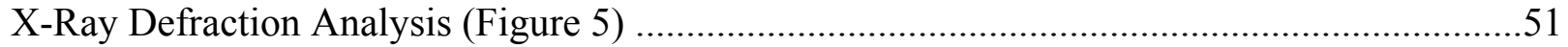

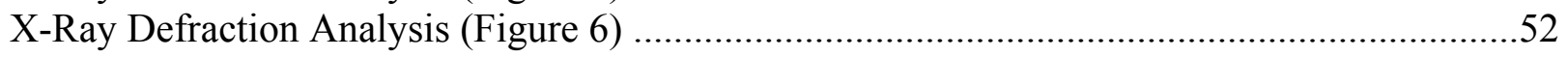

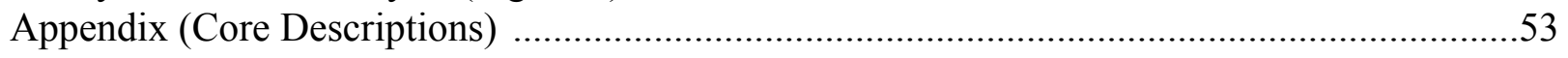




\begin{abstract}
Anastamosing, low gradient distributary channels produce $\sim 30$ gravity, paraffinic oils from the Middle Member of the lacustrine Eocene Green River Formation in the south-central portion of the Uinta Basin. This localized depocenter was situated along the fluctuating southern shoreline of Lake Uinta, where complex deposits of marginal-lacustrine to lower delta plain accumulations are especially characteristic.

The Middle Member contains several fining-upward parasequences that can be recognized in outcrop, core, and downhole logs. Each parasequence is about 60 to 120 feet thick and consists of strata deposited during multiple lake level fluctuations that approach 30 to 35 feet in individual thickness (Craig, I don't understand this, and we do not want to be smashed here by sequence strat people. Give me a call). Such parasequences represent 300,000-year cycles based on limited absolute age dating. The subaerial to subaqueous channels commonly possess an erosional base and exhibit a fining upward character. Accordingly, bedding features commonly range from large-scale trough and planar cross bedding or lamination at the base, to a nonreservoir, climbing ripple assemblage near the uppermost reservoir boundary. The best reservoir quality occurs within the laminated to cross-stratified portions, and the climbing ripple phase usually possesses more deleterious micas and/or detrital clays.

Diagenesis also exerts a major control on reservoir quality. Certain sandstones were cemented by an early, iron-poor calcite cement, which can be subsequently leached. Secondary intergranular porosity (up to 20\%) is largely responsible for the 10-100 millidarcy rock, which represents petrophysical objectives for both primary and secondary production. Otherwise, intense compaction, silicic and iron-rich carbonate cements, and authigenic clays serve to reduce reservoir quality to marginal economic levels.
\end{abstract}




\section{INTRODUCTION}

This report represents an integral and important portion of a larger-scale DOE-sponsored study of the Eocene Green River Formation in which surface exposures are compared to available subsurface data in order to understand the complex details of Green River stratigraphy within the Uinta Basin. Furthermore, stratigraphic understanding and subdivision inevitably leads to detailed study of depositional environments, petrology, and geological petrophysics. All derived data are then utilized for engineering-based simulation of the reservoir during both primary and secondary recovery. The ultimate goal of this study intends to focus attention on the vagaries of these unusual reservoirs, such that present and future operators can maximize their oil and gas production through greater scientific insight and knowledge-based judgment.

Specifically, this small portion of the overall endeavor involves interpretation of the various depositional environments exhibited by siliciclastic and carbonate rocks produced in dominant fluvio-lacustrine settings. These rocks formed in and around Eocene Lake Uinta, a lake that developed in an intermontane setting; mountains initially formed during Laramide time (Cretaceous to Eocene) in NE Utah. In addition to determining under what geologic conditions these deposits formed, details of reservoir and nonreservoir petrology are needed in order to understand reservoir behavior and that of the nonreservoir rocks, particularly (1) during perforation and stimulation, (2) during primary production, and (3) during the numerous waterflood projects currently underway in the Basin. Details of petrology concern basic mineralogy and lithology, textural and structural characteristics, and complex forms of diagenesis, processes which subsequently modified the sediment after initial deposition. Diagenesis usually involves compaction and cementation, potential dissolution of materials, and potential infilling of primary or secondary pores by authigenic clays or other minerals. From an integration of these data, more intelligent petrophysical interpretation is possible from both standard and esoteric downhole logs.

This study was able to combine nonpublished and published (Remy, 1992; Garner and Morris, 1996) field observations with subsurface materials of all kinds. Numerous whole and slabbed cores were available from the Core Sample Library at the Utah Geological Survey in Salt Lake City for both depositional and petrological purposes. An initial foot-by-foot analysis of approximately 25 cores was performed (see appended core descriptions), and upon learning of the ongoing study effort, numerous operators, past and present, supplied additional core material. Supplementary core-related material also was extremely helpful and included data on routine and special core analysis as well as from proprietary geologic/engineering reports. Some sidewall and conventional cores were themselves not successfully located, but in some cases, archived thin sections and/or graduate theses were provided as core substitutes. Additional thin sections were then made from sidewall and whole core material, and after thin section examination was performed, certain samples were selected for scanning electron microscopy (SEM), x-ray diffraction (XRD, data provided from previous DOE work on the Green River Formation by the University of Utah, Energy and Geoscience Institute), and additional routine core analysis testing (found in another portion of the report). In most cases, corresponding openhole logs were obtained for the cored intervals, using both proprietary materials and government-held sources at the Utah Division of Oil, Gas, and Mining facility in Salt Lake City. 
Numerous geological achievements were accomplished using an integrated approach to these reservoirs. Petrophysical conclusions were also provided to the engineering staff associated with simulation activities (Dr. Miland Deo), and constant dialogue regularly occurred with the Principal Investigator, Mr. Craig Morgan, such that his portion of the study benefited from depositional and petrological conclusions.

\section{ACKNOWLEDGEMENTS}

Numerous individuals were especially helpful during the course of this prolonged study. I was aided immensely by Mr. Craig Morgan, the principal investigator of this study, whose constant dialogue served to focus attention on technical problems and possible solutions. Equally helpful were Ms. Carolyn Olsen and Mage Yonetani, who always assisted me with pleasant countenance and disposition during the core examination process while at the Utah Geological Survey. The staff at TerraTek helped immeasurably during the rock testing procedures; Barbara Marin did an especially impressive job with the scanning electron microscopy. Outstanding industry support was provided by an array of individuals: Terry Barrett (Barrett Resources), Roger Hively (Chandler and Associates), Kevin Weller (Inland Resources), Logan McMillan (Sego Resources), and John Osmond (Independent). While company names may come and go, these people were consistent in their support of this project. Numerous discussions with Nan Oleson were also helpful, and her thin sections from lost core helped compensate for the lack of rock from critical wells. Sue Juch-Lutz (University of Utah, Energy Geoscience Institute) was extremely cooperative with providing core and accompanying data from the Institute's past DOE project, also concerning the Green River Formation. Finally, thanks are extended to the DOE Contract Manager, Virginia Weyland, who kept us on track in terms of contract deadlines and financial reporting.

\section{DEPOSITIONAL ENVIRONMENTS}

\section{General}

Although much has been written concerning depositional environments of the Green River Formation during the past several decades, this study's goal of comparing surface exposures to subsurface analogues has produced both some predictable and some surprising results. A milestone publication by Ryder and others (1976) established major facies categories for the Green River and for other units ranging from Cretaceous to Lower Eocene: (1) alluvial, (2) marginal lacustrine, and (3) open lacustrine. Other important articles followed and, among others, included major publications by Fouch and Dean (1982) and by Fouch and others (1992). The thesis of Oleson (1986) was particularly insightful in terms of detailed Green River paleoenvironmental interpretations. Based largely on the major contributions of these authors, our project may be able to refine some of the previously accepted major conclusions. 
This study is exclusively concerned with the Green River Formation sedimentary materials derived from the south or southeast, and this detritus was shed northward toward the open lacustrine setting of Ryder and others (1976). Most specific efforts concerning depositional environments involve an interpretation of the marginal lacustrine facies mosaic occurring along the fluctuating southern shoreline area of ancestral Lake Uinta. Additional concern for the alluvial and open lacustrine settings was also important to admittedly a lesser degree. In a sense, we have taken the detailed work of Colburn and others (1985), and attempted to supply some heretofore little known stratigraphic detail based on detailed measurement of field exposures and on analysis of numerous conventional cores and corresponding electric logs. In terms of stratigraphic subdivision and correlation, results from the surface to subsurface correlation can be found in a separate section of this report. This particular section attempts to emphasize the depositional characteristics of the various subsurface stratigraphic units.

\section{Alluvial Facies}

Very little studied core material clearly originated from an alluvial facies, but we lately acquired core clearly containing some evidence of true alluvial materials. The Chevron Marsing \#16 slimhole core from a Uinta Basin setting to the southwest of the outlined study area did contain numerous red bed facies belonging to the Wasatch or Colton tongue. Although not examined in detail due to time constraints imposed on this study, a portion of this core consisted of red and green stained siltstone and sandstone, some of which was subjected to major amounts of soft sediment deformation and burrowing. Numerous rip-ups were also recognized as well as discrete zones of purported soil development. Other than this example, the only real presence of these alluvial tongues was usually manifested in the medium-grained impure sandstones with numerous mudstone fragments, some of which possessed source area, hematitic alteration and were logically recycled into the most "alluvial" of marginal lacustrine environments, particularly during moments of alluvial progradation from the southerly source area.

\section{Marginal Lacustrine Facies}

This complex collection of environments separates the alluvial regimes typified by the Colton or Wasatch tongue from the comparatively quiescent settings of the deeper lake portions (Open Lacustrine Facies). Not only does one have to consider the comparatively simplistic, shallow to deep depositional settings and trends, numerous environmental interpretations arise due to the establishment of variable lateral "microenvironments", that is along the irregular shoreline morphology of Lake Uinta. As a reminder, the southern portion of the Great Salt Lake of today contains a myriad of carbonate and siliciclastic environments, some of which are described by Eardley (1966) in a major work on the Great Salt Lake edited by Stokes. Some analogous deposits clearly occur in both lacustrine systems. In terms of the marginal environments, one can clearly recognize the major influence of the deltaic systems that supplied most of the siliciclastic material. Moreover, interdeltaic areas obviously occur between regions of active sediment supply, and thirdly, a variety of carbonate and siliciclastic environments occupy positions along the shoreline itself. Oleson (1986) categorized these three main environmental settings within the marginal lacustrine setting as (1) deltaic, (2) interdeltaic, and (3) lake-margin carbonate flat. 


\section{Deltaic}

Although evidence of vigorous deltaic sedimentation can be recognized in the field or surface portion of the study, little evidence exists for this environment from subsurface investigation regarding the most oil-productive regions. Based on careful generation of isopachs and detailed cross sections, utilizing the variously-named carbonate datums as revised by this study, one can now appreciate the distinctive morphology of the active lower delta plain sand bodies, as distinguished from the near-absent, active deltaic deposition (lower alluvial to upper delta plain conditions).

If isopachs are not carefully compiled using one or more of the reliable carbonate datum points, this exercise will commonly produce an expansive sand accumulation over one mile wide. If such sand truly belongs to a fluvial system situated in a single channel, such a channel is unbelievably wider than that of the Recent Mississippi River. Cross sections among various wells also illustrate the difficult reality of the depositional system: using a reliable carbonate datum, subsurface geologists recognize that supposedly correlative fluvial sands in fact do not perfectly correlate from place-to-place. What is eventually mapped either by isopachs and crosssections are sandstone events or pulses, which in reality, represent anastamosing channels that constantly shift positions in time and space, but usually remain within the confines of a mappable valley. Furthermore, investigation of core confirms the existence of superimposed sandstone pulses commonly possessing lowermost scour surfaces in each instance, complete with rip-ups on many occasions (See core descriptions). This phenomenon probably occurs when channels criss-cross the terrain within the confines of the valley, and younger sand transport conveniently comes to rest over portions of the underlying and clearly older pulse. This occurrence can also be seen in many field exposures, and visibly available in three dimensions, the progressively younger pulses are geometrically imbricated over the older episodes. Mistakes in the subsurface concerned with the recognition of distinct pulses within a sandstone event can lead to huge interpretive errors in both exploration and development strategies. The current industry activity devoted to extensive secondary recovery efforts in the region will inevitably lead to several disappointments, especially if the imbricated pulses are separated by unbroken shale interlayers, This stratigraphic partitioning by shale would be most deleterious in a remote geometric position unaffected by hydraulic fracturing.

The morphology of the distributary system can also be discerned through the careful examination of the many cores available to this study. In addition to the numerous rip-ups and multiple scours, many of which involve sand-on-sand contacts, lending evidence to superposed or imbricated channeling, a great deal of information is supplied by the numerous sedimentary structures situated within the channels themselves. As a means of qualification on their usage, changes in dynamic sedimentary structures do not always imply that different and distinct sedimentary environments result. In many cases, a similar environment varies morphologically, resulting in somewhat diverse sedimentary structures due to the major interplay between sediment load and velocity of the transporting medium (Plates 4, 5 of slab photograph suite). Other factors affect results as well: Oleson (1986) mentions lake level and water chemistry as additional complicating mechanisms. In short, a distributary system may exhibit different physical characteristics, and yet, some variability in sedimentary structures should be expected 
for a distributary channel without resorting to geologic niche partitioning.

As Green River Formation examples, distributary channels confirmed by subsurface mapping can exhibit numerous sedimentary structures near their basal portions: (1) scours and rip-ups, (2) steep cross-bedding perhaps of the trough variety, (3) planar laminations, (4) wavy laminations, (5) distinct current ripples, (6) megascopically structureless, (7) ripple laminae in phase, and more rarely, (8) ripple drift or climbing ripples (Plates 2-5 of slab photograph suite). It may be possible that certain dynamic structures are indeed reflective of specific distributary-related regimes, but it may also be likely that the aforementioned interplay of load and velocity simply created variations upon a general distributary theme.

In some instances, fining upward sequences clearly exist as evidenced from both core and openhole logs, initiating with discernible scour and rip-ups composed of dolomitic mudstone, carbonate allochems, and organic debris. The very-fine to medium-grained sandstones fine upward and pass through moderate angle, trough cross bedding, to low angle cross lamination, to planar or wavy lamination, and in some cases, to pronounced accumulations of poorly sorted sandstones with abundant ripple drift lamination. Such ideal, channeled fining upward sequences are comparatively rare, and likely represent streams of initial vigorous velocity, whose downcutting capabilities wane comparatively suddenly with time.

Such a sequence might represent cutting of a true fluvial channel, with occasional accumulations of point bar deposits bringing the channel to a situation where increased bed load and higher velocities force rapid filling of the channel and eventual "spilling" of material into two of the possible deltaic subenvironments postulated by Oleson (1986): subaqueous levees or distributary channel margins. It may be somewhat logical to see this development in the upper portions of the distributary system between the alluvial facies and the distal distributary deposits.

For the most part, basal or initial portions of distributary channels are most commonly planar to wavy laminated, both with or without channel lags, are less commonly characterized by imperfect current ripples, logically associated with small scale cross lamination, and are less frequently structureless or even initially ripple drift laminated. Plates 4 and 5 from the slab photograph suite most typically illustrate this structural assemblage. As implied earlier in the discussion, many sedimentary structures are related to velocity-viscosity-bed load interactions. The dominant theme, however in terms of sedimentary structures, involves a climbing ripple or ripple drift laminated phase contrasting with one or more of the other phases (see Plates 2 and 3, slab photographs). This contrast is also clearly recognized in surface exposures although the climbing ripple phase appears more common in surface exposures than in cores of the more northerly and distal subsurface

Climbing ripples are a dominant feature and probably represent deposition in the waning stages of a periodic flood. Such deposits likely occur when suspended load is laid down as flow velocities decrease, perhaps in a single, relatively abrupt phase. This depositional mechanism would explain the commonly observed fining upward trend seen in both core and in corresponding log signatures (climbing ripples represent the upper reaches of the fining-upward trend). In some cases however, the climbing ripple phase occurs as a stratigraphically isolated 
deposit or in a stratigraphic position not associated with a clear fining-upward sedimentological trend. Such an occurrence may reflect a "spilling" phase as well, where the lack of accommodation space in a distributary channel forces the suspended load to cut through the channel margin and unceremoniously to dump material in the original interdistributary regions - akin to a vigorous version of a crevasse splay or subaqueous levee (Oleson, 1986).

This sedimentological phenomenon does have a bearing on exploration and development as climbing ripple deposits possess very poor innate reservoir quality-finer grained quartz and feldspar (silt-sized to very fine grained sand), comparatively abundant mica, all tightly packed and partially cemented.

In contrast to the high velocity of the "spilling"streams that deposit poorly sorted material as climbing ripples or in ripple drift lamination outside of the main distributary channel, slower moving distributary channels can still "spill" if accommodation space does not exist in the established channel. These sand bodies apparently can represent crevasse splays, and the very fine-grained sandstone is structureless to faintly laminated, contains abundant plant rootlets, and is in close proximity to occasional thin coals and shoreline carbonates. These sandstones are probably laid down in a mud flat lacustrine environment, in what may be likened to a lacustrine marsh environment with limited hydrodynamic circulation.

\section{Open Lacustrine Facies}

Rocks of this environment were not studied in excessive detail, but most observed materials were of a mudstone composition. As many workers have noted, dark gray to black organic-rich shales are common in the formation's lower portions, and gray-green mudstones are found in an area above the Lower Douglas Creek Member, where the lacustrine turbidites are traditionally observed. The contact between the two mudstone types is not consistent stratigraphically, but the contact does stay in the general stratigraphic vicinity as described, and the pronounced color change may be related to a profound change in the chemistry of the lake associated with changes in depth and/or circulation. Other materials include the presence of distinct basinal carbonates of argillaceous dolomite or limestone. In some cases, nonreservoir mudstones contain scattered phosphatic debris from mostly vertebrates and modest ostracod accumulations. Both the dark gray to black mudstones and argillaceous carbonates are excellent source rocks in terms of Type 1 kerogen and proper maturation for oil generation.

\section{Lacustrine Turbidites}

In the Monument Butte producing field, most distributary sandstone bodies measure no more than 30 feet in thickness, and these 30-foot accumulations usually consist of superposed sandstone bodies with internal erosional contacts. Thus, the individual sand events result in even thinner deposits. One unusually thick sandstone body, which occurs in a consistent stratigraphic position just above the Castle Peak Limestone marker, occurs also in the youngest deposits of the so-called "black shale facies" (Picard and others, 1973). These sandstone accumulations can measure upwards of 200 feet in its thickest portion and can thin to zero in a less than a one-mile lateral distance. This sandstone/siltstone accumulation forms in distinct pulses, readily 
recognizable from conspicuous log signatures, some pulses of which include a "ratty"gamma log trace reminiscent of sand/silt alternation on almost a laminated basis. Porosity logs commonly reveal greater than $10 \%$ porosity, even for the obviously silty pulses or portions thereof. In a lithologic sense, two major lithotypes are common to this interval, and include (1) a chaotic, poorly sorted sandstone/siltstone deposit with erratically dispersed, abundant breccia clasts, probably derived from the sublacustrine channel walls, and (2) a rhythmically laminated very fine-grained sandstone facies that occasionally exhibits classic grading but with better sorting. The latter facies appears to possess better reservoir quality as selective sorting allows for the development of void space at least during the transportation phase (apart from the later possible effects of diagenesis). The chaotic deposit is so poorly sorted that indigeneous void space is clearly less, and in fact, many framework grains remain coated by detrital mud. The chaotic deposit was also deposited more abruptly (reflected in the poor sorting), and dewatering and/or synsedimentary folding or faulting cause degradation in reservoir quality as well (see Plates 6 and 7 , slab photograph suite.

Given the textural and structural characteristics of these thick accumulations, it is very difficult to call upon simple distributary sedimentary mechanics to produce these deposits. It is clear that numerous sedimentary pulses of fairly rapid deposition comprise the total accumulation, and such pulses could result from development of lacustrine turbidites as previously proposed by Nielson and others (1996). They call upon a collection of debris flows, fluxoturbidites, and grain flows to account for the origin of these deposits (Plates 6 and 7, slab photograph suite). Abundant evidence also exists for major amounts of internal slumping and dewatering that occurred here. In detail, these deposits likely represent brusque deposition in active, stacked channels along with the development of proximal sublacustrine levees adjacent to the active channels, levees that are represented by the ratty, gamma log signatures of sand/silt materials on the edges of the channels.

If this theory and resulting conclusions are correct as proposed by these workers, origin of these highly unusual Green River Formation reservoirs was perhaps abetted by a deepening of the lake, perhaps evidenced by the surrounding black shale material. Moreover, it is possible that the conspicuous east-west faults of the Duchesne Fault System also had an Eocene equivalent, which allowed for the localized and accommodatingly deepening of the Uinta Basin as the Uinta Mountains continued their Laramide emergence to the north. These lacustrine fault scarps could have allowed the accumulation of debris on an upthrown block, and then some sort of depositional trigger could have initiated the deposition to lower lake portions. The lateral control on the distribution of these sands is unknown at this time, but other more northerly fracture trends are also recognized in this basin. Perhaps, these fracture trends helped establish some of the north-south trends that this particular sandstone accumulation exhibits. It is also interesting to note that immediately after the deposition of these turbidites, the entombing shale of Lake Uinta went from a black to a green coloration, perhaps reflecting a rapid filling of the lake and/or a shallowing due to tectonic uplift. From this moment on, the remaining sandstones likely represent deposition from a shallow distributary or true fluvial system.

In attempting to correlate these individual turbiditic sands from one well to another, given the state approved 40-acre spacing of development wells, these sands to not extend from one 
location to another with any stratigraphic certainty. Therefore, primary production can occur from this substantial sand collection to varying degrees of success in individual wells, but secondary waterflooding of this interval may be disappointing because of relatively poor reservoir quality and because of poor to nonexistent correlation of objective sandstones, at least as viewed on a 40 -acre spacing basis.

Apart from the inherently poor matrix permeability, available FMI data from the lacustrine turbidite interval indicate the presence of near-vertical fractures at various places within the potentially thick deposit. Such fractures usually occur when comparatively brittle strata (sandstones) are stratigraphically juxtaposed against more ductile rocks (shales). These fractures are usually confined to the brittle strata and terminate against the mechanically bounding shales. Most are incipiently cemented with calcite, and the majority of natural fractures trend ENE, not surprisingly sub-parallel to the Duchesne Fault zone, which dominantly strikes N 80 degrees W. Thus as is the case with many reservoirs in the Monument Butte region, normal production based on matrix porosity/permeability numbers can drastically improve if the naturally occurring fractures become accessed through either perforation and/or stimulation.

\section{Depositional Environment Summary and Conclusions}

- Most sandstones of the Green River Formation from this portion of the Uinta Basin were derived from more southerly sources. Based on the detailed description of basement rocks from the Uncompaghre Uplift (Case, 1991), the Green River sandstones were likely derived from this uplift as structural reactivation occurred in this source terrain.

Reworked sedimentary debris may have originated from the San Rafael swell or from the internally reworked material of the Green River Formation elsewhere.

- Sandstone deposition in this southern portion of the basin largely occurred in moderate to low gradient distributary channels. These channels were part of an anastomosing system that laterally migrated with time, but mostly in a confined valley, a valley that potentially extended over one mile in width. Detailed isopach work by several workers in several densely drilled portions of the Monument Butte producing area suggests this channel morphology.

- Most sand and carbonate deposition occurred along the southern margin of Lake Uinta (marginal lacustrine setting); occasional evidence for a more alluvial setting occurs in the interval between the Uteland Butte carbonate reservoir (Basal Limestone facies of Picard and others, 1973) and the Castle Peak limestone (or carbonate marker of Ryder and others, 1976). Red bed facies and coarser grained sandy material are most prevalent in this interval previously referred to as the Wasatch Tongue or Colton Tongue by previous workers.

- Although many variations in dynamic sedimentary structures occur in these rocks, most variations can be accounted for through differences in Reynolds Numbers within the distributary environment. These Reynolds Numbers can vary from the interplay between 
stream velocity, fluid viscosity, and resulting transported load within various portions of even a modestly sinuous channel.

- In some cases, distributary sands appear subaqueous beneath lake level with abundant dewatering phenomena; in other areas, root casts, associated coals seams, mud cracked horizons, and penecontemporaneous dolomites indicate proximity to subaerial conditions.

- Distributary sands can be structureless, planar or wavy laminated, or weakly to strongly rippled in almost a depositional continuum with little or no change from the very fine- to fine-grained size material. Aside from the medium grained material found below the Castle Peak Limestone (carbonate marker of Ryder and others, 1976), very fine to finegrained sandstones are consistently observed elsewhere within the formation.

- A separate depositional phase is indicated by the more poorly sorted, silt very finegrained sand assemblage in sets of climbing ripples or ripple drift lamination. In many cases, this climbing ripple phase is located in the upper sand portions of fining-upward sequences. This phase likely represents rapid deposition of suspended load in a geologically brief moment as fluid velocity abruptly wanes.

- In other cases, climbing ripple sets are not necessarily found in fining-upward trends, and might reflect the same abrupt deposition outside of a distributary channel because accommodation space in the shallow channel was inadequate for that moment of time. Thus, the climbing ripple phase might also reflect a "spilling" onto dolomitic mudstones, siltstones and shales of typical interdistributary regions.

- Although nonreservoir rocks were not studied that intensively in many cases, the common overbank deposit consists of a light gray-green, wavy laminated, commonly bioturbated, occasionally mud-cracked, dolomitic mudstone or shale. Silt laminae are commonly present as interlaminations (See Plate 1 of slab photograph suite).

- Open lacustrine materials dominantly consist of light gray-green or dark gray to black mudstones, and dark gray argillaceous basinal carbonates. These more northerly carbonates are basinal, deep-water facies equivalents to the grain supported, ostracodal, algal and oolitic deposits generally found to the south in the Monument Butte producing area.

- Lacustrine turbidites are also recognized at a consistent stratigraphic level, also where the dark gray to black open lacustrine mudstones pass upward into the gray-green mudstone varieties. This Lower Douglas Creek Member contains a debris flow facies with chaotic poorly sorted materials including deformed breccia clasts, and a rhythmically laminated, partially graded, silt/very fine grained sand facies that may represent more gradual deposition from a turbiditic "tail." Slumping, cut and fill features, and soft sediment folding and faulting are very common to this deposit. 


\section{SANDSTONE PETROGRAPHY}

In addition to megascopic examination, sandstones were analyzed using classic (stained) thin section examination, scanning electron microscopy, and limited amounts of x-ray diffraction (XRD). In terms of petrological varieties, four classes of sandstones consistently characterize the Green River Formation: (1) Medium grained sands are almost restricted to sands deposited between the carbonate marker (Ryder and others, 1976) and the Basal Limestone facies (the latter also referred to as the Uteland Butte carbonate reservoir in this study). (2) Very fine-to fine-grained sand is volumetrically the most common and is associated with most of the up-hole sands in the Douglas Creek and Garden Gulch intervals; (3) Very fine-grained sands with significant micaceous silt are typical of the ripple-drift laminated facies, abundantly found both in surface and subsurface deposits; and finally, (4) Very fine grained sand with appreciable coarse silt content is typical of the stratigraphically anomalous Lower Douglas Creek interval, an especially thick and sedimentological enigma possibly linked to lacustrine turbidites. Previous work on the petrology of the Green River sandstones has been accomplished by Pitman and others (1982), and by Colburn and others (1985).

\section{Medium-Grained Sandstones}

\section{General}

In the case of medium grained material, the increased grain size is perhaps reflective of the comparative proximity of the Wasatch Tongue, whose presence is almost exclusively seen in the "black shale facies, a oft-published and described interval that roughly is synonymous to the strata between the aforementioned carbonate marker and Uteland Butte carbonate reservoir )or Basal Limestone facies). The Wasatch Tongue is clearly alluvial in part and the coarseness of framework elements logically indicates that the ultimate source areas were particularly elevated and/or proximal at this particular moment of Green River deposition.

\section{Provenance}

The medium-grained sandstones (0.36-0.44 mm, approximate median grain size), mostly lithic arkoses or feldspathic litharenites, contain better evidence regarding the likely provenance for the Green River Formation compared to similar clues offered by the very fine-grained clastic deposits. In the medium-grained deposits, framework elements include abundant monocrystalline and polycrystalline quartz (some rutilated), potassium feldspar (orthoclase and microcline), plagioclase, chert (some of possible volcanic origin), sheared metaquartz, recrystallized metaquartz, hydrothermal quartz, intrusive rock fragments, very rare volcanic rock fragments, schist and questionable phyllitic metamorphic rock fragments, dolomitic siltstone and mudstone clasts (some clearly hematitic), carbonate ooids and/or intraclasts, reworked sandstone grains, isolated mica booklets (biotite, chlorite, and muscovite), occasional red-brown hematitic staining, and assorted heavy minerals including zircon, epidote, tourmaline, sphene and very rare amphibole (See Plates 8-10 of thin section plates).

From this mixed assemblage of minerals and rock fragments, it is clear that sedimentary, 
metamorphic, and igneous sources provided material to the distributaries entering Lake Uinta's south shore. Based on the volume of metamorphic rock fragments, feldspars, and to a much lesser but important degree, the intrusive material, a basement complex likely was very instrumental in supplying Green River detritus.

Along this line of source terrain detection, based in part on the regional stratigraphic work of Colburn and others (1985), a southerly source is clearly indicated for these particular Green River materials, and several other workers have also alluded to southwest/southeast source areas. In terms of a hypothetical basement origin, the late Mesozoic and early Cenozoic versions of the Uncompahgre highlands seems a good choice for these materials. From studying the remnants of today's Uncompahgre highlands, geologists recognize that sedimentary rocks of Late Paleozoic and Mesozoic ages mantle the Precambrian or Proterozoic basement complex. Acute dissection by Paleocene/Eocene streams would actively erode the entire sequence especially if the Uncompahgre region were being reactivated during the late stages of the Laramide (Heyman and others, 1986).

Case (1991) describes the Proterozoic rocks of the Uncompahgre region and lists approximately 10 lithologies present in the basement complex, most of which might be found in the mineralogy and rock composition common to the theoretically resultant Green River sandstones. These theoretical parallels between the Uncompahgre highlands and the Green River Formation include the following similarities:

Quartz - polycrystalline quartz common from plutons and metamorphic material, rutilated quartz from plutons

Sheared and Recrystallized Metaquartz - from gneisses and metaquartzites

Hydrothermal Quartz - from pegmatitic material

Potassium Feldspar - including microcline from at least two pervasive Uncompahgre rock types

Biotite - an extremely common ingredient in many of Case's observed basement lithologies

Plagioclase - abundant with An30 approximate composition

Heavy Minerals - as described including significant amounts of sphene

About the only material not commonly found in the Green River formation (but still rarely so) would be the abundant amphiboles found in many Uncompahgre equivalents. Even the resulting plagioclase in the Green River demonstrates similar An30 compositions, a figure repetitively evident for numerous Uncompahgre basement assemblages

\section{Textural Features}

Most of this Green River material is poorly to moderately sorted, and the rounding characteristics run the complete gamut from angular to very well rounded grains, although many details concerning rounding are masked by the intense compaction, cementation, and dissolution of these deposits. The especially well rounded grains may be recycled from other sedimentary deposits, and rounded overgrowth cements clearly present additional recycled evidence. This medium-grained lithotype is consistently highly compacted in that grain contacts are commonly 
interpenetrative even to the point of partially exhibiting crenulated grain boundaries (approaching metamorphic textures). The softer mudstone and phyllitic grains are deformed into pseudomatrix, and coupled with extensive quartz and feldspar cementation, an extremely tight rock would result if it were not for the dissolution phase that affects mostly feldspars and subordinate amounts of rock fragments. Compositionally, the medium-grained sands are lithic arkoses unless the reworked mudstone frameworks are especially abundant. In the latter case, feldspathic litharenites are formed.

As mentioned, most medium grained sandstones, although not all examples, are affected by selective leaching. The most frequent dissolution affects potassium and plagioclase feldspars, and because these ingredients are relatively common, dissolution can be pronounced especially for plagioclases, perthites, and microclines. Orthoclase dissolution is usually less pronounced. Selective rock fragments, micas, and modestly abundant low magnesium calcite cements are also dissolved. Because of this solution process, reservoir quality can be significantly enhanced, although the severity of leaching (permeability enhancement) does vary from sample to sample and even within feldspars from a single sample (Plates 8-10 of thin section suite).

\section{Diagenesis}

The diagenetic processes impacting the medium-grained reservoirs are similar to the numerous diagenetic stages that modified most other Green River sandstones. The major differences with these specific coarser grained deposits involve (1) the intense degree of grain compaction and cementation, (2) the severity of feldspar dissolution, (3) greater abundance of kaolin ostensibly from feldspar dissolution, and (4) the comparative paucity of calcite diagenesis, both of ironpoor and iron-rich varieties (Plates 8-10 of thin section examples).

A paragenetic history is proposed below in which the chronology of observed events is only approximated, usually through the use of cross-cutting textural relationships observed either in thin section or through scanning electron microscopy (SEM) investigations.

Deposition of materials in alluvial or distributary sytems; derivation is largely from an igneous/metamorphic basement complex either mantled by sedimentary materials or areally adjacent to a sedimentary assemblage. This reworked sedimentary assemblage is clearly recognizable, but one must also include in the sedimentary package the almost autochthonous dolomitic mudstones, ooids, and ostracod-bearing sediments from nearby, shallow lacustrine settings.

Intense compaction of grains followed soon after deposition and progressively developed until interpenetrative and/or crenulated grain contacts eventually resulted. Pseudomatrix forms when dolomitic or hematitic mudstone fragments are deformed into original pore space. Formation of illitic and/or chlorite grain coatings around framework elements.

Formation of silica overgrowths developed alongside the compaction phase as grain-to-grain pressure solution products; many euhedral overgrowths are recognized both in thin section and in SEM investigations (Plate 6 of SEM plate assemblage). Some overgrowth formation is 
incomplete in that some secondary intergranular pore space remains in the form of small triangular pores, expressed in two dimensions. Also possible that quartz overgrowth development is part of a long-term authigenetic process.

Development of authigenic orthoclase and plagioclase as overgrowth cements.

Minor amounts of early low magnesium calcite cement invaded the already compacted (or reduced) primary intergranular pores. Amount of early calcite is rare compared to other Green River sandstones, perhaps indicating that compaction and silica cementation began almost immediately after deposition.

Dissolution phase of mostly feldspars (See plates 8-10 of thin section examples and Plate 15 of SEM suite), rock fragments, and rare calcite.

Kaolin infilling of isolated dissolution pores.

Dolomite infilling and replacement of leached pores (Plate 4 of SEM suite).

Pyrite occurring as replacement crystals in sandstone matrix, selective replacement of rock fragments and as infilling of pores. Multiple stages of pyrite authigenesis are likely.

Siderite aggregates concentrated in isolated voids.

Iron-rich calcite enveloping vestiges of partially dissolved iron-poor calcite.

Ankerite overgrowths or rims on precursor dolomite crystals.

Illite and/or illite-smectite infilling of pores and as alteration/replacement products on

framework grains (Plates 13 and 14 of SEM suite).

Late stage chlorite authigenesis possible (Plate 8 of SEM suite).

Migration of hydrocarbons.

\section{Pore types}

The major pore type for this group of reservoirs is the dissolution porosity produced through the complete to incomplete leaching of feldspars and rock fragments. Most examples involve partial leaching as seen both in the thin section and SEM photomicrographs. As stated previously, the feldspars are so abundant that significant amounts of void space can be provided as simple dissolution pores or as feldspar micropores associated with a partial leaching process.

Micropores can also be produced as a result of authigenic clay infilling of original dissolution voids. The clays producing this result include most authigenic varieties, namely chlorite, kaolinite, illite, and illite-smectite. Reduced intergranular pores result when quartz overgrowth cement only partially occludes the original intergranular pore space. While this type of pore usually results in the most permeability production, this void type is comparatively rare in these rocks. Finally, fracture porosity is common to some of these rocks, especially in the Brundage Canyon area (T5S, R5W; T5S, R4W), Duchesne County. Most fractures occur near the base of the sandstone reservoirs where the carbonate content is commonly the highest, imparting a decided brittleness to the medium-grained sandstones. Because of the predominance of mostly isolated dissolution voids and micropores, porosity in many examples clearly exceeds $10 \%$, but permeabilities seldom exceed single millidarcies even with pronounced dissolution. 


\section{Very Fine-to Fine-Grained Sandstones}

\section{General}

These sandstones are volumetrically very common and for the most part, are usually found in distributary channels that comprise a great percentage of the reservoirs targeted for primary and secondary production. Most of these sand bodies are located above the carbonate marker (Ryder and others, 1976) in what has been called the Douglas Creek and Garden Gulch members. The median grain size of $0.16-0.20 \mathrm{~mm}$ can be related either to transportation and deposition somewhat distal from the alluvial delta facies or to a preferential grain size provided by erosion of the source area terrain. Plates 1-5 of the thin section suite are excellent representations of this material.

\section{Provenance}

The content of the very fine-to fine-grained sandstones is very similar to the previously described category, and attention might be paid to the major compositional differences, which could be a reflection of provenance and/or selective erosion. These finer grained materials do not commonly contain the red-brown hematite-stained mudstones, polycrystalline quartz, or granitic rock fragments to any significant degree. In most cases, the near-complete lack of intrusive rock fragments and polycrystalline quartz is simply a function of grain size, in turn related to degree of transportation and erosion. The missing hematitic stained mudstones are perhaps related to the increased distance separating active alluvial deposition akin to the Wasatch Tongue from the site of very fine-to fine-grained sandstone deposition. In fact, most mudstone fragments in these finer grained deposits are medium gray dolomitic and/or ankeritic mudstones and/or pronounced carbonate allochems, including ankeritic/dolomitic ooids, ankeritic/dolomitic rip-ups, ostracods, or intraclasts. Moreover, micaceous material is more abundant in these finer grained rocks; biotite/chlorite is clearly more abundant, and muscovite is also more prevalent. Other than these exceptions, the framework assemblage is very similar both in composition and in relative abundance, and continues to be derived from the Uncompahgre upland surfaces and adjacent sedimentary deposits, perhaps similar to those found in the San Rafael Swell.

\section{Textural Features}

These lithic arkoses or feldspathic litharenites possess a median grain size $(0.11-0.17 \mathrm{~mm})$, which approximately straddles the two sand classes as described by many workers. The boundary between very fine and fine sand is $0.125 \mathrm{~mm}$, according to the classification established many years ago by Wentworth and Udden. In these deposits, sorting ranges from moderately well sorted to well sorted, and most grains occur in the subangular to subrounded categories. Grains also occupy the angular and well-rounded extremes although most well rounded material may be recycled detritus as discussed earlier; evidence for rounded overgrowth cements also occurs in these deposits.

Pseudomatrix is also a common textural feature as mudstone fragments, although decidedly 
smaller than those mudstone clasts commonly found in the medium grained sandstones, are clearly squeezed into then-existing pore space. This sort of compaction is arguably of the softsediment variety and contrasts with the compactive effects described subsequently.

Chemical compaction and cementation are highly variable within these finer grained materials, and the degree of such destructive processes is perhaps controlled by the presence or absence of an early, iron-poor calcite cement. In some cases, the timing of compaction versus calcite cementation also controls the level to which reservoir quality is ultimately developed or destroyed. Thus, the range of grain-to-grain contacts in these fine grained sediments is certainly extreme. In instances, chemical compaction effects are nonexistent when early calcite steps in to virtually preserve the original textures. In other examples, grain-to-grain contacts are linear, gently curved (consertal), or slightly interpenetrative (Plates 1-5 of thin section suite aptly illustrate this gradation of compaction). The crenulated contacts seen in the medium grained materials are generally lacking for this category of detritus.

\section{Diagenesis}

Specific to these sediments, the precipitation of calcite occurs fairly early in the sequence of diagenetic events. If the process is especially early, occurring just after deposition of the original materials, very little compaction has had ample opportunity to occur. If this is the case, the iron poor calcite cement produces a very tight rock, but one that infills near-original, virtually uncompacted pore space (Plate 4 of thin section suite). Alternatively, if this cementation episode occurs somewhat after both deposition and significant burial, the grain-to-grain compaction will have had some time to alter the original texture, and subsequent calcite cementation will occupy less interparticle pore volume, largely because some space will have already been reduced due to some initial compaction and possible silica overgrowth effects. Finally, if compaction and silica cementation are allowed to proceed for some time, the calcite cementation phase will virtually have no remaining pore space for its potential impact (Plate 5 of thin section suite is a good illustration). Thus, the amount of calcite cement can vary from pervasively present to virtually nonexistent.

Occasionally, these sandstones remain very tight throughout if the calcite cementation phase remains unmodified. In many cases however, this early cement is later dissolved perhaps through the activity of organic acids commonly produced just prior to hydrocarbon migration. The creation of secondary intergranular pore space results from this calcite dissolution, and the amount of secondary voids is commonly related to the original pervasiveness of the iron poor calcite cement, remembering that the amount of such cement is, in turn, related to the degree of silica compaction occurring prior to the calcite phase. In short, very early calcite cementation, when subsequently leached, can leave a very desirable porous and permeable reservoir (Plate 1 of thin section examples is an excellent illustration). Because of the inherent fine-grained nature of the reservoir, "secondary" permeabilities seldom exceed 100md and more commonly measure in the tens of millidarcies. Secondary porosity under such circumstances can exceed $20 \%$.

In addition to the calcite cementation and dissolution cycle, other forms of authigenesis are similar to those observed for the medium grained sands. Dolomite, ankerite, siderite, and iron- 
rich calcite are processes that can all affect sandstones to greater or lesser degrees. In many individual situations, evidence for all processes can clearly be recognized. In some instances, these destructive cementation processes still leave a certain amount of pore space unscathed; many impacted sands still exhibit over $10 \%$ void space and remain attractive reservoirs as a result. On the other hand, reservoir quality in some sandstone is completely destroyed, usually by some secondary, iron-rich carbonate cement—ankerite or iron-rich calcite. In one instance, thorough cementation by poikilotopic anhydrite performs this deleterious function.

Authigenic clay precipitation also occurs in roughly the same order as previously detailed. In the finer grained sands, a chloritic clay coating appears more commonly than illite as recognized for the medium grained sands, and pore bridging illite-smectite is especially evident in regions where feldspar dissolution has occurred (See XRD data for bulk and fine analyses, Figures 3-5. Thus, with little alteration, the paragenetic scheme proposed for the previous sandstone category is appropriate for these finer grained mineralogical equivalents. For the latter group, compaction/pressure solution is not so severe, and early and late carbonate cementation (along with rare anhydrite) is more abundantly recognized.

In essence, sandstone diagenesis of the Green River Formation can take various paths on their way to becoming reservoirs of varying reservoir quality. The factors of leaching, compaction, and cementation all play vital roles, and the complicated paragenetic scheme can be viewed in Figures 1 and 2 (partitioned for easy inclusion into this report). This variation may also be due to the proposed conclusion that the various sand bodies are often diagenetically isolated because of the originally isolated anastomosing geometries.

\section{Pore types}

Many pore types can be present in this sandstone class, but the most preferable variety is the secondary intergranular voids, the majority of which are produced through the early calcite cementation and dissolution processes (Plate 1 of thin section suite). Reduced secondary pores can also result through the incomplete precipitation of quartz overgrowth cements in intergranular voids (Plate 2 of thin section examples). Such silica is commonly produced when framework elements compact, releasing "free" silica at grain-to-grain contacts. These reduced intergranular voids are conspicuously triangular in two dimensions, although not necessarily so (Plate 2 of thin section examples).. Nonetheless, the two types of intergranular pore space usually produce some much-needed permeability as previously described. Reduction of intergranular pore space can be carried further by any of the additional cements including dolomite, ankerite, iron-rich calcite, feldspar, pyrite, and a variety of authigenic clays

Other void types include dissolution pores (Plate 5 of thin section suite), particularly when feldspars and rock fragments are preferentially leached. If these specific materials are not completely leached, microporosity remains from the partial dissolution. Other forms of microporosity are directly related to clay authigenesis, and include kaolinitic pore filling, illitesmectite pore bridging, and illite (or chlorite) pore lining and infilling. Both dissolution voids and microporosity can add significantly to the porosity volume, but permeability is usually not enhanced, particularly if dissolution features are somewhat isolated from one another. A 
multitude of SEM plates illustrate these variations.

As seen elsewhere, calcite-lined fractures (partially open) are normally seen close to the bed boundaries within the sandstone reservoirs.

\section{Ripple Drift Laminated Sandstones (Variation of Very Fine- to Fine-Grained Sandstones)}

This prevalent facies is characterized by ripple drift lamination and/or clear evidence of climbing ripples, and such sedimentary structures are commonly related to development of an increased sediment load, varying amounts of which are carried in suspension (Jopling and Walker, 1968). In this facies, both very fine-grained sand AND abundant coarse silt are distributed throughout, and grains commonly conform or are aligned with ripple morphology in the vicinity. Intricate patterns of cross-lamination are usually evident. Furthermore, gamma ray signatures are slightly higher or "hotter" compared to normal sandstone reservoirs because of increased mud content.

This mud manifests itself in many ways, the most common of which include (1) abundant detrital clay coatings (mostly illite) of framework grains and (2) increased mica content, especially muscovite. The latter is also conspicuously aligned subparallel to existing bedding or ripple lamination. Severe compaction is strongly evident in this rock type and must have occurred soon after or during sedimentation. Compaction is also manifested in the abundant microstylolites, which are discontinuously present subparallel to distinct trends in ripple lamination. Such stylolites are also made more visible through the opaque pyritic precipitation along the length of the stylolitic features. Very few traces of early calcite cement are detectable in the ripple drift facies, and porosity/permeability are usually fairly low due to the gently curved to distinct interpenetrative grain contacts. Porosity types usually involve dissolution features related to feldspar leaching and clay microporosity, and primarily as a result of tight packing and grain interpenetration, porosity is usually low with permeability next to negligible.

In terms of framework elements, the mineralogy/rock fragment content is similar to that of the very fine- to fine-grained sandstones, with the exceptions as noted. Sorting is poor, and a greater percentage of grains fall into the angular-subangular category. Rounding is not very well attained because of the largely suspended bed load and/or inherent relationships that exist between rounding and grain size.

\section{Very Fine Sand/Coarse Silt of the Lower Douglas Creek Interval (Lacustrine Turbitites)}

As discussed elsewhere, this lacustrine turbidite reservoir interval can attain enormous thickness of over 200 feet, and is stratigraphically comprised of several superimposed sandstone pulses involving some sort of particularly brusque deposition (cut and fill) into Lake Uinta. The Lower Douglas Creek interval occurs roughly at the boundary between the lower black shale nonreservoir facies and the superjacent green shale equivalents. The color shift of these mudstones may be related to a major chemical shift in lacustrine conditions, perhaps initiated by major structural movements nearby. 
Two major rock types characteristically occur in this interval: (1) a very poorly sorted combination of silt/very fine grained sand that commonly contains detrital clay coatings around many grains as well as large clasts of seriously compacted dolomitic and illitic mudstones; and (2) a distinctly laminated assemblage of very fine- to fine-grained sand that is characteristically folded/faulted through soft sediment mechanisms. This latter rock type possesses some patchy reservoir quality and does contain mudstone fragments as well, but usually concentrated at the top of individual laminations.

In the laminated lithotype, sandstone composition and textural relationships are similar to the very fine- to fine-grained distributary channels described in (2) at the beginning of this section. Compacted mudstone clasts are more common at the top of the lamination, and such regions are sometimes poorly porous compared to the immediately underlying laminar portion. Grain-tograin compaction is not overly severe, point and linear contacts are most common, but in poorly sorted portions of the reservoir, extremely tight packing of grains can produce a tight fabric, especially when detrital clay remnants help to seal interparticle pore space. While these detrital coatings are not everywhere present in the laminated lithotype, they still microscopically adversely affect reservoir quality (Plate 7 of thin section samples).

The individual laminations are not strikingly graded although some grading occurs in some instances (Plate 6 of thin section suite). In the graded intervals, the basal portion of the lamination is loaded or scoured into the underlying layer, fine sand passes upward to very finegrained sand and/or coarse silt, and the uppermost portion is characterized by the highly compacted and elongate carbonate mudstone clasts. These clasts are so elongate and seriously compacted, one can almost recognize the incipient development of stylolites or microstylolitic swarms. In a sense, numerous vertical permeability barriers are present on a laminar scale mostly due to mudstone concentration, compaction, and near-stylolitization, although hydraulic fracturing would adequately break these millimeter-scaled barriers. Although high resolution logging still might not be able to resolve these porosity contrasts, the effort to acquire detailed logging data might yield unexpected dividends because of numerous subtle variations in all reservoir facies investigated.

As implied in the preceding paragraphs, porosity is locally variable in these rocks, but some secondary, reduced intergranular porosity can occur especially when early calcite cement is subsequently dissolved, Other than in these spatially modest examples, other voids include ineffective dissolution pores and clay microporosity. Because of the grain packing, sporadic detritial clay coatings, pseudomatrix formation of mudstone clasts, and "traditional" Green River cementation history, these Lower Douglas Creek sandstone/siltstone bodies are, for the most part, of inferior reservoir quality (Plates 6 and 7 of thin section suite are particularly illustrative).

The second lithotype megascopically resembles a chaotic breccia, characterized by haphazardly distributed carbonate mudstone clasts in very poorly sorted silt to very fine-grained sandy matrix. The rock also is profoundly affected by soft sediment dewatering effects, is microscopically very poorly sorted, and possesses very tight packing of grains. Grain-to-grain contacts do not reveal intense pressure solution, mostly point to linear contacts, but most grains 
are delicately coated by an illitic clay, which is both detrital and authigenic. Mineralogically, these rocks approach the ripple-drift laminated category in which muscovite occurs in abnormally high percentages, and grain angularity is more evident. Other than those differences, composition remains similar although feldspathic litharenites are more common due to the significant mudstone content. Some clasts appear as distinct breccia fragments, compacted to some degree, and other clasts are flattened to the point of developing clear stylolitic seams of modest lateral extent.

Because of the detrital/authigenic clay coatings (See XRD data, Figures 3-5), tight packing, and overall lack of secondary intergranular pores, these rocks are among the worst of the Green River sandstone reservoirs. The most commonly developed void space is clay microporosity and fairly isolated dissolution voids. In general, primary oil production from this particular suite is unpredictable because of the stratigraphically sporadic reservoir quality. Fractures do occasionally occur at rare intervals, but mostly the rock is not brittle enough due to the cushioning effect of the detrital clays to possess a complex fracture network. In terms of secondary recovery efforts, this material is equally unsuitable for successful waterfloods due not only to the lack of predictable porosity network but also due to the stratigraphic unreliability of the identified, better-quality pay zones. Prior to this study, one oil company attempted a waterflood effort in these rocks, and such well-intended energies resulted in near-complete failure.

\section{Fractures}

In many cases, cored intervals and FMI logging have clearly indicated the presence of open or partially open fractures within the sandstone reservoirs. The presence of fractures is also indirectly indicated through abnormally good production from reservoirs with mediocre electric log characteristics. This better-than-average production is especially common to the Brundage Canyon-Sowers Canyon areas in T 4 and $5 \mathrm{~S}, \mathrm{R} 4$ and $5 \mathrm{~W}$ in Duchesne County. This region lies to the west of the recognized Monument Butte producing area as discussed in this report. In particular, the deeper sandstones of the Green River Formation, between the Uteland Butte Carbonate Member and the Castle Peak Carbonate Marker, can perform unusually well from reservoirs with poor matrix characteristics. One core from the 2-25 well clearly provides conclusive evidence concerning what operators have intuitively surmised for years. The reservoir is densely cut by subvertical fractures particularly in the more brittle sandstones (see Plate 2 and 3 , slab photographs). The tight, climbing ripple facies contains a partially filled fracture (Plate 3 , slab photographs), which is occupied by calcite cement. Other completely open fractures also exist in this reservoir (no calcite), and not surprisingly, documented production is unusually good here.

Instances similar to these also exist in the Monument Butte producing area but are not quite so pervasively present. Partially filled fractures (supported in part by calcite cement) have been observed in regions proximal to or directly overlain by obvious or subtle geologic structures. Most fracturing takes place at the lithologic boundaries between ductile and brittle rock, and the calcite-supported fracture is dominantly confined to brittle sandstones or carbonates as they stratigraphically abuts softer mudstone. Fracture trends commonly parallel the Duchesne Fault 
Zone in N 80 degree $\mathrm{W}$ orientation, and such trends are verified by both surface geology and by formation imaging log data. The fracture trends are more complex than this simple example especially in the vicinity of the Brundage Canyon-Sowers Canyon areas where the dominant trend turns more acutely to the NW. While fracture study is beyond the main objectives of this endeavor, operators should be aware of the fracture-enhanced possibilities in their lease holdings by performing some simple examination of Eocene rocks on the surface. Seismic data also exists for this potential investigation.

\section{Sandstone Petrologic Summary and Conclusions}

- Most Green River sandstones are either feldspathic litharenites or lithic arkoses.

- The Uncompaghre Uplift to the south provided the majority of detrital grains present in these Eocene sandstones. Evidence for an igneous/metamorphic source is provided by abundant feldspars, metamorphic and granitic rock fragments, composition of heavy minerals (including sphene), rutilated quartz, and significant amounts of biotite (partially altered to chlorite in some instances), common to many of the basement rocks of the Uncompaghre Uplift

- Sedimentary source terrains also contribute significant amounts of material (mudstone, chert, and recycled sandstones).

- Poor reservoir quality is related to depositional environments in two cases: (1) the rippledrift laminated sandstones contain micaceous poorly sorted materials, and (2) the lacustrine turbidites of the Lower Douglas Creek interval are commonly composed of abundant silt/sand combinations with detrital clay coatings on framework grains.

- Apart from these two depositional instances described above, reservoir quality is largely determined by the diagenetic path of most distributary sands. The possibilities in diagenetic paths are indicated by the flow chart combined from Figures 1 and 2. The highest reservoir quality usually results from early iron-poor calcite cementation and subsequent dissolution; the poorest quality rock occurs through extensive packing of poorly sorted materials and grain-to-grain compaction, and either quartz and/or iron-rich carbonate cementation (anhydrite cementation in one instance). In addition to the variation in the various thin section examples seen in the numerous sandstone Plates, Figure 6 of the XRD data reveals a typically wide variation in bulk mineralogy, especially concerning the carbonate and clay species.

- Clay diagenesis involves many authigenic episodes that can partition existing pores into tortuous micropores. Authigenic clay species include chlorite, kaolinite, illite, and illitesmectite. See XRD and SEM data for details although kaolin specifically is not identified using XRD; thin section evidence is more obvious (Plate 9 of the thin section photomicrographs) 
- The actual diagenetic path for a particular reservoir may vary significantly when compared to even correlative sands elsewhere. Perhaps, isolated channels within an anastomosing system also possess individually isolated diagenetic histories.

\section{CARBONATE ROCKS}

As previously described in the section on detailed stratigraphy, the value of the lacustrine carbonates for detailed correlation purposes encourages further stratigraphic dissection as well as detailed petrologic/environmental investigation. Most carbonate rocks in a volumetric sense are situated in the Basal Limestone Facies (also called the Uteland Butte carbonate reservoir), which effectively separates the underlying Wasatch Formation from the overlying, dominant siliciclastic assemblage of the Green River Formation. The Basal Limestone measures anywhere from 125-250 feet, and according to Little (1988), among other authors, the stratigraphic content can vary appreciably from place-to-place although accurate correlations can be accomplished either along depositional strike or within a localized area. The results of this core-based study confirm these conclusions. Other carbonate strata are also distributed throughout the entire Green River section, and these zones are usually very thin (less than 20 feet as an individual package) but equally persistent in many cases. As a result, many carbonate intervals serve as fairly precise lines of correlation within an interval dominated by irregularly distributed or irregularly imbricated distributary sandstone packages.

With respect to the Uteland Butte carbonate reservoir, the paleoenvironmental mosaic is extremely complex. On the basis of the six cores confined to this stratigraphic interval, and on the basis of the written literature (Williamson and Picard, 1974, among others), light brown to medium dark gray shoreline deposits (See Plates 8 and 9 of the slab photograph collection) of varying environments are common to the southern region of the producing Monument Butte Field (T10S, R17E) including an approximate lithostratigraphic equivalent trend extending to the east and west. Correlative packages to the north are mainly comprised of deeper water argillaceous carbonates of a medium dark gray to dark gray hue. In all likelihood, the intergradational shoreline-basinal transitional lithologies occur in the southern tier of sections within T9S, R17E as an approximate reference point.

\section{Reservoir Carbonates}

\section{Uteland Butte carbonate reservoir}

The Uteland Butte carbonate reservoir actually contains a myriad of lithologies within the 125200 foot interval at the base of the Green River Formation. Not only are limestones and dolostones common as the stratigraphic name partially implies. Calcareous mudstones, siltstones are also prevalent as are occasional porous sandstones and mixed rocks (containing both carbonate allochems and siliciclastics. Reference to the core descriptions verifies these observations as does a careful scrutiny of the correlative electric logs. The reader is also referred to the extensive work of Little (1988), in which many of the following observations are 
extensively summarized.

As an observational generality with respect to the Uteland Butte, one notes the presence of clean, somewhat dolomitic limestones alternating with an array of fine-grained sandstones, mudstones, and mixed rocks (See Plates 8 and 9, slab photographs). These commonly porous (and sometimes permeable) carbonates represent the potential targets for both primary and secondary production. The grain-supported limestones (packstones and grainstones as defined by Dunham, 1962) are fairly similar to one another in that ostracod carapaces comprise many of the recognized allochems. Ostracods occur as (1) broken or whole, (2) disarticulated or articulated, (3) compacted or noncompacted, or (4) a single carapace or as concentric instars. Other allochems include (1) fresh-water mollusks including disarticulated pelecypods or turriform gastropods, (2) ooids or superficial ooids, (3) algae, (4) fish fragments, (5) intraclasts, (6) peloids of indeterminate origin, and (7) varying amounts of sand or silt-sized siliciclastics.

Most importantly, ostracods are common to both mud supported and grain supported limestone categories (wackestone, packstone, and grainstone). It is difficult to state conclusively, but these organisms appeared to inhabit the quiet, muddy environments just basinward of the grain supported equivalents. The latter lithotypes likely reflect accretionary shoreline deposits related to the modest wave or swash activity, which could be mostly wind-driven in these cases (Plates 11-13, thin section photographs). Many grain supported beaches or bars contain ostracods with muddy (commonly dolomitized) interiors indicating potential derivation from these shallow, muddy lagoons of questionable salinity. In summary, these ostracodal carbonates (Plate 12, thin section micrographs) contain one or more of the following void types when not totally surrounded by nonporous lime mud or spar cement: (1) intraskeletal porosity, (2) shelter porosity (immediately beneath a disarticulated carapace), (3) partial dissolution of allochems or matrix, and (4) microporosity or microintercrystalline porosity (in dolomitized sample). The keys to permeability decidedly involve compaction and/or dolomitization in this suite of samples. Compaction allows the ostracod to pass from a closed oblate spheroid (football-shape) to a more open and communicative entity, in which ostracod terminations are not morphologically closed. Ideally, the ostracodal carbonate, that potentially possesses better reservoir quality, would be a grain supported limestone or dolomite in which the individual carapaces have "open" terminations due to serious compaction (see Plate 13, thin section micrographs).

In selective instances, a low gamma ray bench is located at the stratigraphic top of the Uteland Butte, which is comprised of ostracods associated with lime mud. In most cases however, such compacted wackestones reflect a quiet water assemblage although allochems were abundantly washed into this setting. Compaction has seriously deformed many ostracod carapaces, and the wackstone/packstone lithology was sufficiently compacted and grain supported to permit dolomitizing fluids to pass among the many allochems and muddy elements. This dolomitization, likely facilitated by hypersaline conditions, sometimes provides an extremely high porosity (greater than 20\%) not easily recognized on traditional downhole logs run on a common 2.68 matrix density for the bulk of the sandy Green River Formation. This cryptocrystalline dolomite is unfortunately so finely crystalline that resulting permeability values are disappointingly low. No quantification of permeability is possible due to sample limitations (drill cuttings in selective cases), but permeability values are probably in the single millidarcy range based on visual 
estimation. If dolomitization is a pervasive phenomenon in this uppermost carbonate bench, exploitation of this interval becomes important because of the comparatively good reservoir quality not seen at other stratigraphic levels.

Ooid packstone/grainstone reservoirs are also common to shoreward accumulations of the Uteland Butte, and are stratigraphically associated with other current swept-deposits proximal to the southern lake levels as they fluctuated during various highstands and lowstands. It is tempting and somewhat appropriate to draw an obvious depositional analogy between the Recent ooids of the Great Salt Lake, and those from the southern margin of Lake Uinta. Both deposits are clearly from the nearshore, and the Recent ooids from the Great Salt Lake are mostly beach deposits in a region where high evaporation rates co-exist with a dominant north to south wind direction, which could provide some agitation for ooid formation. It is clear however that these ooids are not of the Bahamian type, where agitation is near-constant in a variety of shallow subaqueous conditions - tidal bars, beaches, submarine dunes, and related regimes. In Eardley (1966), he documents the geologic setting of the ooids, and distinctly alludes to the wide oolitic beaches at the southern end of the lake; Eardley also describes an oolitic bar extending from the southwestern end of Antelope Island, and such a bar is profoundly affected by the prevailing currents. Many oolitic deposits are ripple marked, and the Eocene Lake Uinta equivalents demonstrate many textural, structural, and depositional similarities to their Recent counterparts.

Sedimentary structures are rare or not always obvious in the grain-supported limestones. Ripups, lag deposits, and modest channeling are observed, usually near the base, and lamination or very low angle cross lamination perhaps reflective of small ripple features on the bedding plane surfaces can be observed in both hand specimen and thin section. Because much limestone can be correlated from place-to-place, especially in an approximate east-west direction (along depositional strike), shallow lacustrine shoals or beaches are most likely represented in this area. These deposits may be similar to the oolitic beaches observed today at the southern margin of the Great Salt Lake. Ostracodal offshore bars may be present but are comparatively rare because steeper cross lamination typical of bars is notably missing. Continuity over reasonably great distances, while not excluding an offshore bar setting, more strongly points to a shallow shoal separating the offshore lacustrine lagoon from the hypersaline mud flat located even more shoreward. Ooids may form similar shoal deposits where salinities are locally elevated within irregular re-entrants along the border between the current-swept shoal and the more quiescent and apparently landward mud flat.

In occasional instances, gradual coarsening upward trends allowed these beaches or shoals to develop as culmination to these trends, in that mud supported mollusk-bearing wackestones commonly pass stratigraphically upward to grain supported equivalents. Not all trends of this sort reflect a shallowing upward progression as many muddy units are instead representative of extremely shallow mud flat environments just basinward of potential subaerial conditions. Some laminated, muddy units even appear stromatolitic and could be partial lateral equivalents of the grain-supported limestones. Other clearly subjacent lithologies include poorly fossiliferous mudstones and thin sandstones, the latter laid down by the omnipresent distributary system. For some reason, vigorous distributary activity is not common to this basal member; perhaps the source areas were particularly inactive during the formation of these lowstand deposits. 


\section{Castle Peak Limestone (carbonate marker, Ryder and others, 1976)}

Elsewhere, higher in the Green River section about 500 feet above the Uteland Butte, a recently discovered reservoir is observable as cored in the PG and E 15-24B well from T9S, R19E, Uintah County. This abnormally thick section from the stratigraphic region, previously called the Castle Peak Limestone, consists of a variety of lithologies, the most striking of which, are porous carbonates referred to as a stromatolite mound by Osmond (2000). Although Osmond (2000) alludes to numerous constituents from this mound facies, we feel that he underestimates the role of algal material in constructing this buildup (Plates 16, 17, 18, thin section photomicrographs). In fact, evidence of algal filaments and associated microstructure is pervasive intermittently throughout both shallowing upward parasequences in the West Willow Creek field as described. Even the truly stromatolitic and oncolitic portions of the interval contain the algal filaments responsible for constructing the feature, an observation very rarely seen in true stromatolites (Plates 17 and 18, thin section micrograph suite). In reality, the buildup that Osmond (2000) describes is in large part an algal bioherm containing clear evidence of algal filaments and colonial microstructure (Plate 16, thin section photomicrographs). Such bodies have been found in the Great Salt Lake of Recent times as described by Eardley (1966). These Recent equivalent buildups are found in the shoreward areas of the Great Salt Lake and are commonly associated with oolitic deposits. Such algal bioherms are clearly recognized during climatic moments of low lake level, and some details concerning morphology are provided by Eardley (1966).

The bioherm contains both limestone and finely to microcrystalline dolomite, the latter commonly present as an admixture (dolomitic limestone). Because of the finely crystalline nature of the dominantly subhedral dolomite, most intercrystalline pores are relatively small, and resulting permeabilities within this bioherm fall within the single millidarcy range. The demise of the bioherm can be directly attributable to an eventual flooding surface at 4768 feet in the PG and E 15-24B well (see core description) as the lake level significantly deepened into a conspicuous black shale facies.

Osmond also mentions that the Willow Creek area to the southeast also appears as a buildup although the prolific oil production is uniquely associated with West Willow Creek Field. In any case, both regions contain porous buildups within the stratigraphically thinner Castle Peak Limestone, at least compared to the Uteland Butte at the base of the Green River Formation.

What is intriguing about both carbonate intervals (Castle Peak and Uteland Butte) involves the constant facies relationships that exist near-consistently from shoreward to basinward (SE to NW). Although log signatures are similar in both paleogeographic positions, the true reservoir rocks, (ostracodal packstones/grainstones, oolitic packstones/grainstones, finely crystalline dolostones, and algal buildups) are located to the SW, and that the basinward (lake bottom) stratigraphic equivalents are dark gray micritic limestones or dolostones with very little matrix porosity (also read comments for "Other Thin Carbonate Interbeds" immediately below). These nonreservoir equivalents, produce mudlog shows related in part to high total organic carbon (TOC) measurements, appear porous on logs when a 2.71 limestone matrix density is selected. In reality, the correct matrix density is in the 2.50-2.60 range due to excessive organic and/or 
hydrocarbon content, and the true porosity is essentially nil. These organic-rich rocks produce significant mudlog shows related to either the organic content or to the free oil situated in the natural fractures that commonly affect these strata.

\section{Other Thin Carbonate Interbeds}

Mostly in field exposures of the Green River Formation described in the stratigraphic portion of this report, carbonate beds, generally reflective of nearshore conditions along the southern shore of the lake, occur as mostly thin interbeds within the dominant clastic sequence. Not surprisingly, these interbeds are largely oolitic, ostracodal, pisolitic, stromatolitic, and algal, reflecting the array of nearshore conditions proposed earlier. Many of these interbeds have been recognized as the equivalent to subsurface markers that serve to partition the major portion of the middle and lower Green River Formation. Similarly to those instances described above, these nearshore facies pass basinward (northward) to equivalent carbonates whose composition has also changed to micritic, organic carbonates of lake bottom conditions and unusually low matrix densities (Plate 15, thin section micrographs). Thus, many of these thin correlative carbonate markers pass from grain-supported reservoirs to mud supported nonreservoirs from south to north within the Monument Butte producing area. Gamma ray signatures remain recognizable in almost all cases, but density porosity values for the mud supported equivalents are not accurate due to the low matrix density of these organic-rich basinal deposits.

\section{Nonreservoir Lithologies in "Carbonate" Settings}

The non-reservoir lithologies associated with carbonate deposition are derived from three major lacustrine settings: (1) mud flats, (2) shallow lacustrine environments involving both carbonate and siliciclastic deposition, and (3) lake-bottom environments involving deeper water conditions.

\section{Mud Flat}

The mud flat lithology is recognized by its persistent laminated structure, by its apparent mud cracks, by diastemic surfaces and gently discordant strata, and by its abundant accumulations of compacted thin-shelled pelecypods. The dark and light laminations reflect not only variations in organic content, but also discrete shell-rich and shell-poor laminations related perhaps to very small tidal cycles. Many such laminations strongly resemble the micro-irregularities of algal stromatolites with very low amplitude convex-upward and undulatory laminations. Algae are not apparent in thin section, but such algal mats are common to the very shallowest of lacustrine environments in the present-day Great Salt Lake. To the east within the Uinta Basin where the Eocene Basal Limestone is actually exposed, traditional "cabbage head" stromatolites of the LLH variety (Logan and others, 1964) are commonly observed. Hemispherical stromatolites in the Green River Formation are abundantly present at several surface exposures along the southern and eastern edges of the Basin.

Associated with a purported mud flat environment are very finely crystalline dolostones that bear remarkable similarities to the primary or penecontemporaneous dolostones associated with paralic marine environments. Much more work needs to be done with this lacustrine lithotype, 
but a laminated fabric associated with occasional rip ups and subtle soft sediment deformation is reminiscent of these extremely shallow, evaporative analogues. Yellow-brown hues are also potential clues to near-subaerial conditions of formation.

\section{Shallow Lacustrine Environments}

Siliciclastics are present as very fine-grained sand and/or silt. Most accumulations form in very shallow, sediment choked channels (abundant interference ripples are observed). Nonchannel siliciclastics are also common as overbank or floodplain deposits, which mix with a variety of nearshore carbonate facies. Based on detailed regional work done by Colburn and others (1985), such deposition was derived from the south with resulting, anastamosing channels dissecting the carbonate shoreline in a more northerly direction.

Although these very fine-grained sandstones are all tight within this core, occasional porous and permeable sandstones are found within this carbonate interval. Many are oil saturated and thus prospective at approximately 50 millidarcies. Apparently, these intricately cross-bedded sandstones are areally discontinuous and probably reflect bypassed channel sand that ultimately accumulates in an offshore shoal setting. One such productive reservoir may be located above the cored interval in the WDS 11-20-10-17 well between 4,934 and 4,940 feet, log depth. From an exploration/exploitation perspective, these offshore sandbars may be elongate parallel to the purported east northeast-west southwest shoreline.

Another common nonreservoir lithology involves medium gray molluscan wackestones, in which fresh water pelecypods and/or turriform gastropods accumulate as mostly broken and/or disarticulated materials. These deposits commonly underlie the grain-supported ostracodal or oolitic packestones or grainstones in part of a shallowing upward parasequence. Most trends are usually recognized in the Uteland Butte carbonate reservoir and occasionally in the Castle Peak Limestone Marker. These wackestones possess little to no porosity, and fall definitely into the nonreservoir category.

\section{Lake-Bottom Settings}

Finally, the medium gray to medium dark gray illitic mudstone found at 5,003 to 5017 feet in the WDS 11-20-10-17, which is associated with remnants of pyritic, bioturbated, very fine grained sand and/or silt probably reflects the lake bottom assemblage, The sand occasionally fines upward and appears locally graded. Commonly, this mudstone is noncalcareous as opposed to the calcareous mudstones containing clear evidence of micrite (lime mud) in thin sections. From a sequence stratigraphy perspective, the mudstone overlying the oolitic limestone at 5,017 feet may represent a localized maximum flooding surface as the lake level apparently rose, and the areal extent of Lake Uinta significantly increased.

\section{Carbonate Petrology Summary and Conclusions}

- Carbonates are present as both nonreservoir and reservoir rocks in the basal member of the Green River Formation, which directly overlies the Paleocene-Eocene Wasatch 
Formation. This basal member is called the Uteland Butte carbonate reservoir and usually measures $150-200$ feet in thickness.

- Other carbonates are present as intermittent stratigraphic markers among the more prevalent siliciclastic sandstone, siltstone, and mudstone packages. These thin carbonates can also be producing horizons, but more commonly are nonporous argillaceous, hydrocarbon-rich limestones and dolomites especially in more basinal (northward) depositional settings.

- Most reservoir rocks consist of grain-supported oolitic and/or ostracodal packstones or grainstones, which were deposited as shallow shoals along the southern margin of Eocene Lake Uinta. These shoals are locally correlative, especially along depositional strike, which logically ran subparallel to the lake's shoreline.

- The reservoirs above commonly possess acceptable porosities but varying permeabilities. Poor permeabilities ( $\sim .1 \mathrm{md})$ exist where intraorganic and moldic void space remains isolated within articulated and calcite cemented ostracod carapaces and selectively leached concentric ooid laminae.

- Better permeabilities occur when ostracod carapaces are compacted but not flattened (Plate 13, thin section photomicrographs). Open rather than closed terminations of biconvex shells allow the connectivity of dominant intraorganic void space. Good permeabilities also result when secondary, finely crystalline dolomitization affects originally poorly permeable limestones; a certain amount of intercrystalline void space is generated during dolomitization.

- Algal bioherms have also been recognized in certain shoreward portions of the Basin, particularly in the Castle Peak Limestone Marker (Osmond, 2000). A combination of intraorganic void space and dolomitization provides for reasonably good reservoir quality (Plate 16, thin section photomicrographs).

- Both the Uteland Butte carbonate reservoir and other producing carbonate markers usually pass northward into nonproductive argillaceous carbonates (limestone and dolomite), with very high organic content (between 1 and $6 \%$ TOC). These argillaceous rocks possess very low matrix densities $(\sim 2.55)$, densities that serve to mislead operators into recognizing nonexistent matrix porosities through possibly erroneous log interpretation.

- Origin of dolomitization is officially unknown, but high evaporation rates on the edge of Lake Uinta likely play a strong role in dolomite formation. Penecontemporaneous dolostones have possibly been recognized in several cored localities pertaining to this study. 


\section{REFERENCES CITED}

Case, J. E., 1991, Geologic map of the northwestern part of the Uncompahgre uplift, Grand County, Utah and Mesa County, Colorado, with emphasis on Proterozoic rocks: USGS Miscellaneous Investigations I-2088.

Colburn, J. A., Bereskin, S. R., McGinley, D. C., and D. M. Schiller, 1985, Lower Grren River Formation in the Pleasant Valley producing area, Duchesne and Uintah counties, Utah. In Geology and Mineral Resources, Uinta Basin of Utah (M. D. Picard, ed.): Utah Geological Association Guidebook 12, p. 177-186.

Dunham, R. J., 1962, Classification of carbonate rocks according to depositional texture. In Classification of Carbonate Rocks (W. E. Ham, ed.): Amer. Assoc. Petroleum Geologists Memoir 1, p. 108-121.

Eardley, A. J., 1966, Sediments of Great Salt Lake. In The Great Salt Lake (W. L. Stokes, ed.): Guidebook to the Geology of Utah \#20, Utah Geological Society, p. 105-120.

Fouch, T. D., and W. D. Dean, 1982, Lacustrine and associated clastic depositional environments. In Sandstone Depositional Environments (P. A. Scholle and D. Spearing, eds.): Amer. Assoc. Petroleum Geologists Memoir 31, p. 87-114.

Fouch, T. D., Nuccio, V. F., Osmond, J. C., MacMillan, Logan, Cashion, W. B., and C. J. Wandrey, 1992, Oil and Gas in Uppermost Cretaceous and Tertiary rock, Uinta Basin, Utah. In Hydrocarbon and Mineral Resources of the Uinta Basin (T. D. Fouch, V. F. Nuccio, and T. C. Chidsey, eds.): Utah Geological Association Guidebook 20, p. 9-48.

Garner, Ann, and T. H. Morris, 1996, Outcrop study of the lower Green River Formation for reservoir characterization and hydrocarbon production enhancement in the AltamontBluebell Field, Uinta Basin, Utah: Utah Geological Survey Misc. Pub 96-2, 61p.

Heyman, O. G., Huntoon, P.W., and M. A. White-Heyman, 1986, Laramide deformation of the Uncompaghre Plateau - Geometry and mechanism. In New Interpretations of Northwest Colorado Geology (D. S. Stone, ed.): Rocky Mountain Association of Geologists Guidebook, p. 65-76.

Jopling, A. V., and R. G. Walker, 1968, Morphology and origin of ripple-drift cross-lamination, with examples from the Pleistocene of Massachusetts: Jour. Sedimentary Petrology, v.38, p. 971-984.

Little, T. M., 1988, Depositional environments, petrology, and diagenesis of the basal limestone facies, Green River Formation (Eocene), Uinta Basin, Utah: Unpub. M. S. thesis, University of Utah, 154p.

Logan, B. W., Rezak, Richard, and R. N. Ginsburg, 1964, Classification and environmental 
significance of algal stromatolites: Jour. Geology, v. 72, p. 68-83.

Nielson, D. L., Lutz, S. J., Lomax, J. D., and John Dyer, 1996, Stratigraphy and image log interpretation (Chapter 1 of DOE Class 1 Green River Formation Water Flood Demonstration Project Report), 39p. (figs).

Oleson, N. E., 1986, Petroleum geology of the Eocene lower Green River Formation, Duchesne and Uintah counties, Utah: Unpub. M. S. thesis, Baylor University, 173p.

Osmond, J. C., 2000, West Willow Creek Field: First productive lacustrine stromatolite mound in the Eocene Green River Formation, Uinta Basin, Utah: The Mountain Geologist, v37, p. $157-170$.

Picard, M. D., Thompson, W. D., and C. R. Williamson, 1973, Petrology, geochemistry, and stratigraphy of black shale facies of Green River Formation (Eocene), Uinta Basin, Utah: Utah Geol. and Mineralogical Bulletin 100, 52p.

Pitman, J. K., Fouch, T. D., and M. B. Goldhaber, 1982, Depositional setting and diagenetic evolution of some Tertiary unconventional reservoir rocks, Uinta Basin, Utah: Amer. Assoc. Petroleum Geologists Bull., v. 66, p. 1581-1596.

Remy, R. R., 1992, Stratigraphy of the Eocene part of the Green River Formation in the southcentral part of the Uinta basin, Utah: USGS Bulletin 1787, Chapter BB, 79p.

Ryder, R. T., Fouch, T. D., and J. H. Elison, 1976, Early Tertiary sedimentation in the western Uinta Basin, Utah: Geological Association of America Bulletin, v. 87, p. 496-512.

Williamson, C. R. and M. D. Picard, 1974, Petrology of carbonate rocks of the Green River Formation (Eocene): Jour. Sedimentary Petrology, v. 44, p. 738-759. 


\section{Plate Descriptions}
(1) Slab Photographs
(2) Thin section Micrographs
(3) SEM Micrographs 


\section{Slab Photographs}

Plate 1: Image comes from portion of lower delta plain that is typical of interdistributary lithology. Fabric is irregularly laminated and consists of dolomitic mud interlaminated with very fine-grained sandstone of a purported overbank origin. The sand laminations are usually loaded into the underlying shale, and other forms of soft-sediment deformation are modestly present. Some bioturbation is commonly observed from this particular lithotype. In this case, the irregular fracture is not naturally occurring.

Plate 2: View is typical of facies, which exhibits climbing ripples and/or ripple-drift lamination particularly in the upper portion of distributary channels. This lithology is reflected in intermediate gamma ray signatures between the extremely low readings of comparatively clean sandstone and the "hotter" signatures of siltstones and mudstones. Although not restricted to upper portions of fining-upward distributary channels, this rock type is most common in that stratigraphic position and likely reflects the waning stage of seasonal floods where suspended loads are quickly deposited when distributary flow decreases.

Plate 3: Identical sample from above, now clearly exhibiting near-vertical natural fracture partially lined by calcite. This particular facies normally possesses poor reservoir quality in that matrix porosity/permeability values are typically low. Obviously, an array of closely spaced fractures such as this one can overcome the poor oil production usually obtained from such sandstones. In fact, this particular township contains more than its share of unusually good production in regions where the density porosity numbers are clearly below the desired $10 \%$ minimum. Most densely fractured sandstones in this township are from the stratigraphic portion of the lower Green River Formation between the Castle Peak Limestone Marker and the Uteland Butte Carbonate Member.

Plate 4: This sample is continuous with sample from Plate 5, and both samples originate from a mappable distributary channel, which in this case exhibits a range of wavy laminations, imperfect interference rippling, to classic ripple features seen parallel to the number " 7 " in the inch-by-inch scale on the left. Although dynamic sedimentary structures can vary within the channel itself, such change is likely related to the interplay of velocity and bedload, rather than by a change into another distinct sedimentary environment.

Plate 5: Slab exhibits change in sedimentary structures from bottom to top: (1) planar laminated to cross-lamination, (2) possible large scale rippling (megaripple?) between numbers " 8 " and "9", and (3) wavy lamination to irregular small scale ripples at the top. Sample remains oilstained indicating at least some modest reservoir quality. In most cases, the darker the oil stain, the poorer the permeability in that particular slabbed portion.

Plate 6: Photo represents a 10-foot cored section from the lacustrine turbidite facies in the Lower Douglas Creek portion of the Green River Formation. The light gray sandstones are reflective of chaotic debris flow environments in that irregular breccia clasts are recognizable as well as disrupted bedding related to common soft sediment deformation (see steeply laminated interval to the right of center). Lack of any oil stain here likely reflects a corresponding lack of reservoir 
quality. Sample is continuous with the following image of Plate 7.

Plate 7: The darker gray hue was chosen to accentuate the presence of brown, gray-green, and dark gray clasts embedded in the unstained siltstone/very fine-grained sandstone matrix. In some cases, clasts are also affected by the synsedimentary deformation common to this facies. Also note to the left of center the irregularly laminated material represented of the second lithotype common to this environment. Reservoir quality is often better developed in this laminated facies; in some cases, these laminations are graded as the apparent depositional regime waned in intensity, or that these materials could reflect deposition from a turbiditic suspended load "tail" as the material was selectively sorted during the downslope movement. The thin, dark shales likely represent the "hemipelagic" portion of these largely transported materials.

Plate 8: The 10-foot section comes from the Uteland Butte Limestone member where dark organic mudstones are interbedded with light brown (oil stained) carbonate reservoirs. Unlike many of the sandstones from stratigraphically higher intervals, these carbonate benches can be correlative over comparatively long distances. This conclusion would be especially true for the reservoirs on the far right of this 10 -foot core section. In most cases, the reservoir is an ostracodal or oolitic packstone/grainstone, reflective of a shallow shoreline accumulation. In many cases however, the permeability values for this reservoir are minimal in spite of adequate porosity because most void space is restricted to the unconnected, intraorganic voids contained in the interior of the nearly articulated ostracod carapace. In this view, the current-swept reservoirs are preferentially loaded into the more ductile, oil-prone mudstones/shales.

Plate 9: Continuation of the preceding slabbed interval where in this case, the carbonate interval (brown coloration) is more evident in spite of intervening dark mudstones. In the southern portion of the Monument Butte area, these reservoir carbonates are consistent production targets, but these same paleoshoreline reservoirs from the Uteland Butte interval pass northward into into organic limestones of offshore (or basinal) lacustrine conditions where porosity/permeability is virtually nonexistent in these laterally equivalent carbonate source beds-also mature, oil-prone deposits similar to the aforementioned dark mudstones/shales.

\section{Thin Section Plates}

Plate 1: Top view illustrates very fine-grained sandstone from a traditional distributary channel where very good porosity (mauve coloration) is readily apparent. The feldspathic litharenite is in itself well sorted, but during deposition, has cut through an oolitic shoal and incorporated certain ooids (very dark rounded grains) into the dominant siliciclastic assemblage. Middle view is a reflected light image of the previous in which porosity appears light yellow-orange or light yellow-green. The former represents secondary intergranular void space, which usually results in good permeability; the latter is a reflection of carbonate microporosity associated with microcrystalline ankeritic ooids. As it turns out, secondary intergranular porosity arose from the dissolution of early calcite cement, which initially closed off intergranular pore space and prevented the occurrence of grain compaction or tighter grain packing. Finally, the highly magnified and stained bottom view reveals the details of ooid morphology with siliciclastic 
nuclei, and the late ankeritic (stained blue) infilling of secondary pore space; ankerite that commonly nucleated on iron-poor dolomite grains and/or crystals. In this type of reservoir, porosities measure in the 15 to $18 \%$ range with permeabilities extending from 20 to $100 \mathrm{md}$.

Plate 2: If iron-poor early calcite cementation does not take place, the silica rich system involves sediment compaction and quartz overgrowth formation due to pressure solution of grains (top view). Middle view illustrates reduced intergranular pores (blue), formed due to physical and chemical compaction. Framework elements in most Green River rocks include quartz, potassium feldspar, plagioclase, sheared metamorphic rock fragments, chert, micas (biotite, chlorite, and muscovite), volcanic rock fragments, and sedimentary rock fragments of mudstone, carbonate, or recycled sandstone origin. Granitic rock fragments are usually disaggregated into their constituent minerals in the very fine to fine-grained sandstones, but are clearly recognizable in the medium-grained varieties most often occurring in the interval between the Castle Peak Limestone marker and the Uteland Butte Carbonate Member. Certain rock fragments can be recognized in the polarized bottom view, as can the clear effects of chemical compaction and quartz overgrowth cementation. In rocks similar to this example, porosity occurs around the $10 \%$ figure, and permeabilities measure near $1 \mathrm{md}$.

Plate 3: A tight rock can also result when iron-poor calcite cement precipitates early in the rock's diagenetic history, prohibits much compaction, and then is pervasively dissolved. This calcite leaching can be followed by a thorough second phase of carbonate cementation involving ironrich calcite or ankerite. In this view, ankerite (stained blue) has effectively reduced reservoir quality to virtually zero. In localized regions, the ankerite not only infills secondary intergranular voids but also begins to replace framework grains.

Plate 4: Bases of distributary channels are common locations for carbonate cementation as seen in all three views. This thin section originates from a channel base where mudstone lags from interdistributary regions commonly occur. Carbonate shoal material also is preferentially plucked up and incorporated during the initial stages of distributary development. Perhaps diagenesis of these carbonate allochems allows carbonate cement to forms in intergranular regions, producing a low gamma ray signature and very little porosity in the basal distributary portions. Because the carbonate cement is localized at the base, a fining upward trend becomes even more apparent, although part of the trend is accentuated due to carbonate cement. As you can see from the top and middle views, sorting is unusually poor in the basal channel portions. In the bottom view, a conspicuous sheared metamorphic quartz grain is readily observed along with poorly sorted carbonate and siliceous material. Rounding varies considerably among the framework elements, lending some support to derivation of material from a collection of source terrains.

Plate 5: Reservoir quality can even significantly vary within a single sample. The upper view is mineralogically similar (light siliciclastics and dark carbonates) to the underlying image, but the former is unusually well compacted and cemented. The lower view possesses a great deal more in the way of selective dissolution perhaps of unstable rock fragments or minerals. Silica cementation is also less pervasive in the lower image. 
Plate 6: Sample originates from the rhythmically laminated facies of the cut and fill lacustrine turbidites. In some cases, the laminations are characteristically graded, and vertical permeability is greatly impaired by either mudstone partings or by tightly packed silt-sized material (upper view). The lower porosity only image accentuates the varying amounts of fluorescing void space. Note the very dark mudstone parting $1 / 3$ from the photo base (nonporous) and the overlying graded interval in which porosity appears best in the lowermost portion (light yellow-orange). To compound this complex porosity picture, many grains are coated by detrital mud as the sediment was apparently washed down brusquely in a comparatively turbid environment.

Plate 7: High magnification view of turbiditic sand reveals very poor sorting, variable rounding, localized compaction, and detrital and authigenic clays (faint mauve color occurs in microporous authigenic clay patches in upper view). Dark grains in this case are mudstone fragments, which have been physically compacted to varying degrees; note compacted pseudomatrix in dark portion to the extreme right. Lower view is illustrative of varying pore throat size as light yellow orange indicates larger pore throats, and the more reddish hues are indicative of the small pores and pore throats (microporous clays). Microporosity may also be indicated for the grains that fluoresce light green. In any case, this turbiditic zone contains the most variable forms of porosity in rocks that do not effectively correlate. Waterflooding of the Lower Douglas Creek interval could be disappointing compared to flooding of the more traditional distributary channels.

Plate 8: These views, along with those of the next two plates, are taken from deep samples in the Green River Formation. These medium grained-sandstones are usually present in the stratigraphic interval between the Castle Peak Limestone Marker and the basal Uteland Butte Carbonate interval. The latter lies directly on the subjacent Wasatch Formation (PaleoceneEocene). These sandstones are usually tightly packed and intricately compacted, making them difficult reservoirs from a production point of view. However, these rocks are also variously affected by dissolution of grains as seen in the upper view. In most cases, the feldspars (microcline to the extreme right) and certain rock fragments (chert toward the upper left corner) are selectively dissolved, providing a certain amount of reservoir quality. The framework elements are extremely variable mineralogically, lending support to derivation from a multitude of source terrains. Feldspars are comparatively abundant in this interval causing some of these rocks to be classified as lithic arkoses; not unrelated to this observation, granitic rock fragments are occasionally observed. Note the highly birefringent muscovite flake in the lower view.

Plate 9: Another view from the same location reveals partial leaching of large potassium feldspar grains (stained yellow) and a smaller unstained plagioclase. Even in the upper view, one can see the unstained feldspar remnant and accompanying infilling of the secondary pore by clay. Examination of the lower view in cross-polarized light indicates that the clay infilling is largely kaolinite - perhaps derived from the alteration of the feldspar itself. In actuality, other authigenic clays exist in the same pore fill; illite and illite-smectite are the most common species (See SEM plates).

Plate 10: Poorly sorted medium-grained sandstone is again characterized by selective leaching of feldspars, tight packing and compaction of grains, quartz overgrowth cement, and reduced 
intergranular porosity. The latter is characterized by triangular patches of blue epoxy, near lower right corner. Some of these triangular pores are secondarily enlarged through the leaching or dissolution phase (left of center, upper view). Upper view also shows green chlorite (just below center), and dark grain in upper portion of micrograph is a mudstone fragment ostensibly derived from the interdistributary regions. Lower view in cross-polarized light reveals sheared metamorphic quartz (left of center), conspicuous chert grain (lower left corner), tight compaction, and many linear grain boundaries caused by compaction and by terminations of quartz overgrowth cement. Although some permeability results from the reduced intergranular pore network, good reservoir quality is usually produced through the dissolution process.

Plate 11: Mixed assemblage is seen from the basal Uteland Butte Carbonate Member in the upper view. Detrital quartz is admixed with broken and whole ostracod debris although broken and compacted ostracod fragments dominate the lower lamination. Lower view also consists of a laminated fabric where a partially consolidated silty mud-rich lamina is deformed and injected by a subsequent current-swept shoal represented by an ostracodal shoreline grainstone.

Plate 12: Upper view illustrates typical lithology reflective of shoreline accumulations along certain portions of the southern edge of Lake Uinta. These deposits are recognized in more southerly surface rocks as well as in Uteland Butte Member benches as cored from the southern portions of the Monument Butte producing field. Such accumulations are typical current-swept deposits likely to have formed at the southern lake edge during the Eocene. The lower view in reflected ultra-violet light demonstrates that while porosity can be significantly abundant in these rocks (light yellow to yellow-orange), most of these voids lie within individual carapaces and are not necessarily well connected. Thus, the permeability of many uncompacted, undolomitized ostracodal grainstones is very modest $(\sim 0.1 \mathrm{md})$ due to the intraorganic voids that dominate this carbonate-rich member at the formation base.

Plate 13: Rock was originally an ostracodal packstone (note small patches of matrix mud in upper view), which was compacted and subsequently dolomitized. Compaction of ostracods causes the carapace to gape at the shell termination rather than producing a normally closed termination. This type of compaction provides porosity connectivity and permeability, and in this case, the early permeability may have allowed access by the dolomitizing fluids. In any case, the abundance of mauve epoxy in the upper view and the yellow orange fluorescence in the lower view demonstrates better reservoir quality when this view is compared to the views from Plate 12. Dolomitization, although poorly understood from Green River Formation rocks, does commonly produce porosity because of the common decrease of crystal volume when calcite is secondarily replaced by dolomite. The pervasive yellow-orange color indicates the potential effectiveness of the dolomitization process.

Plate 14: Photomicrographs again illustrate the contrast between ostracodal-ooid grainstone and similar rock affected by dissolution and dolomitization. Sample from the upper view remains conspicuously poorly porous, whereas the lower image is from a sample where obvious dissolution and not-so-obvious dolomitization have taken place. In the lower view, certain concentric ooid laminae are selectively dissolved, and other forms of porosity occur both inside and outside of individual ostracod carapaces. Because of the potential for such reservoir 
variability, operators must look for laterally extensive zones of porosity and permeability for both sustained primary and secondary production.

Plate 15: Source rock from the Castle Peak Limestone marker typically associated with the shoreline reservoirs as cored in the southern portion of the Monument Butte producing region. Compacted/disarticulated ostracods and phosphatic debris are associated with thin dolomite (bronze) laminations and with organic-rich mudstones. While many authors have proposed that this facies is typically associated with deeper lake-bottom environments, it may be possible that such rocks come from mud flat regimes rich in the algal debris that serve as a chemical source for the produced and geochemically analyzed oil. Some laminations actually appear stromatolitic (reflective of a potential algal mat), but firm environmental conclusions cannot be made at this time. This sample lies directly on shallow water ostracodal packstones and grainstones, but underlies the proposed flooding surface at 4748 feet in the 15-24 well.

Plates 16, 17, and 18: All three images come from the purported algal stromatolite bioherm as described by Osmond (2000) occurring in two geographic locales within the Castle Peak Limestone marker. These three plates all indicate the direct influence of green and blue-green algae in forming this biohermal deposit. Plate 16 reflects the actual presence of dolomitized green? algal remains with fairly good reservoir quality (yellow-orange color in lower view). Such remains have also been observed in the shallow portions of the Great Salt Lake (Eardley, 1966) Plate 17 originates from a "stromatolite" sample, which in this case is clearly constructed from blue-green? algal filaments. Such preservation of abundant algal filaments in such a stromatolite is clearly rare and astonishing even to stromatolite workers. Finally, in Plate 18, one observes a clear pisoid in the upper low-magnification view, but details of algal filaments clearly comprise this sedimentary structure as seen in the lower view. Again, recognition of the constructive algal culprit is very rarely observed in the sedimentary record.

\section{SEM Plates}

Plates 1-16: Descriptions on photomicrographs themselves.

Details of clay morphology and composition are especially informative here. Thanks to Ms. Barbara Marin of TerraTek for her excellent work with the scanning electron microscope. 

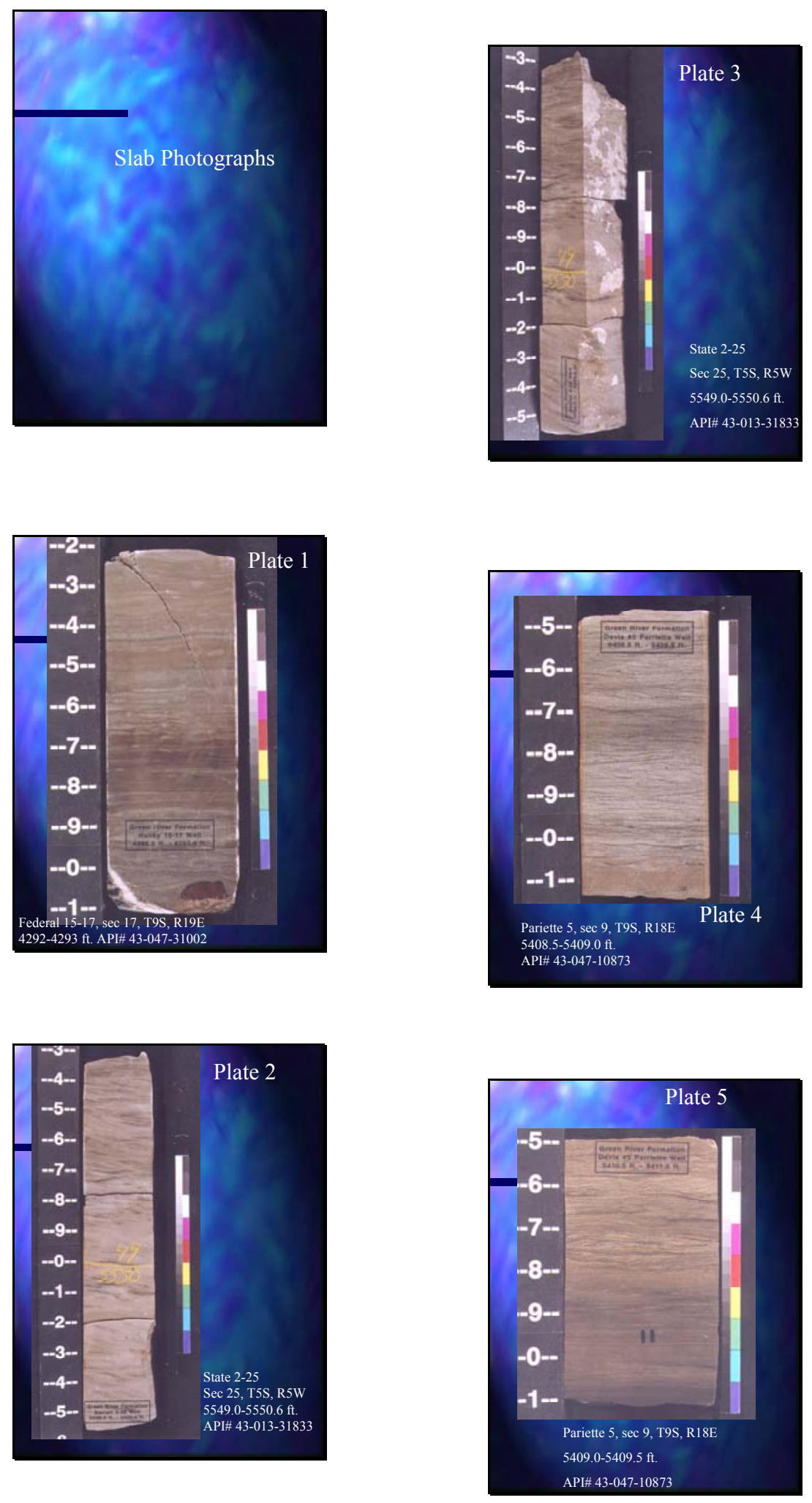

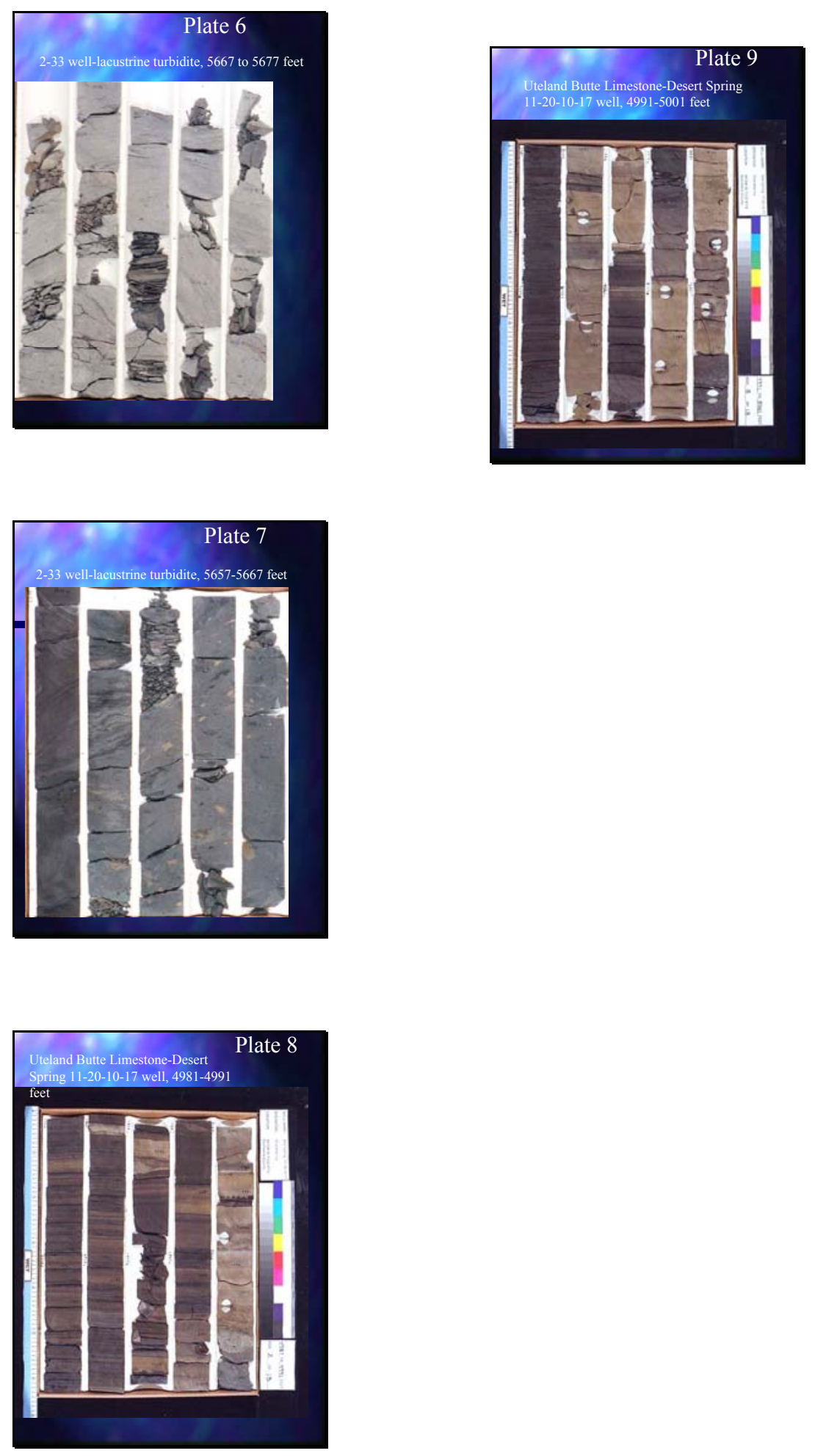

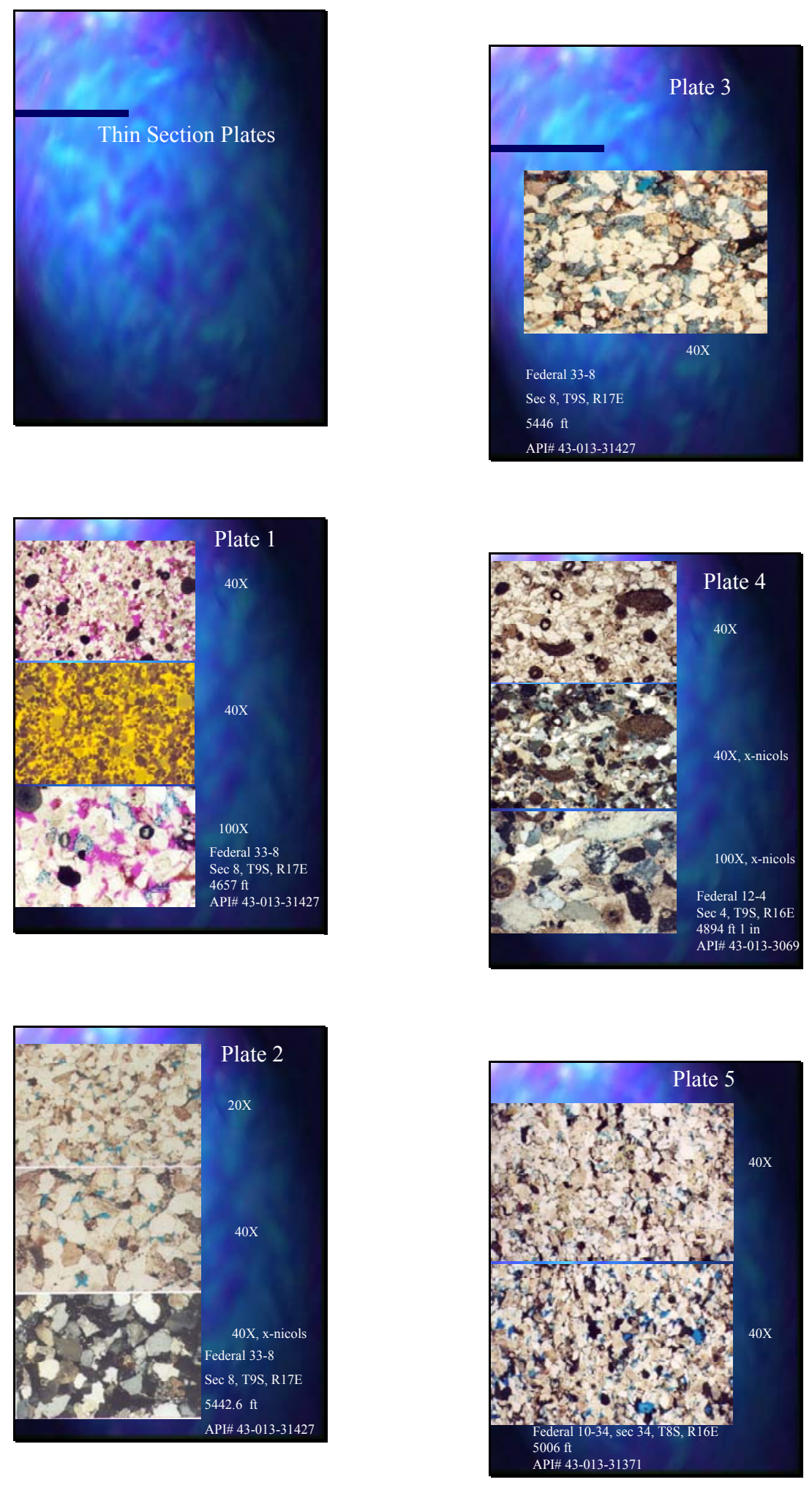

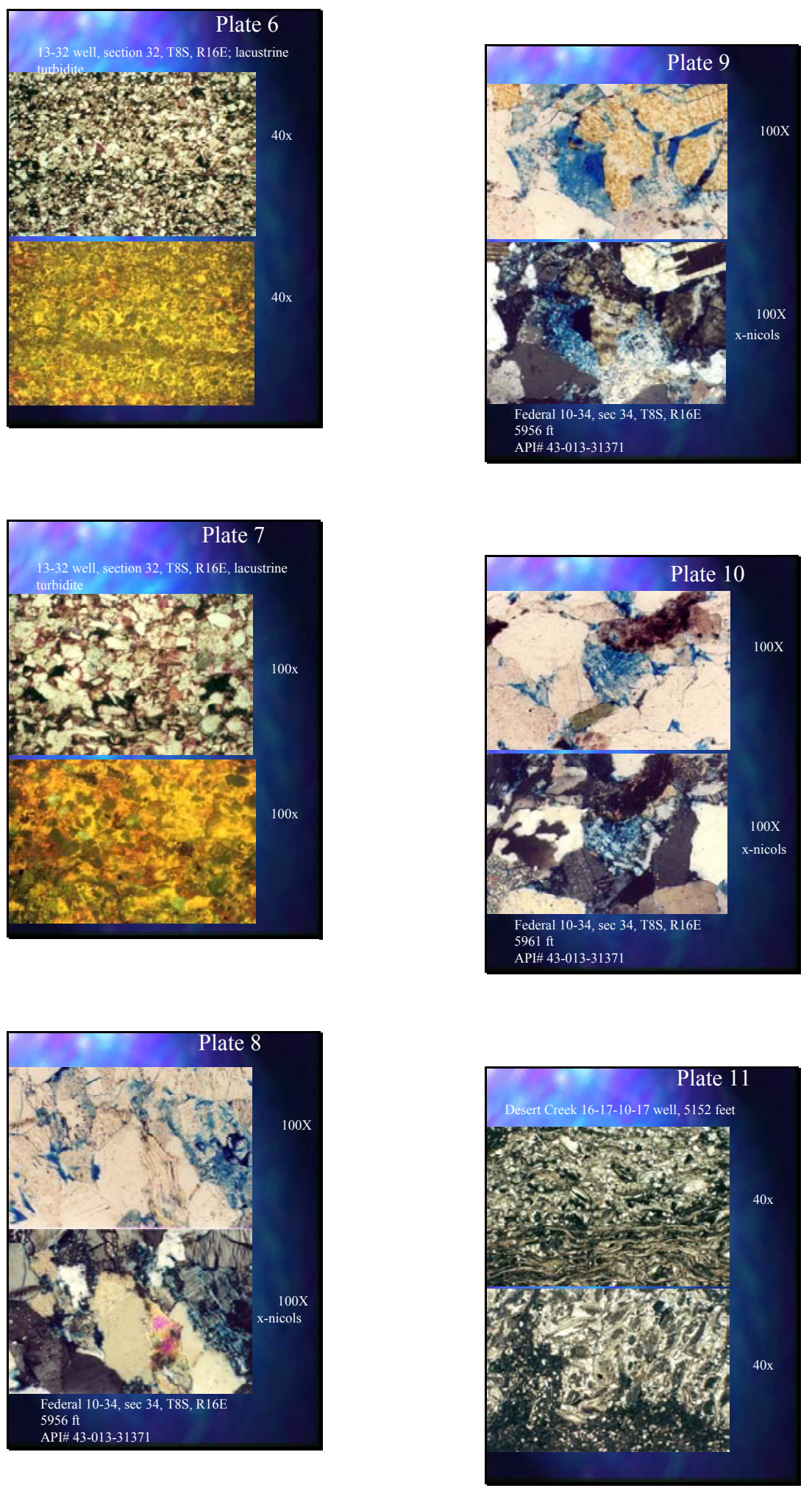

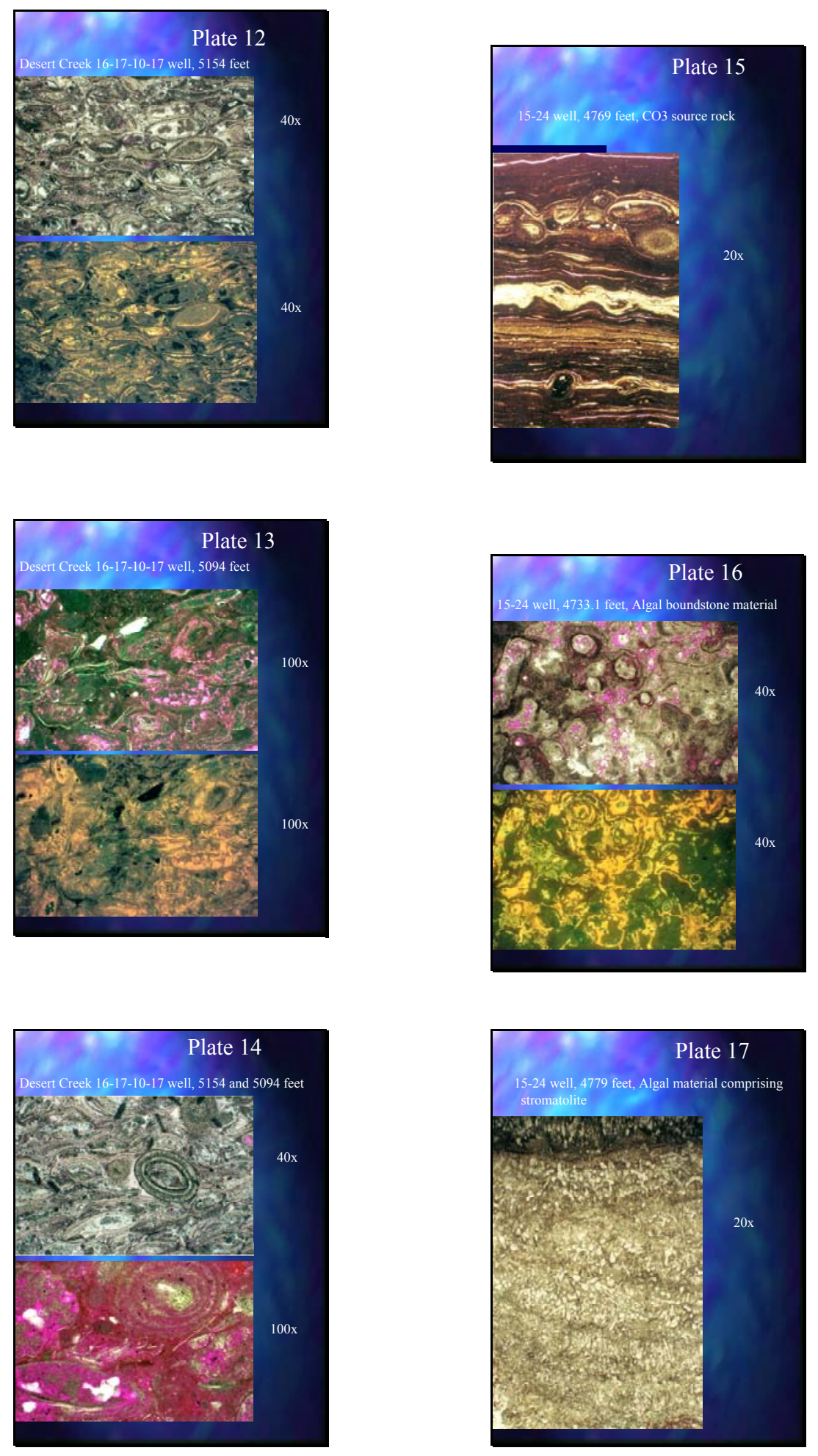


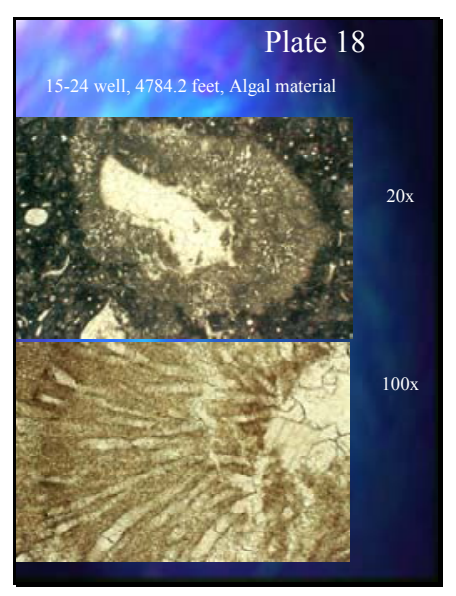



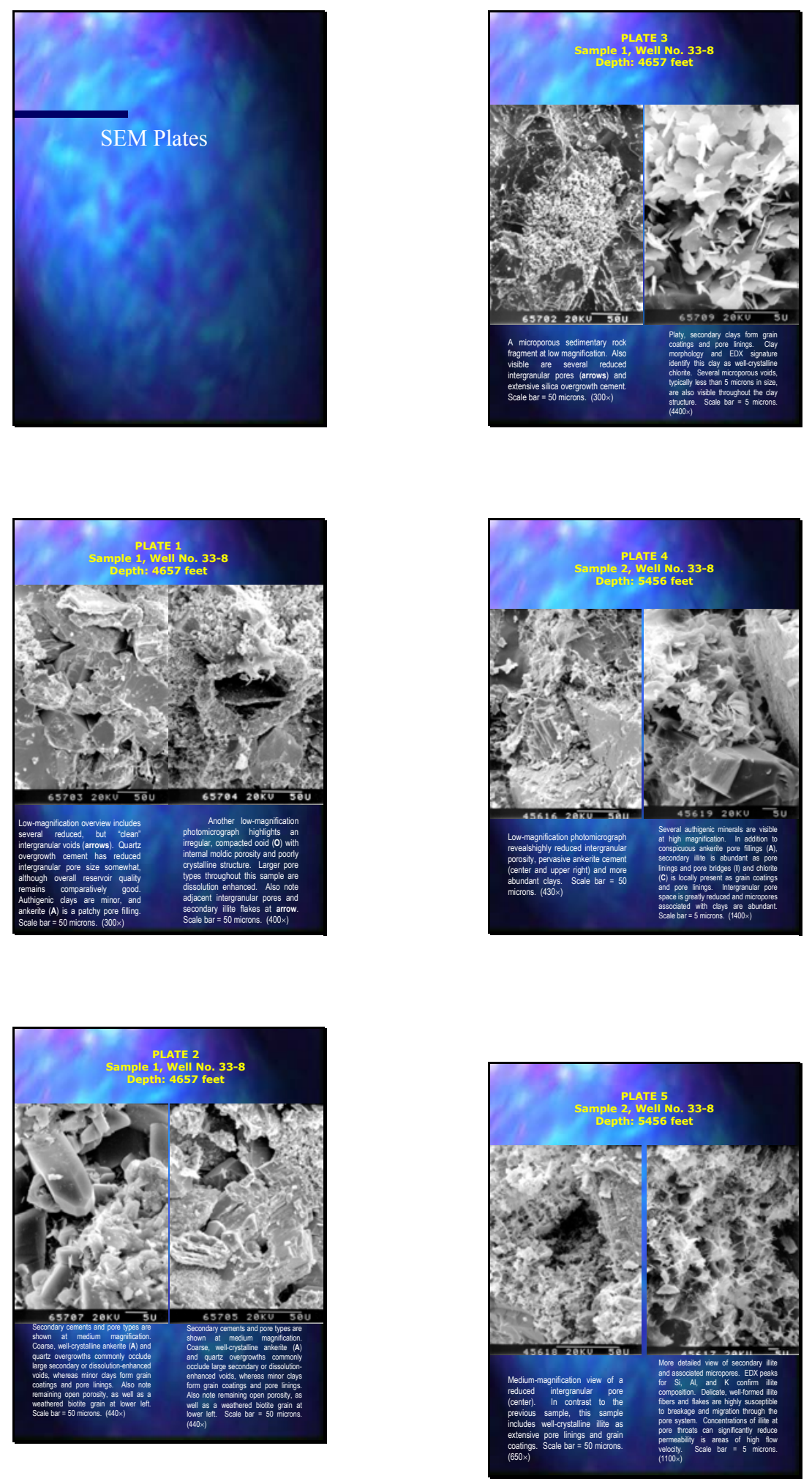

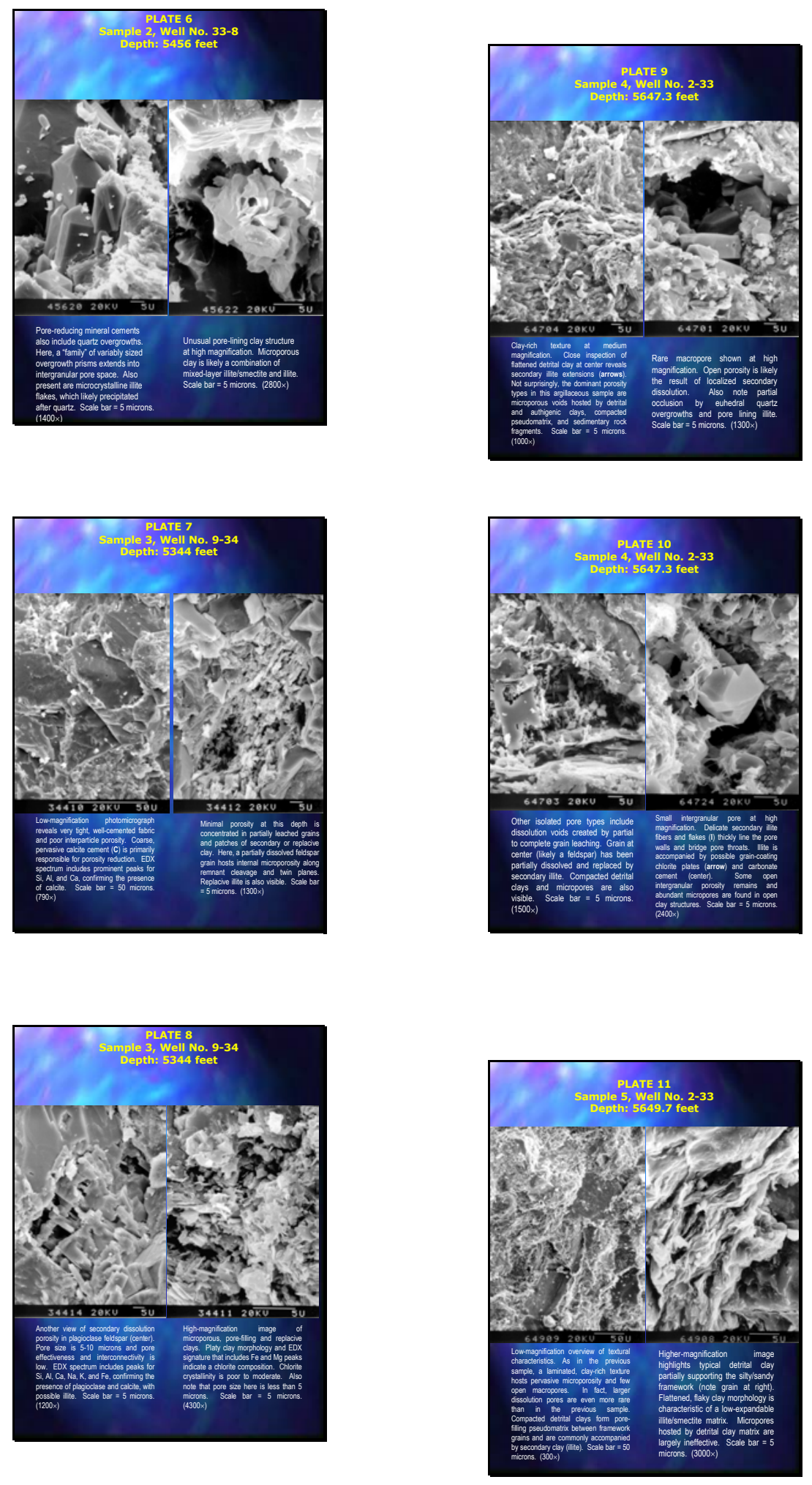

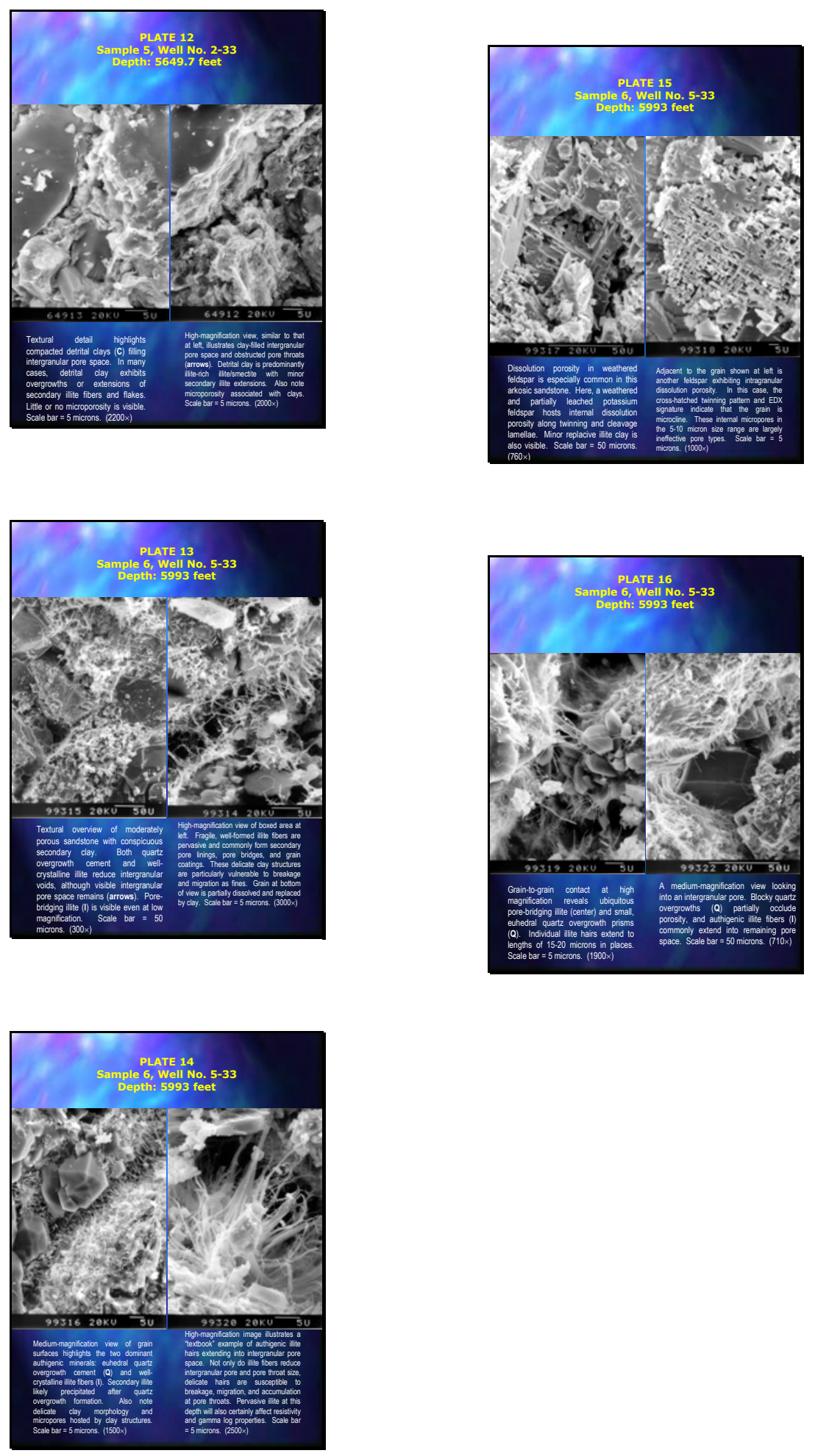


\section{SANDSTONE DIAGENESIS}

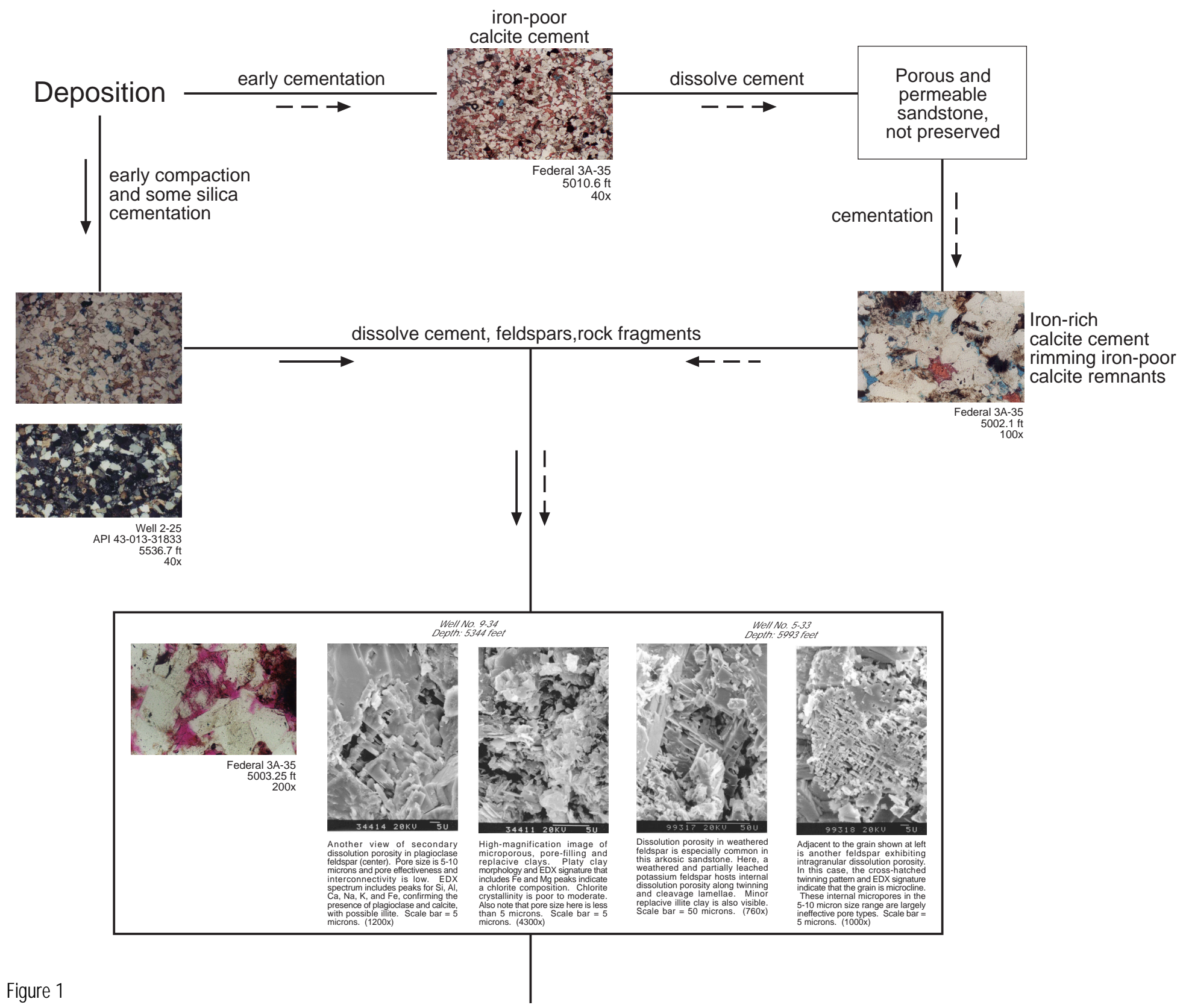




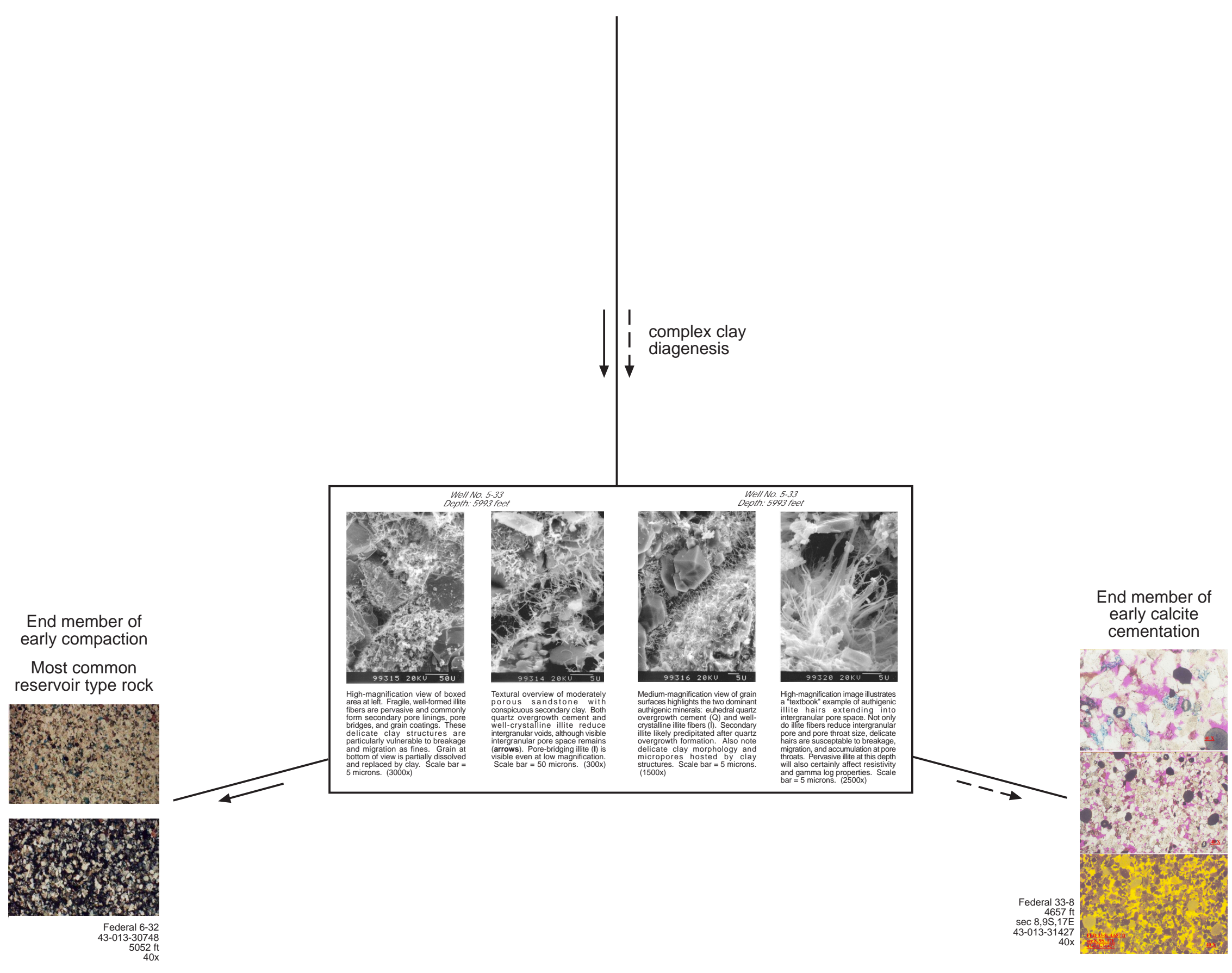

Ggure2 


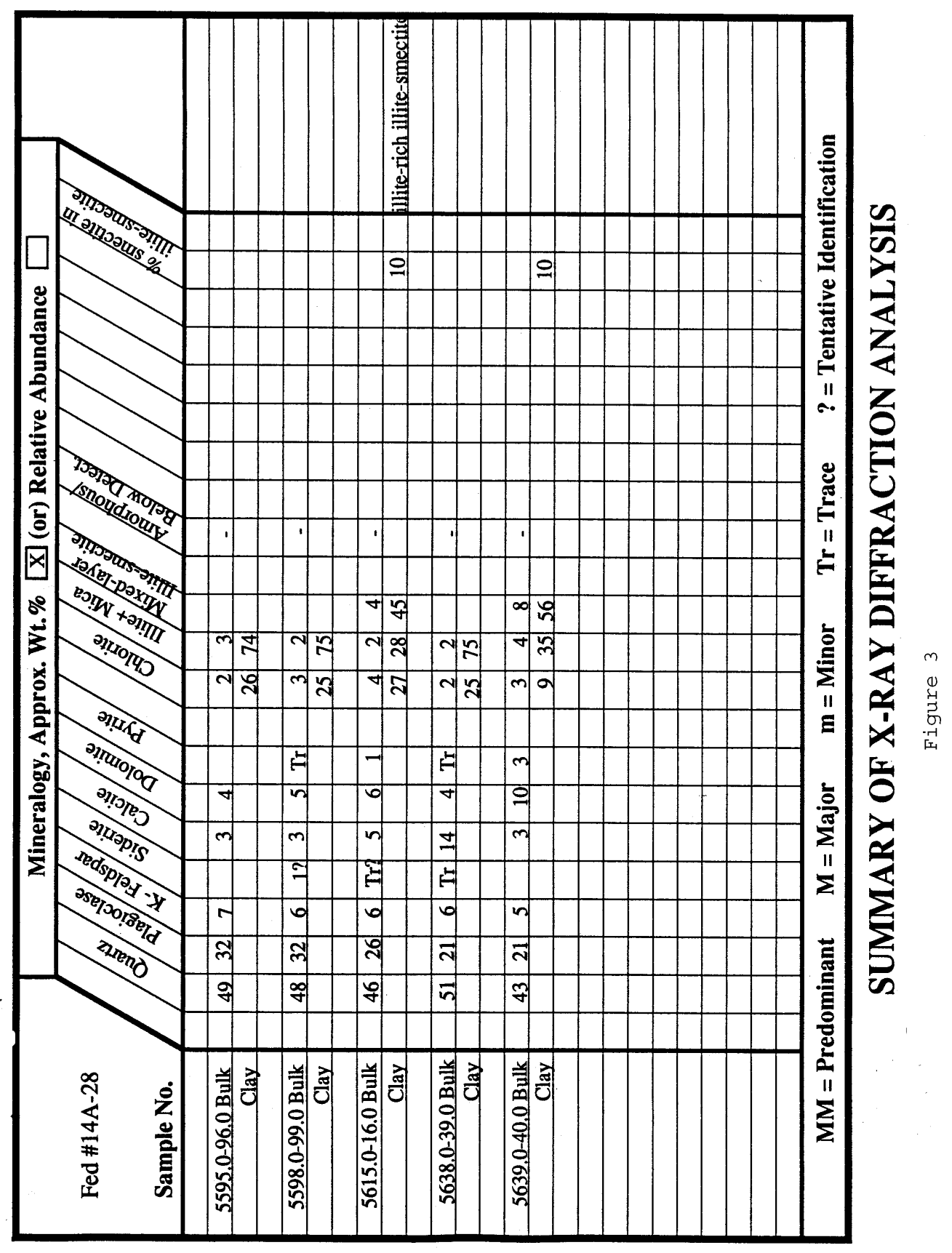




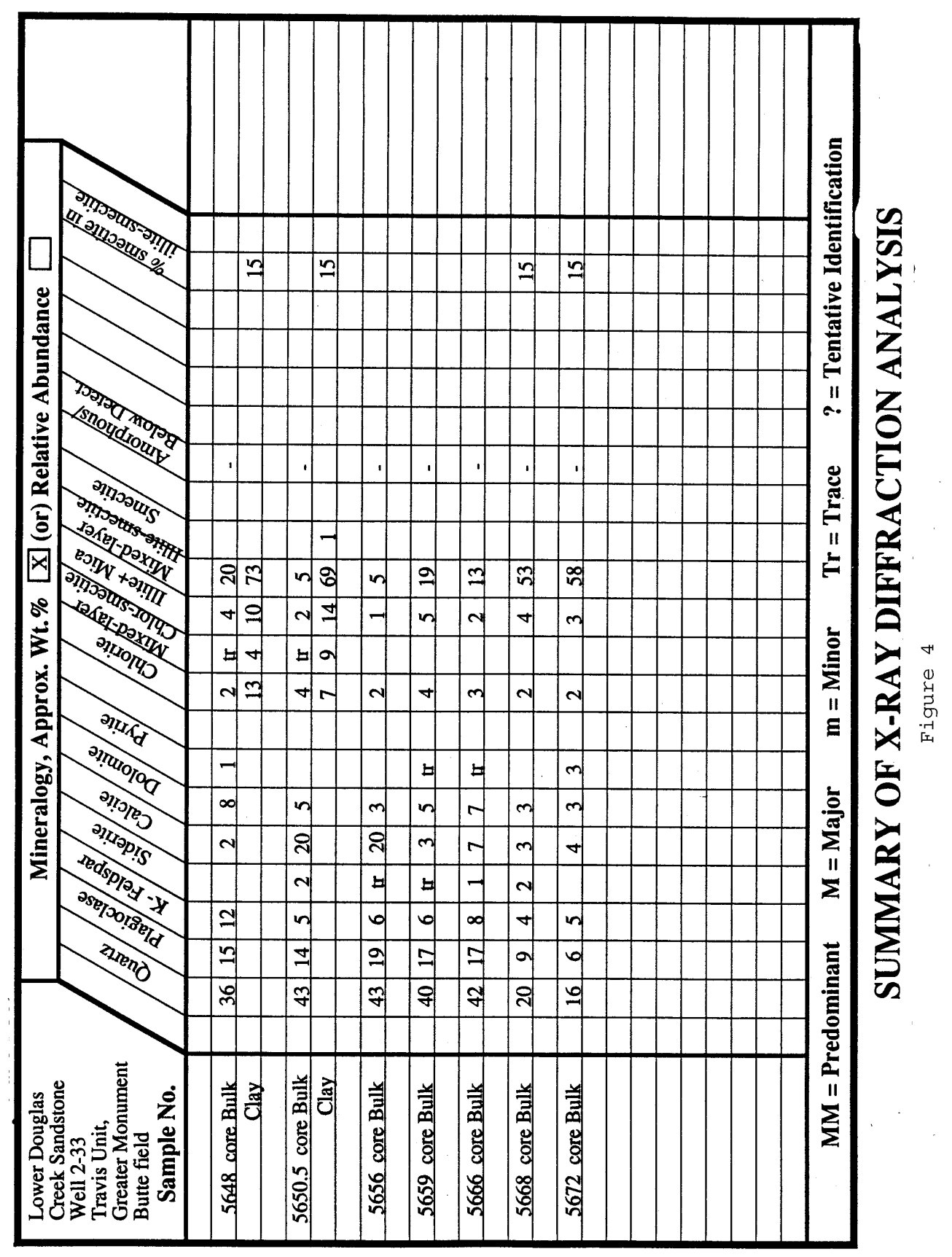




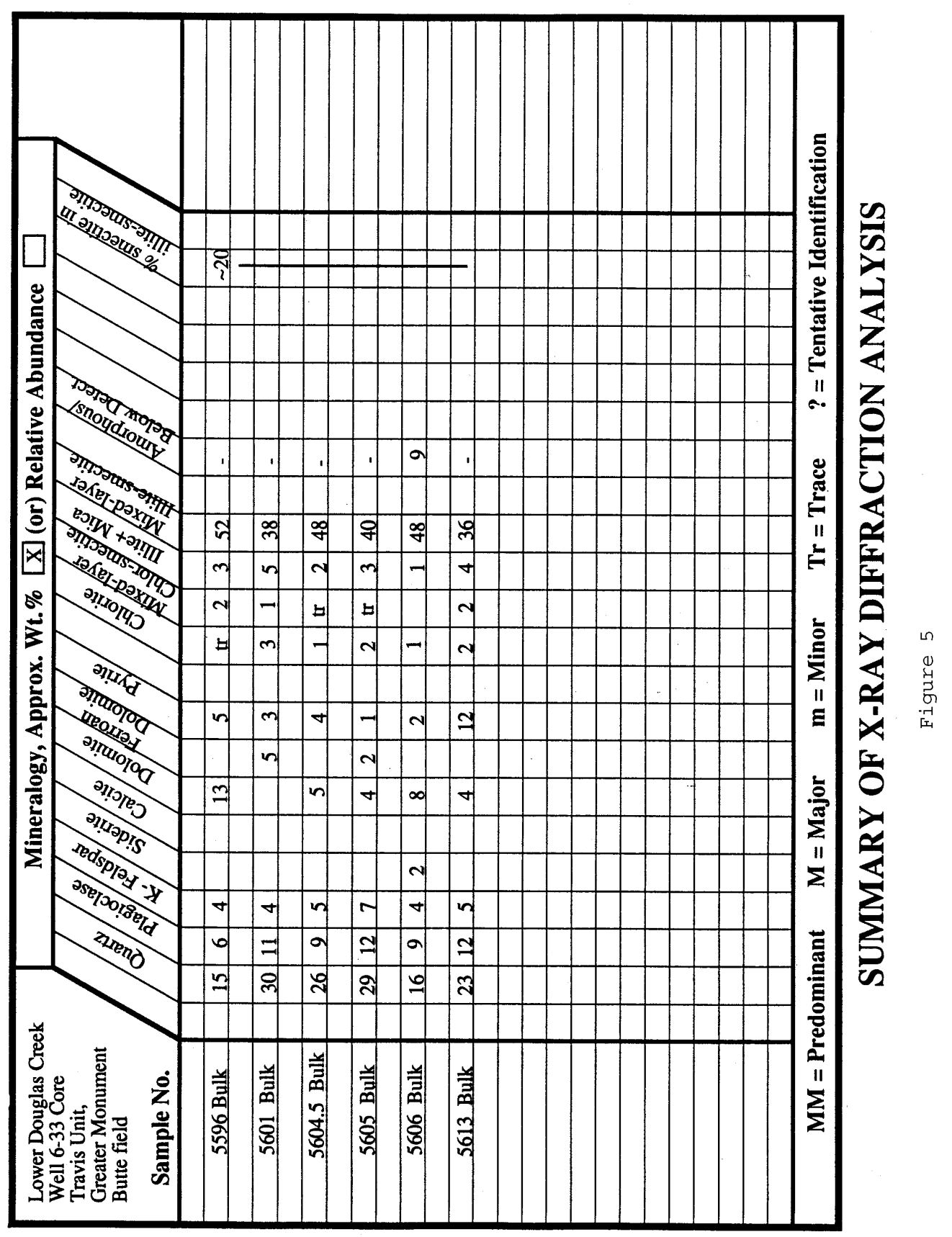




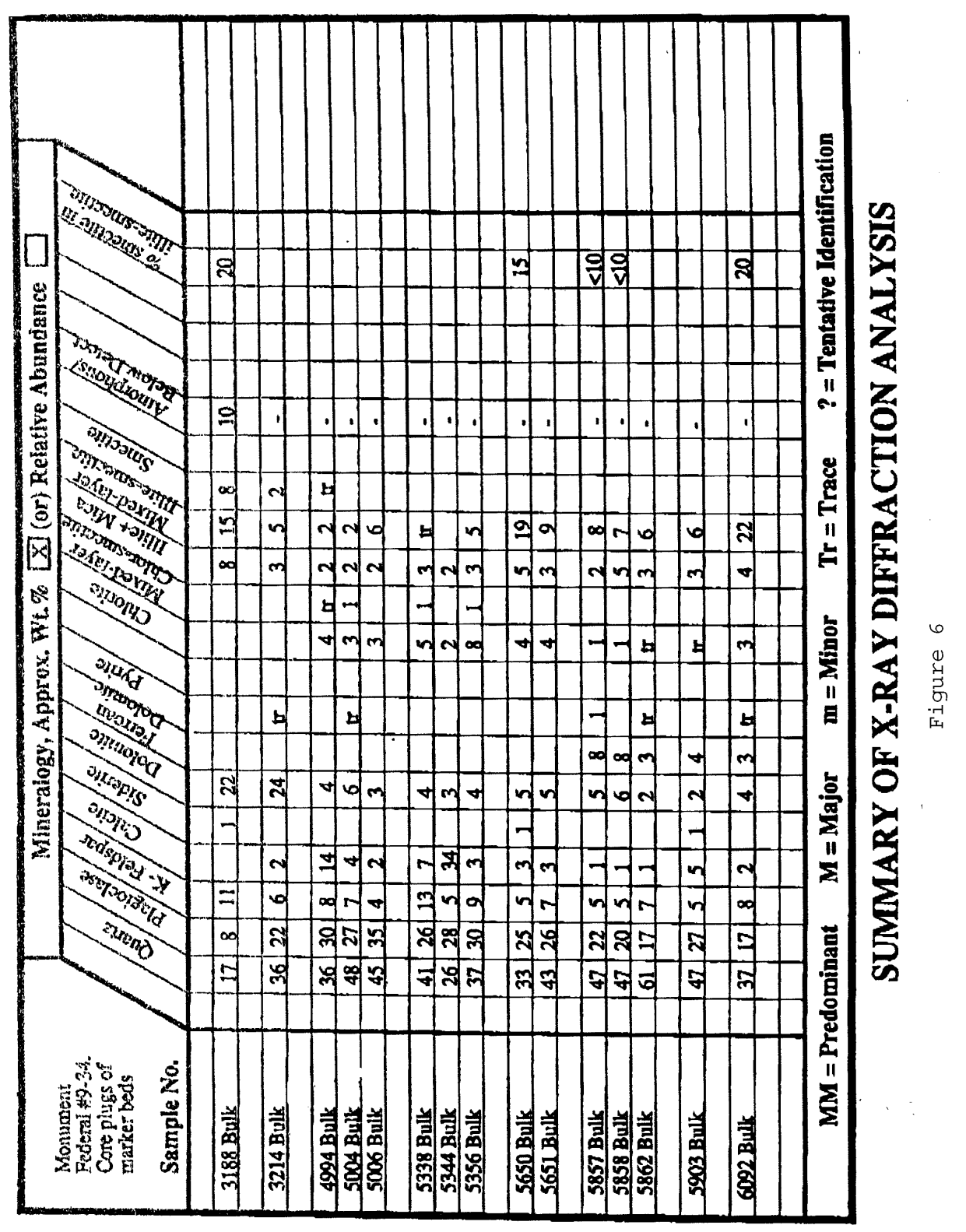




\section{APPENDIX}

CORE DESCRIPTIONS 
Allen 34-5

SWSE Sec 5, T9S, R17E.

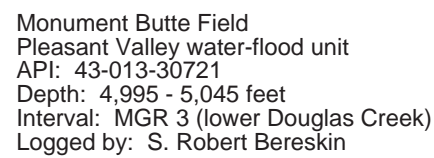

Logged by: S. Robert Bereskin

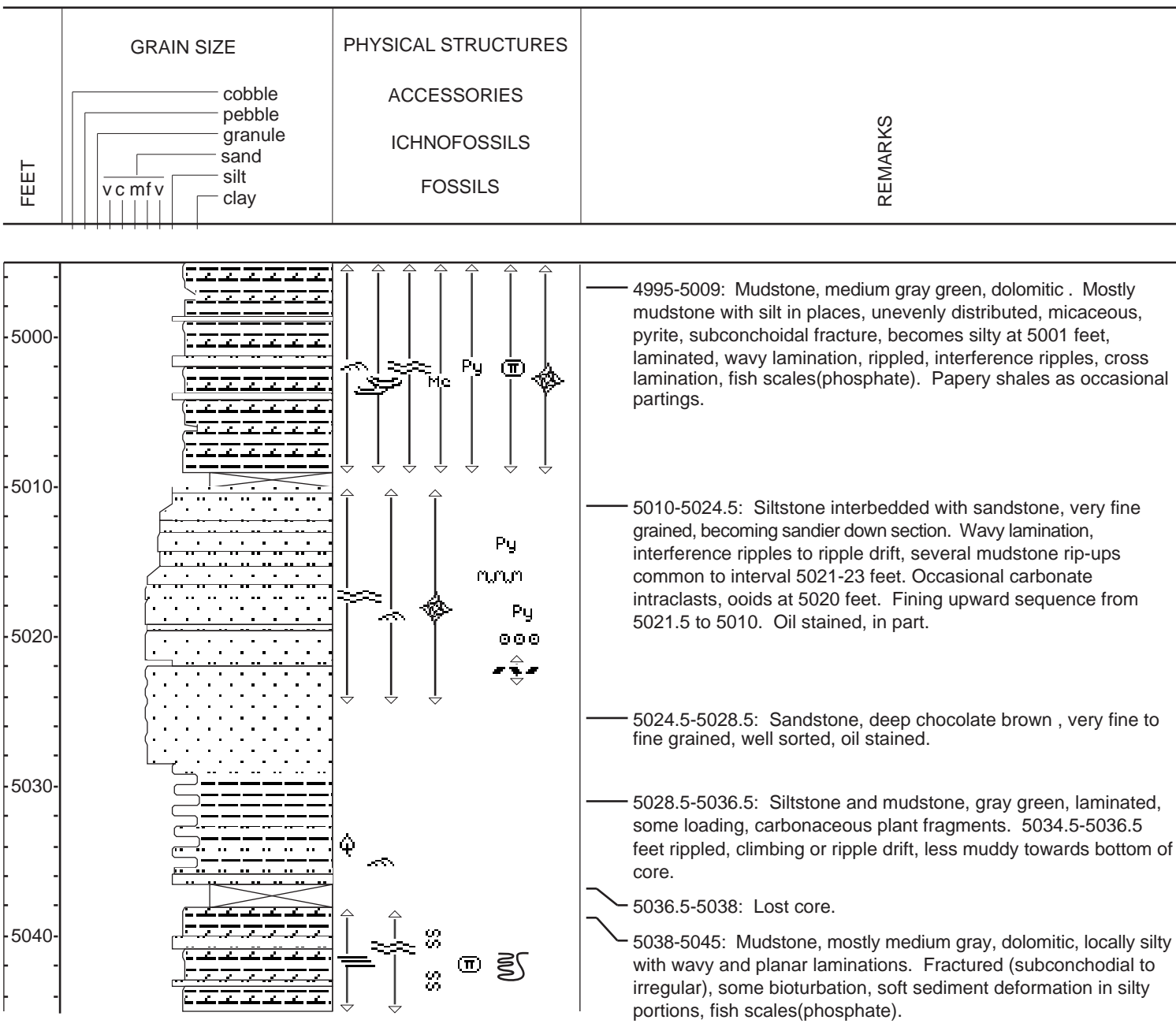

LEGEND

LITHOLOGY

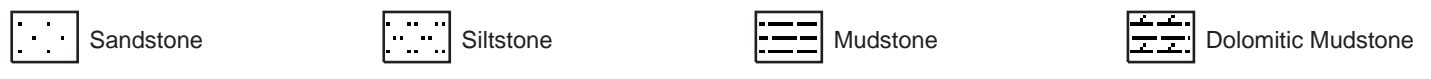

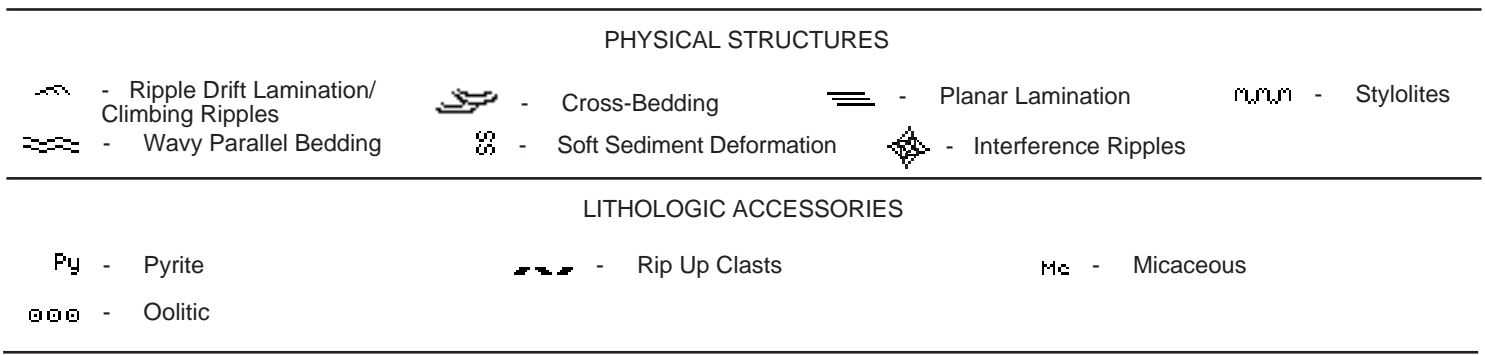

ICHNOFOSSILS

§ె - Bioturbation

FOSSILS

Ф - Plant Remains

(II) - Fish Scales (phosphate) 


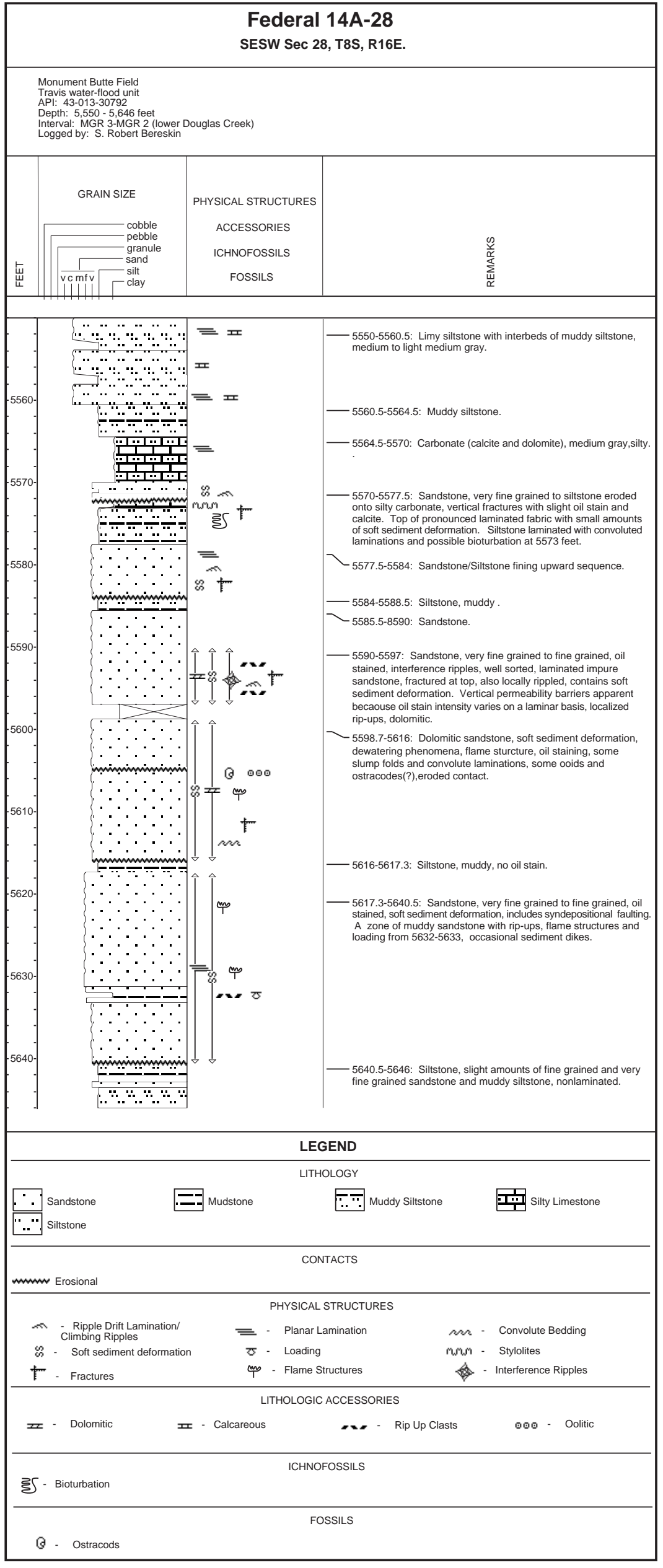




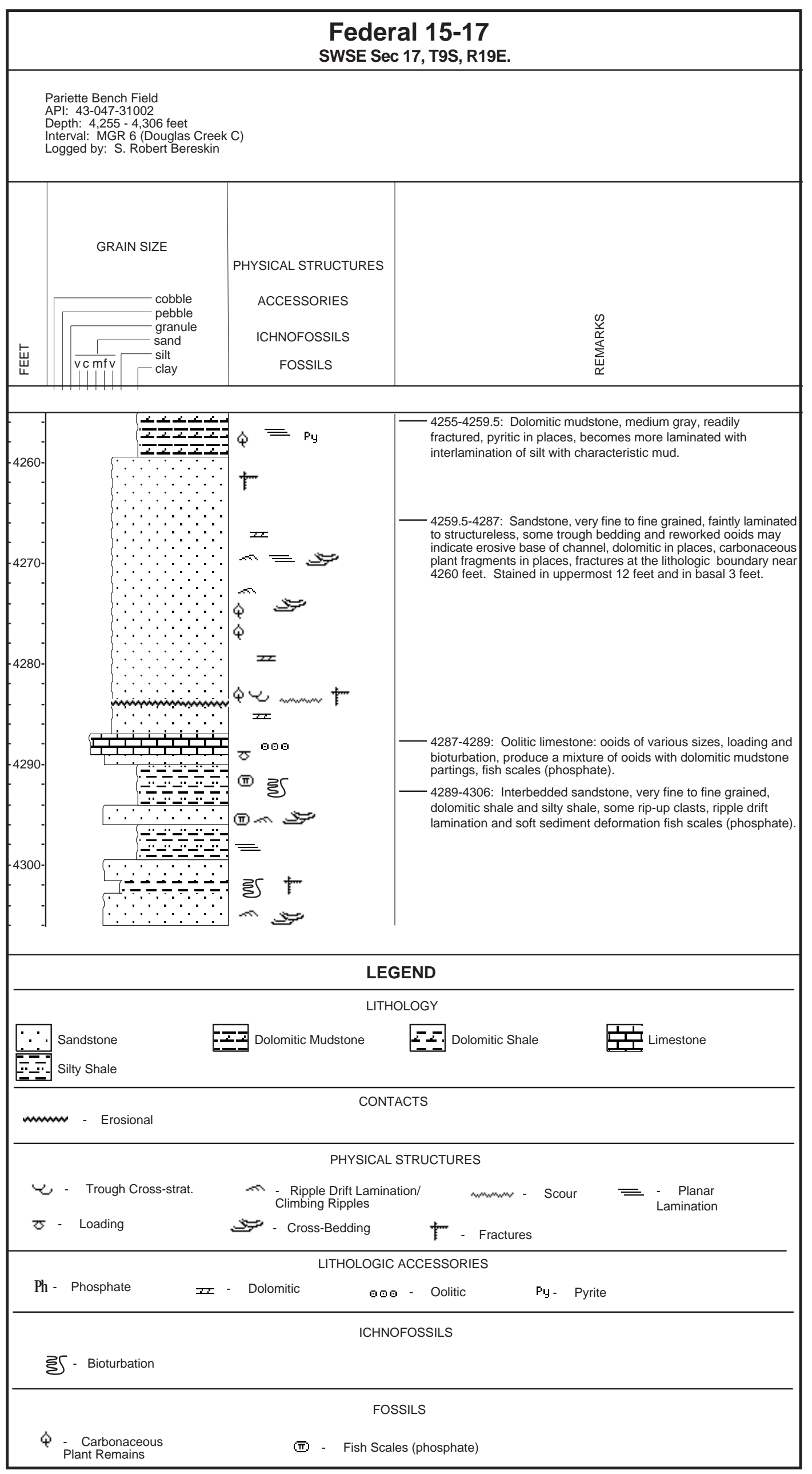




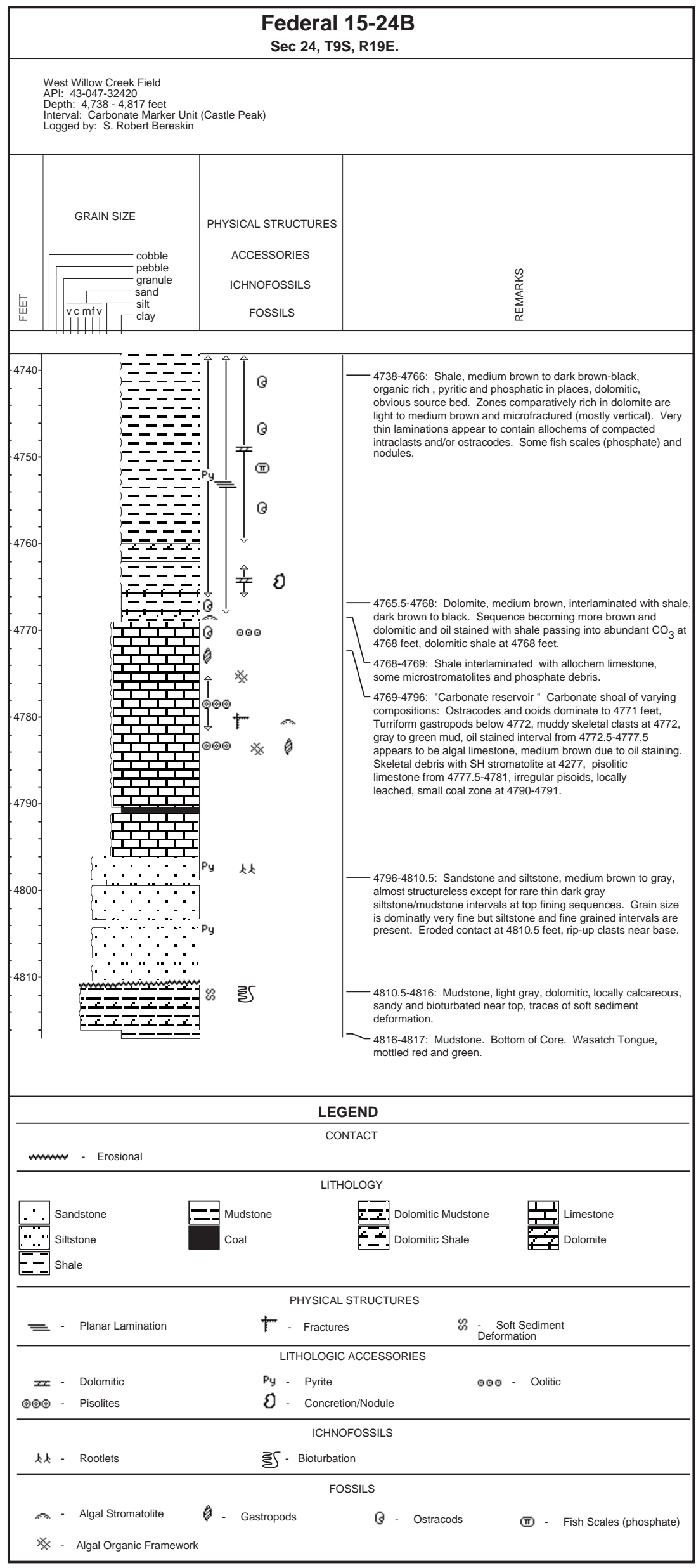




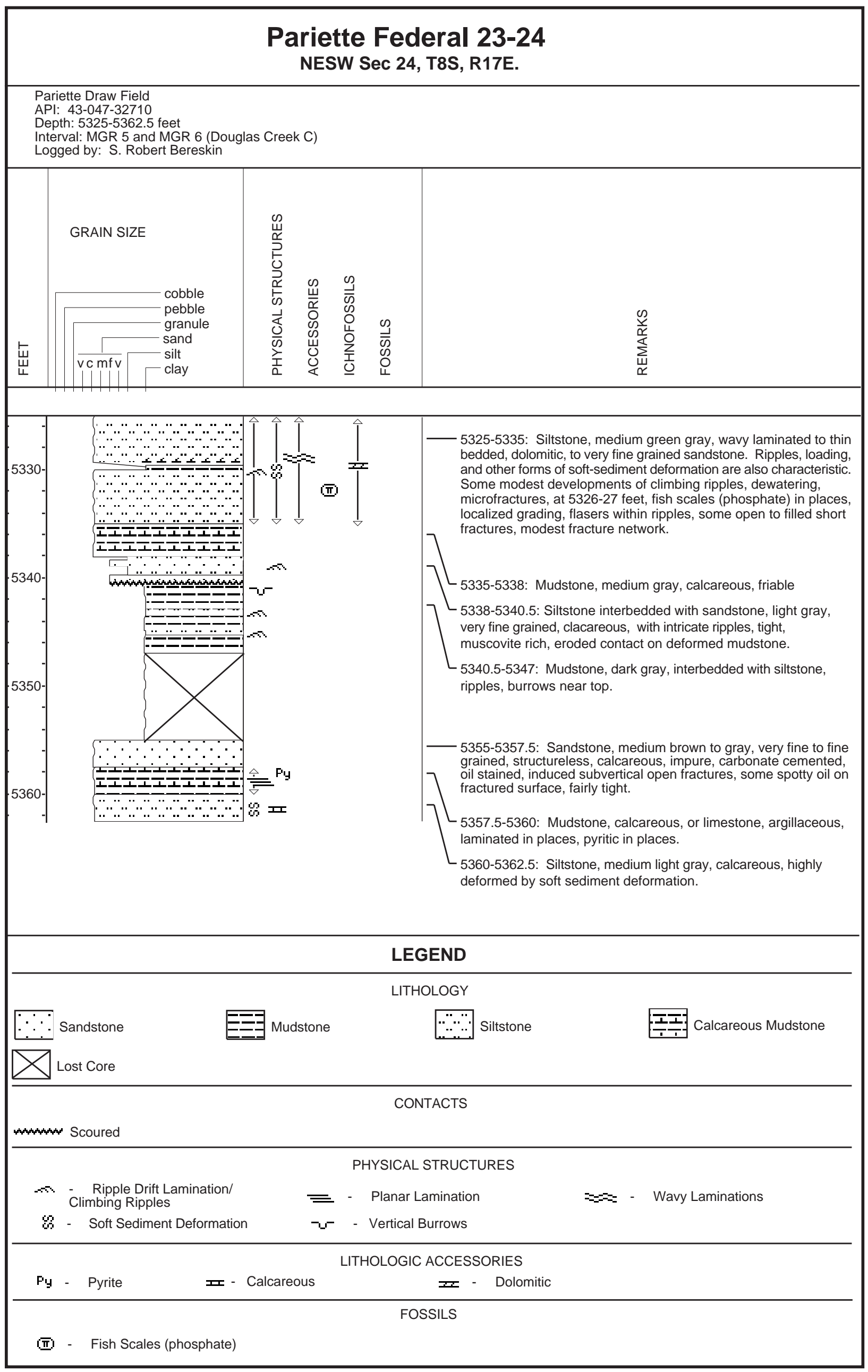




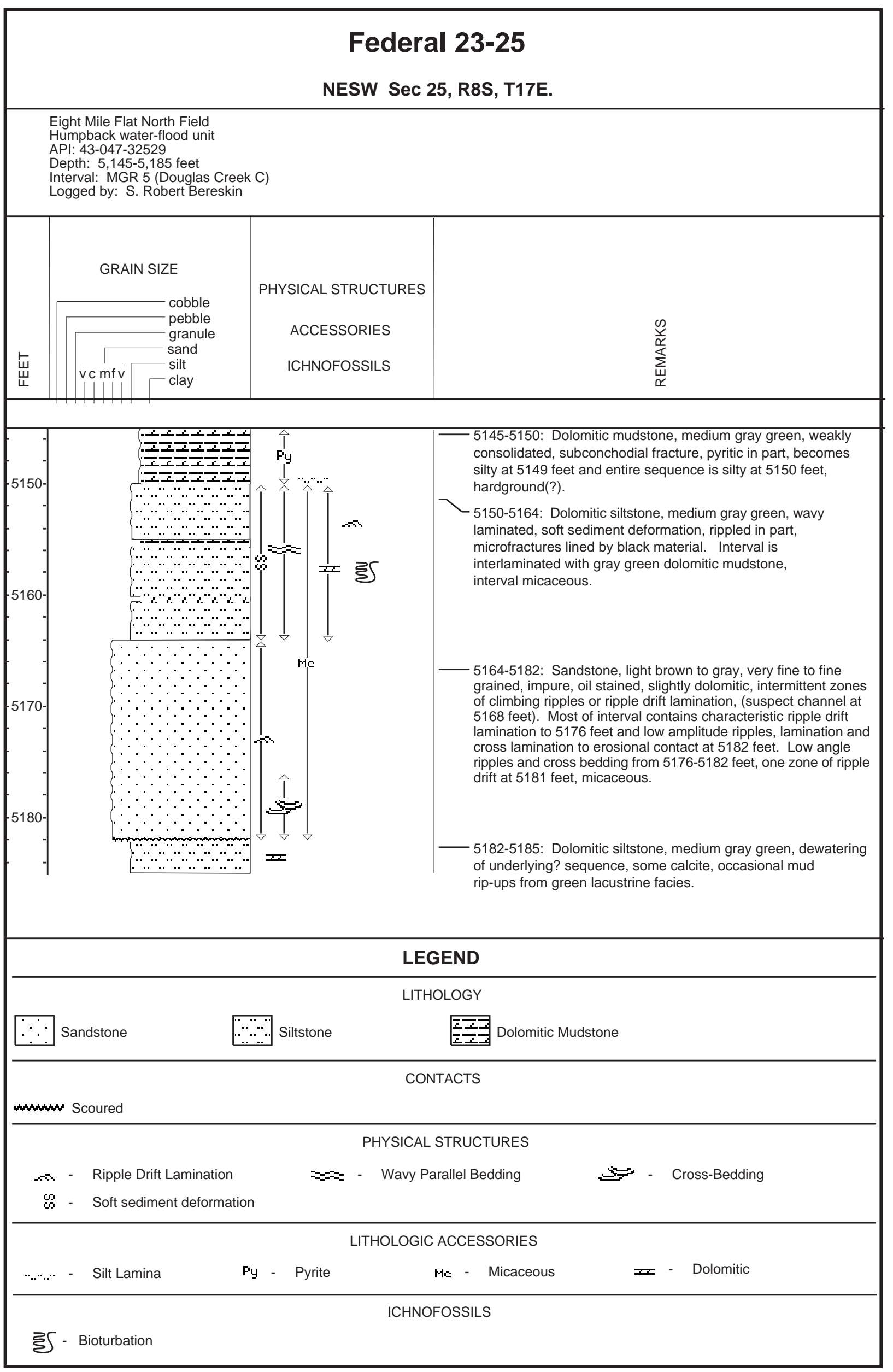


Federal 2-33

NWNE Sec 33, T8S, R16E.

Monument Butte Field

API: 43-013-30749

Depth: 5,647 - 5,676.5 feet

Interval: MGR 2 (lower Douglas Creek)

Logged by: S. Robert Bereskin

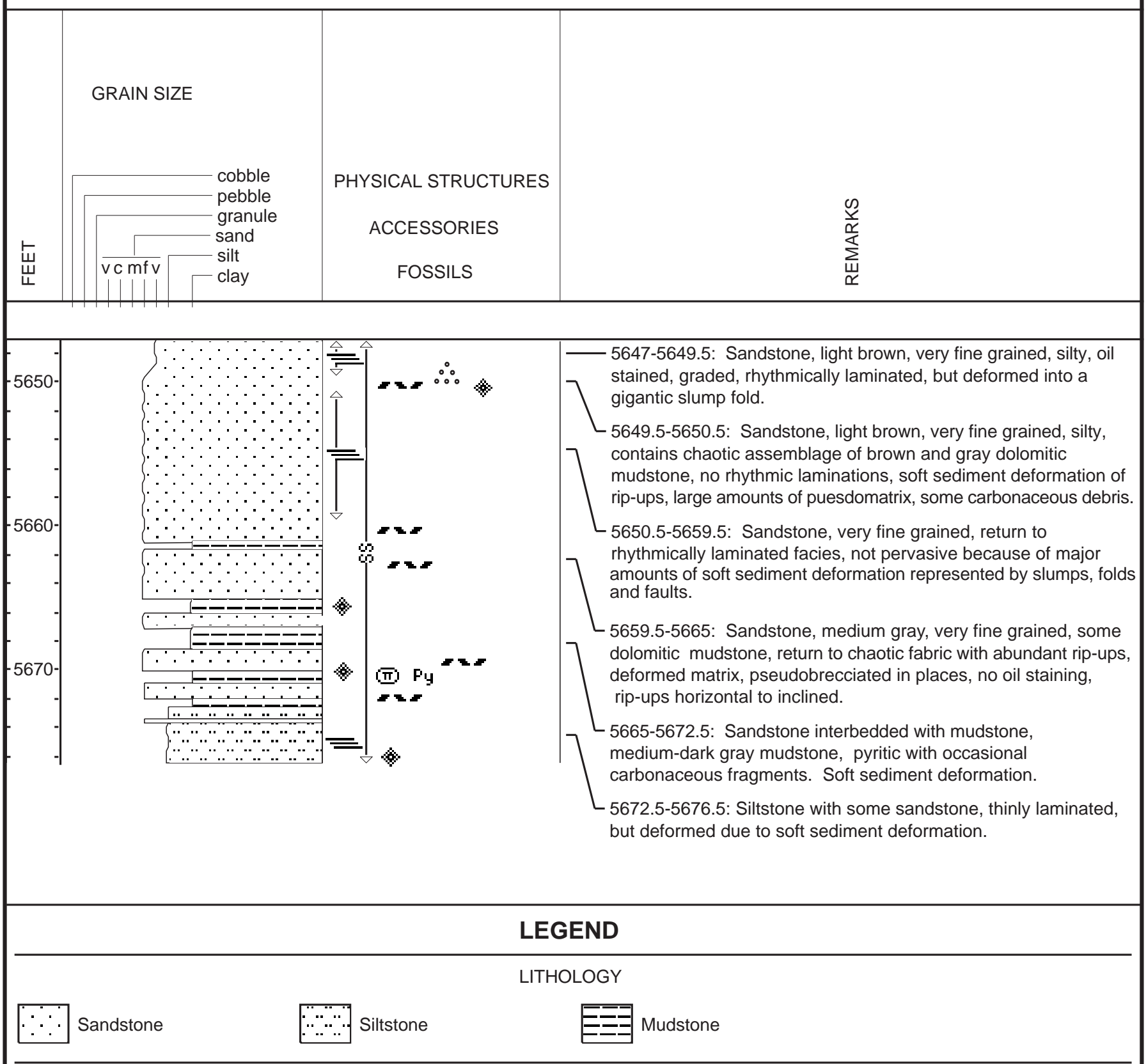

PHYSICAL STRUCTURES

$\equiv$ - Planar Lamination $\quad \mathscr{H}-$ Soft Sediment Deformation $\quad \therefore \quad$ - Graded Bedding

LITHOLOGIC ACCESSORIES

Rip Up
Clasts $\quad$ Py - Pyrite

FOSSILS

- Carbonaceous

Fragments

(II) - Fish Scales (phosphate) 


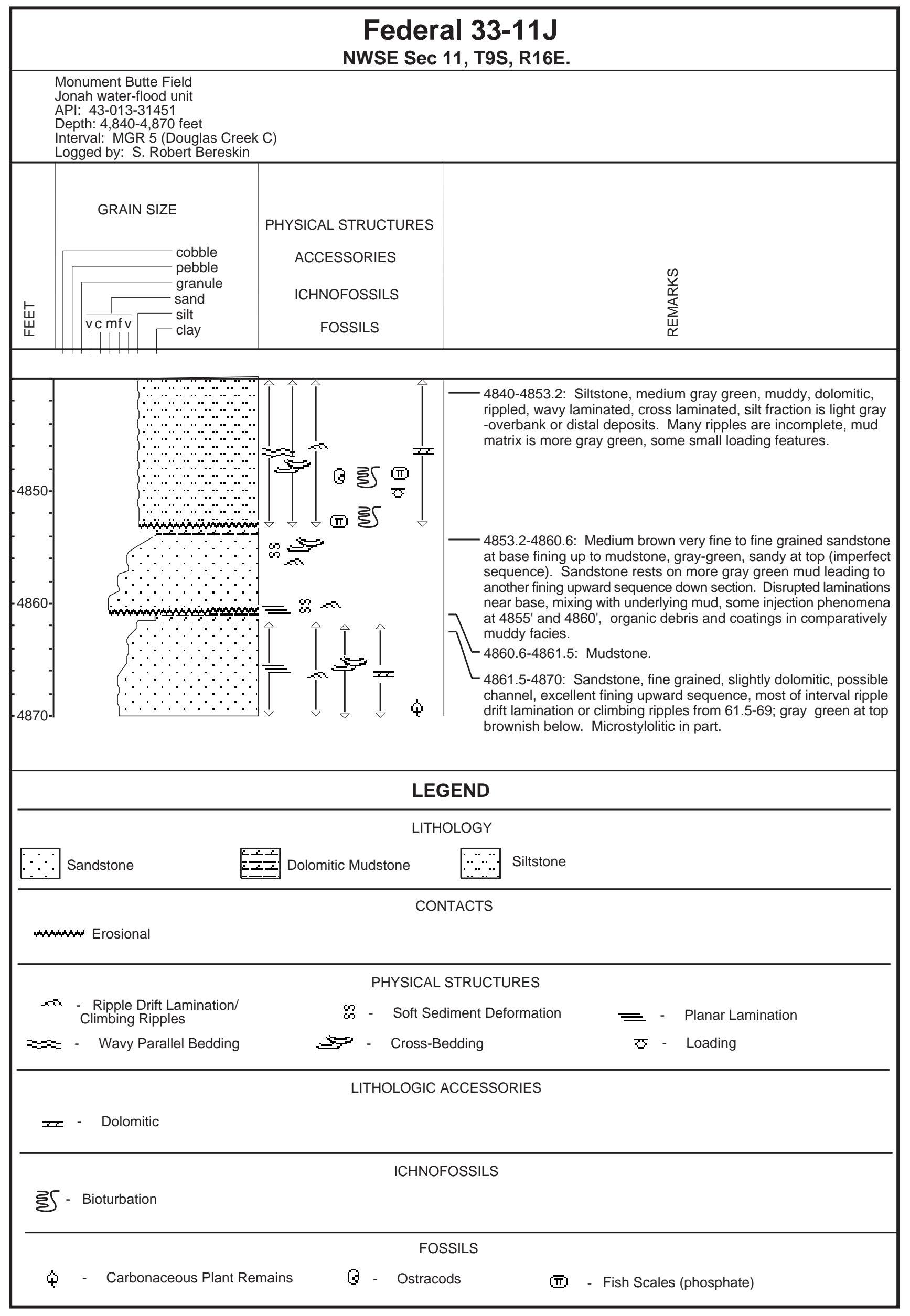




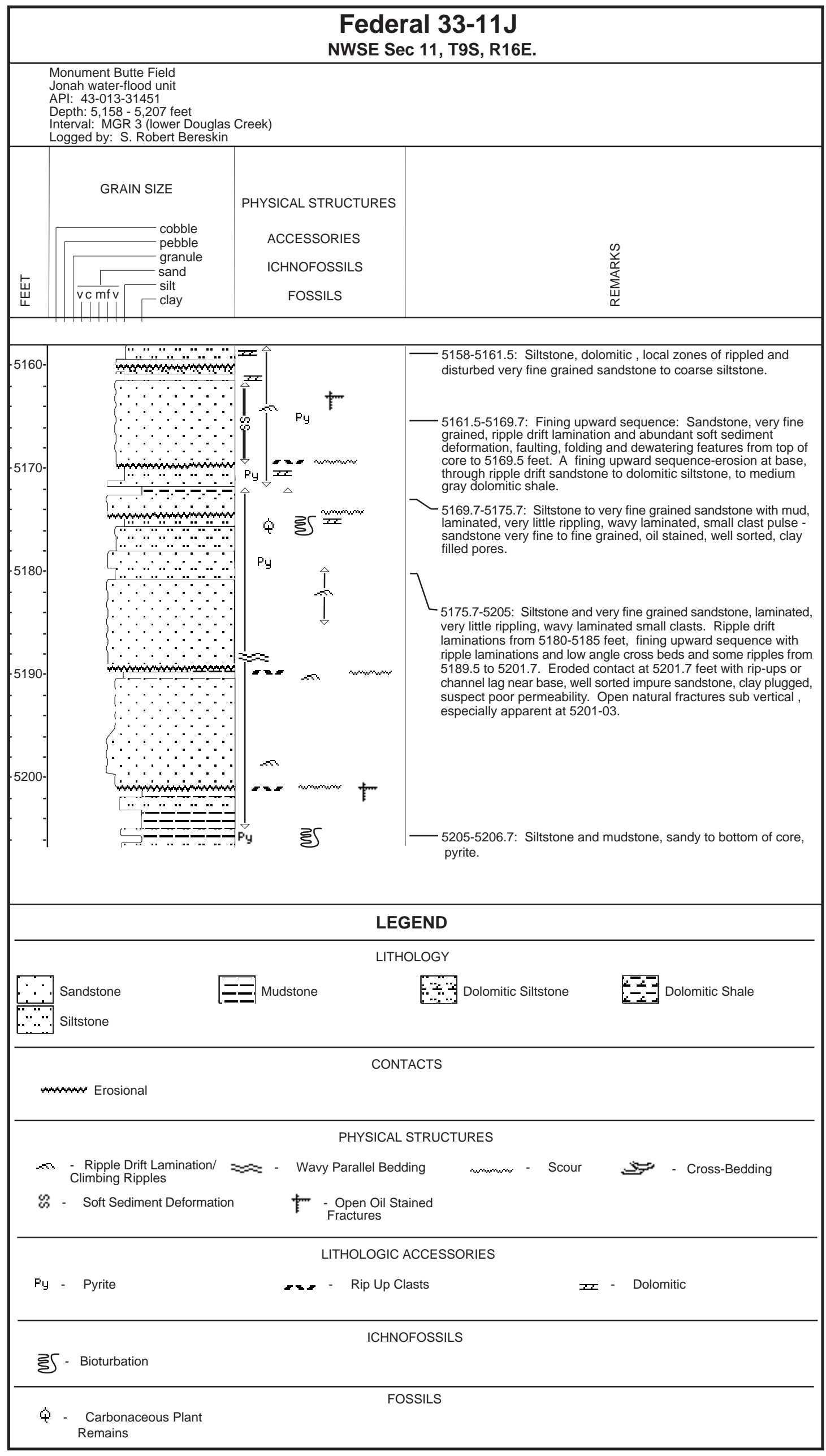




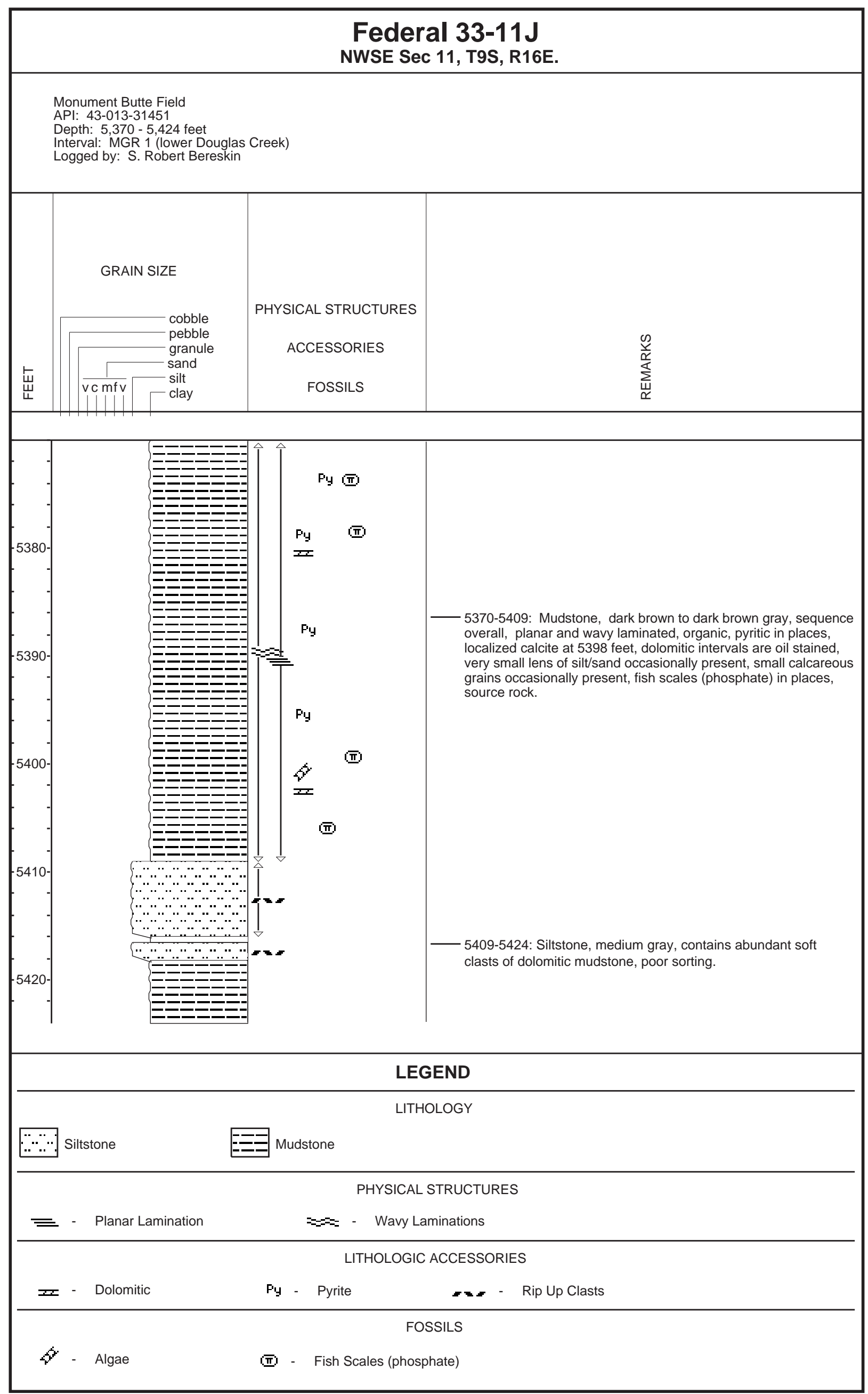




\section{Federal 33-8}

NWSE Sec 8, T9S, R17E.

Monument Butte Field

Beluga water-flood unit

API: 43-013-31427

Depth: 4,632 - 4,660 feet

Interval: MGR 7-MGR 6 (Douglas Creek C)

Logged by: S. Robert Bereskin

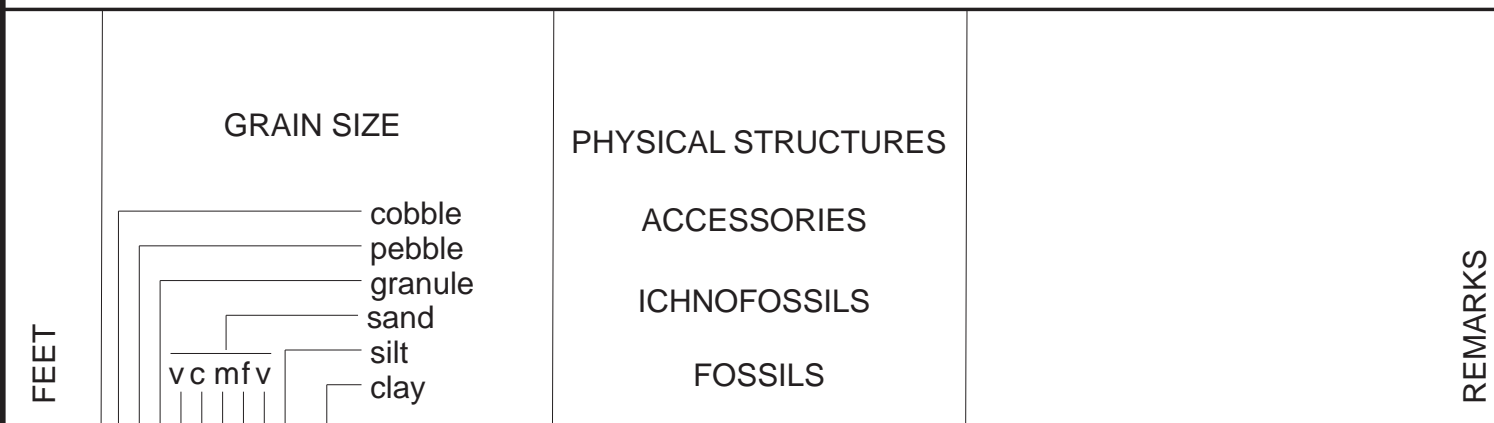

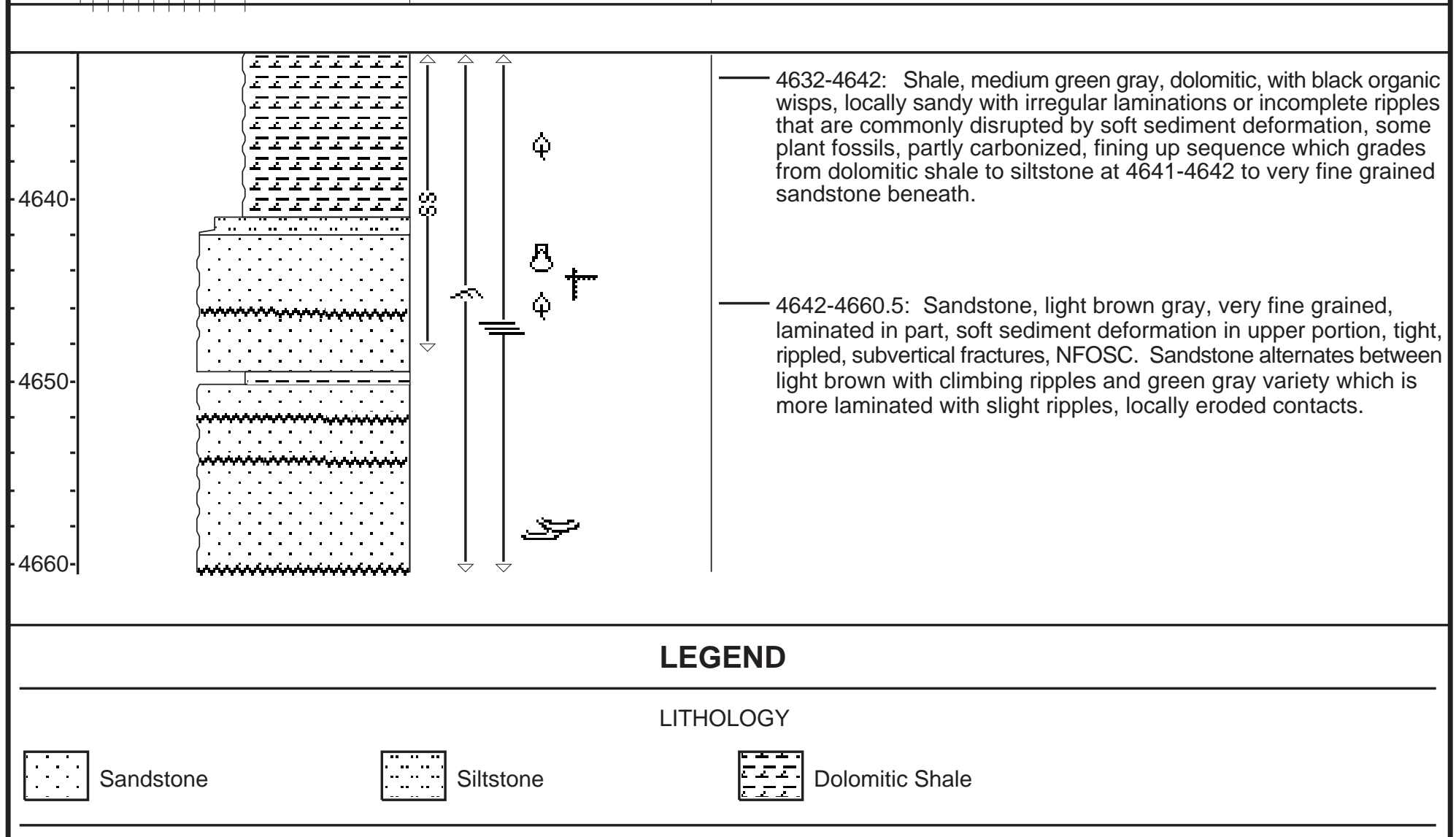

\section{CONTACTS}

mymers Erosional

\section{PHYSICAL STRUCTURES}
- Ripple Drift Lamination/ Climbing Ripples
戸 - Planar Lamination
t" Fractures
$\mathscr{B}$ - Soft sediment deformation
- Cross-Bedding

FOSSILS

囚 - Pelecypods $\$$ - Plant Remains 


\section{Federal 33-8}

NWSE Sec 8, T9S, R17E.

Monument Butte Field

Beluga water-flood unit

API: 43-013-31427

Depth: 5,440 - 5,470 feet

Interval: Carbonate Marker Unit (Castle Peak)

Logged by: S. Robert Bereskin

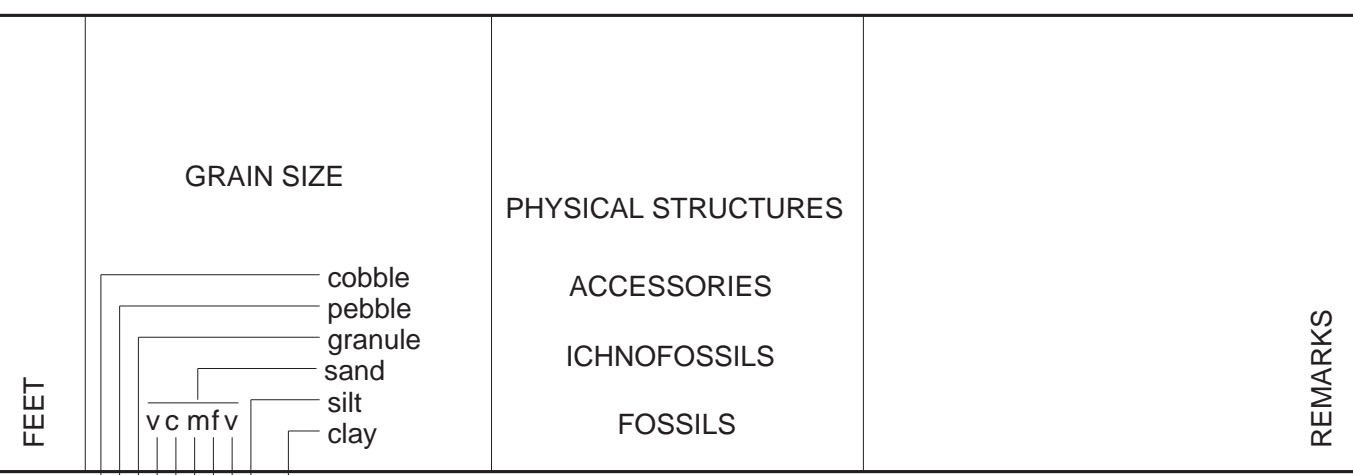

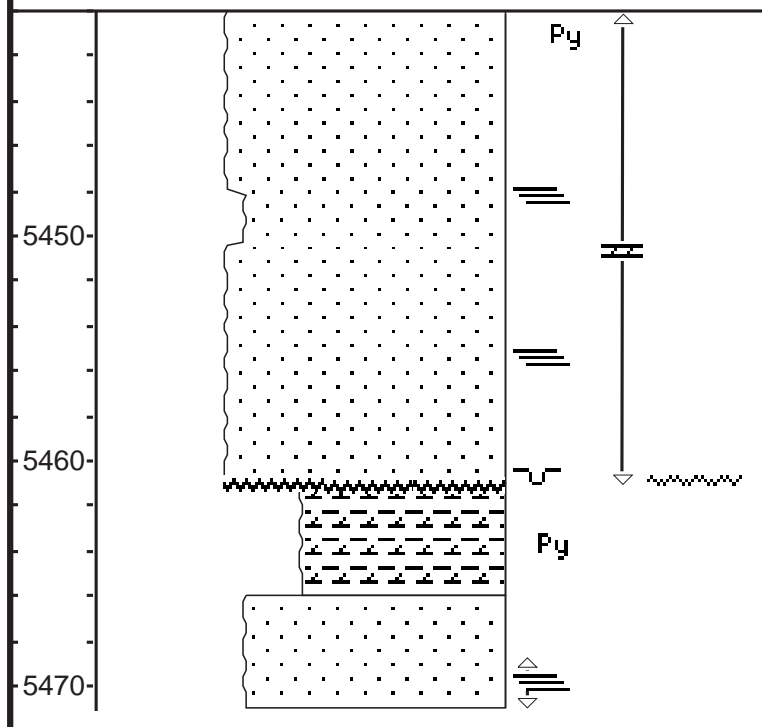

5440-5461: Sandstone, medium brown to gray, dolomitic, fine grained, comparatively structureless, oil stained, but largely clay plugged. Locally, sandstone is laminated and appears channelized at 5461, lag deposits at base of channel are dolomitic shale clasts.

\section{LEGEND}

\section{LITHOLOGY}

$\therefore$ Sandstone $\quad$ Dolomitic Shale

\begin{tabular}{ll}
\hline CONTACTS \\
\hline
\end{tabular}

\section{PHYSICAL STRUCTURES}

戸 - Planar Lamination Scour

Py - Pyrite

LITHOLOGIC ACCESSORIES

F - Dolomitic

ICHNOFOSSILS

u - Vertical Burrows 


\section{Federal 6-33}

SENW Sec 33, T8S, R16E.

Monument Butte Field

Monument Butte water-flood unit

API: 43-013-30747

Depth: 5,596 - 5,616.6 feet

Interval: MGR 7 (Douglas Creek D)

Logged by: S. Robert Bereskin

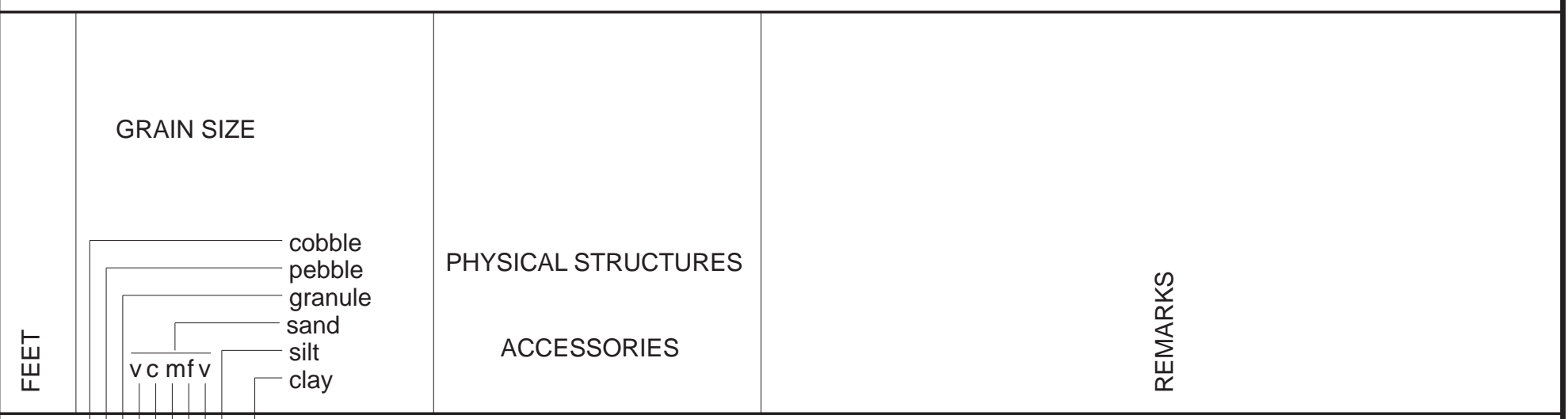

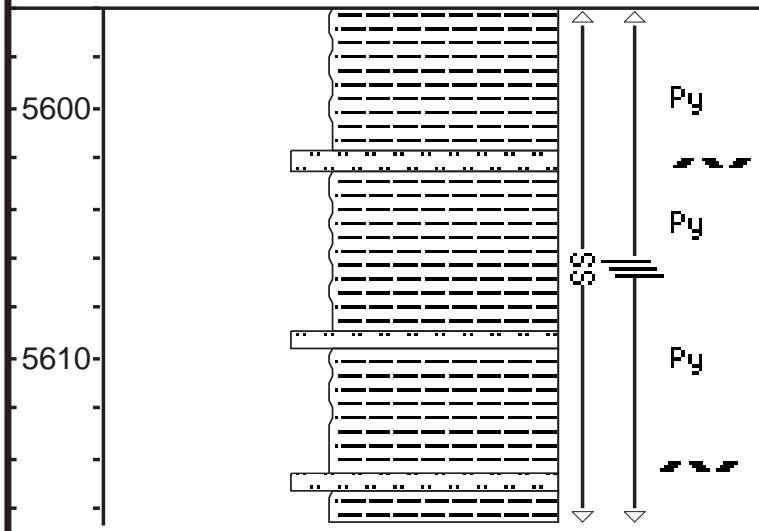

\section{LEGEND}

5596-5616.6: Mostly mudstone to shale, medium to dark gray brown to very dark gray, organic, friable, irregular lamination with some major sedimentary discontinuities related to soft sediment deformation, rip-ups, traces of carbonaceous debris and presence of abundant pyritic wisps, occasional light gray brown siltstone beds contrast with host lithology. Resembles shaly version of chaotic siltstone and sandstone reservoir facies of characteristic Lower Douglas Creek sand in 2-33 well.

\section{LITHOLOGY}

\begin{tabular}{|c|c|c|}
\hline :.....". & Siltstone & E三二二 \\
\hline
\end{tabular}

PHYSICAL STRUCTURES

戸 - Planar Lamination

$\%$ - Soft Sediment Deformation

LITHOLOGIC ACCESSORIES

Py - Pyrite

Rip Up Clasts 


\section{Federal 6-35}

SENW Sec 35, T8S, R16E.

Monument Butte Field

Monument Butte water-flood unit

API: 43-013-30752

Depth: 5,026 - 5,048.1 feet

Interval: MGR 7 (Douglas Creek D)

Logged by: S. Robert Bereskin

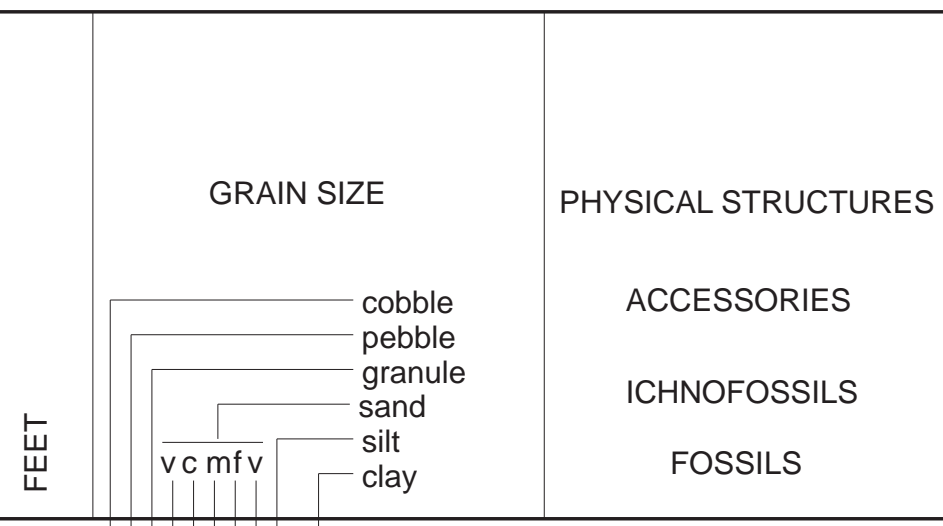

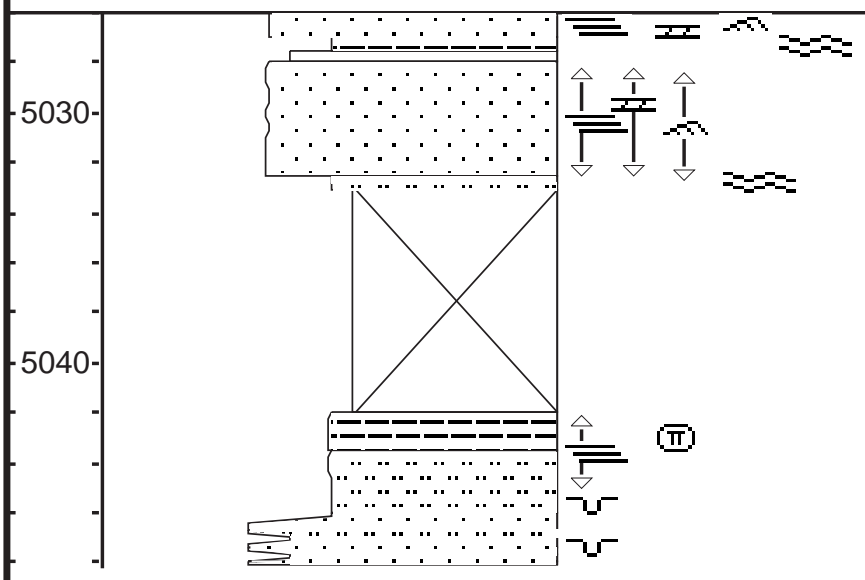

\section{LEGEND}

\section{LITHOLOGY}

$\therefore$ Sandstone $\quad[\because . \cdots . \cdot . \cdot$ Siltstone

PHYSICAL STRUCTURES

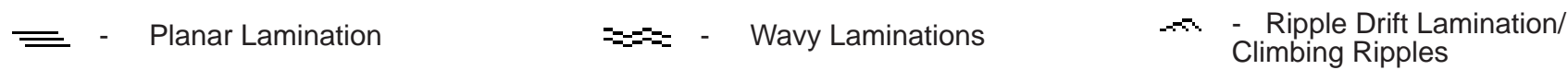

LITHOLOGIC ACCESSORIES

포 - Dolomitic

ICHNOFOSSILS

$\neg$ - Vertical Burrows 


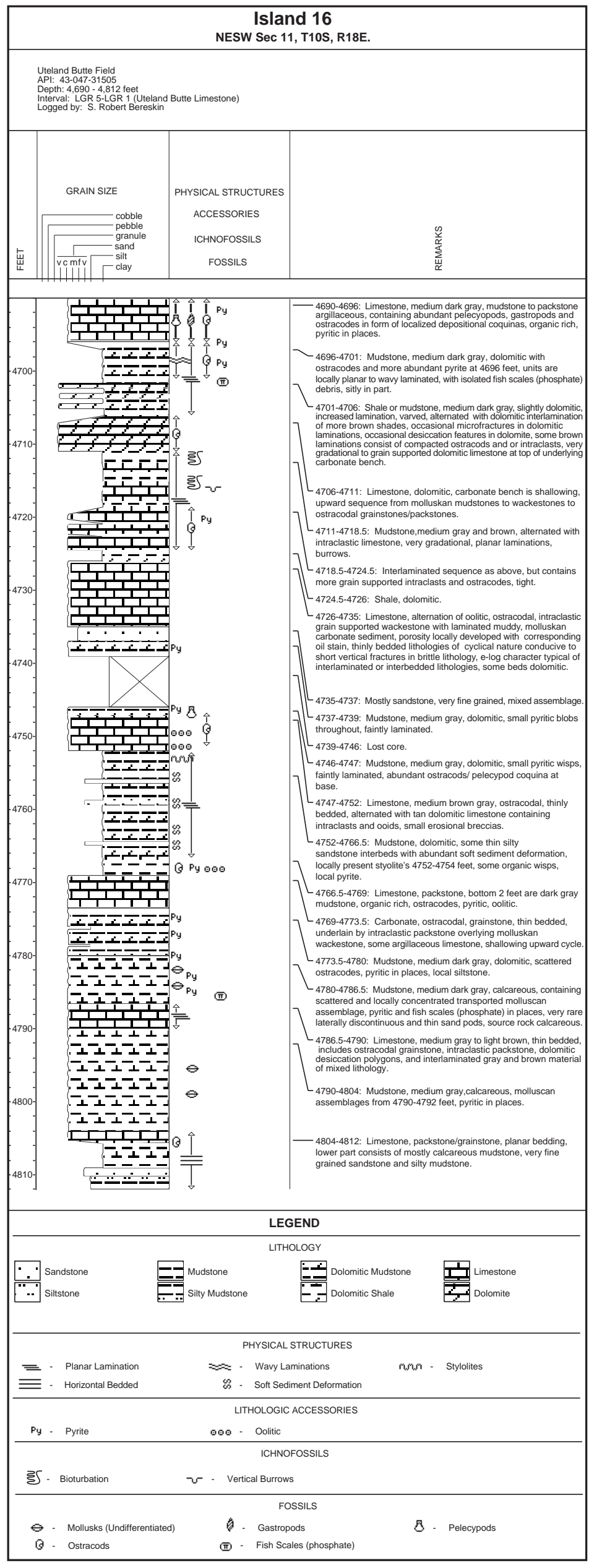




\section{Monument Butte 3A-35}

SWNE Sec 35, T8S, R16E.

Monument Butte Field

Monument Butte water-flood unit

API: 43-013-31738

Depth: 4,993 - 5,022 feet.

Interval: MGR 7 (Douglas Creek D)

Logged by: S. Robert Bereskin

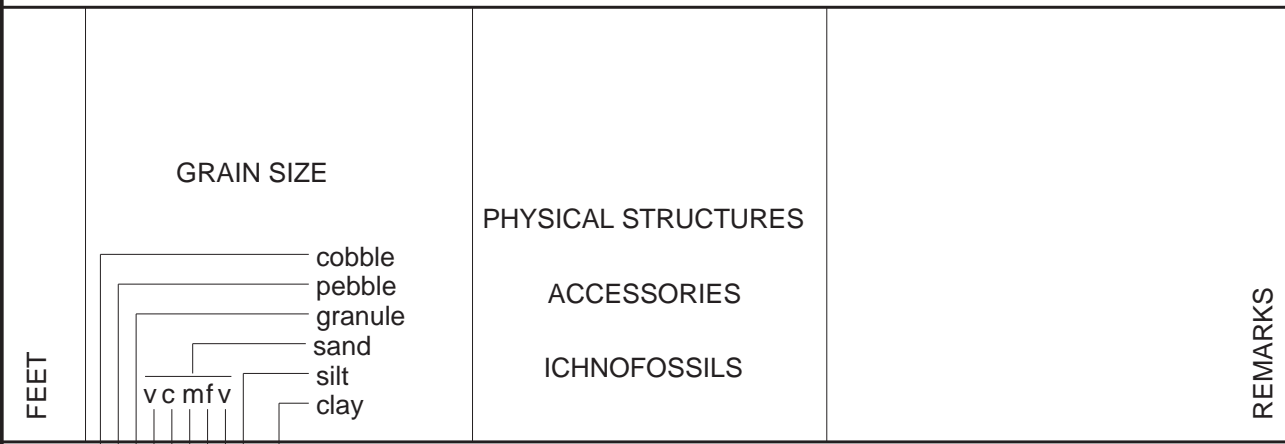

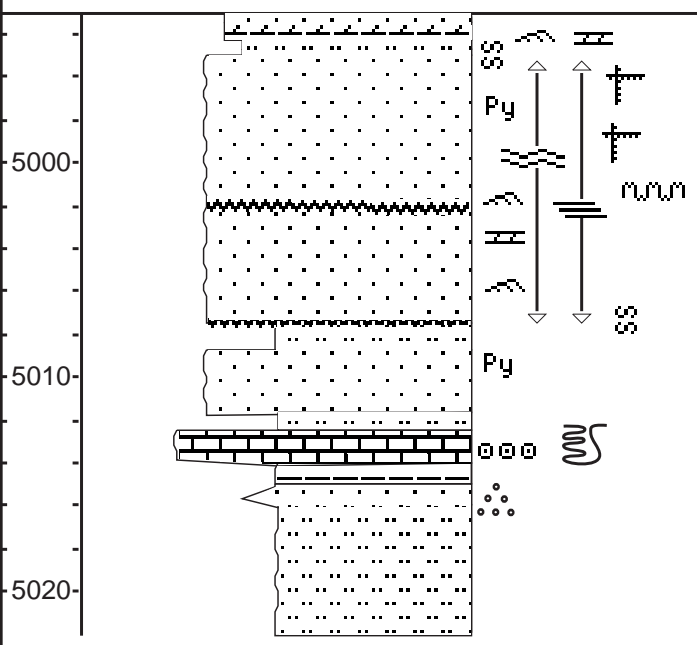

4993-4995: Siltstone, and sandstone, light green gray, very fine grained, ripple drift lamination, dolomitic mudstone/siltstone with flattened clasts, soft sediment deformation.

4995-5007.5: Sandstone, light brown gray to dark brown, fine grained, lithic arkose, with several bedding forms: structureless, oilstained, large and small scale wavy laminations, ripple surfaces confined to planar laminations, ripple drift but little to no vertical climbing, soft sediment deformation, erosive channel at 5007.5 feet, few climbing ripple features at 5006-5006.5, dolomitic in places, stylolitic in places, fractured.

- 5007.5-5022: Sandstone, mudstone, siltstone and limestone, interbedded.

\section{LEGEND}

LITHOLOGY

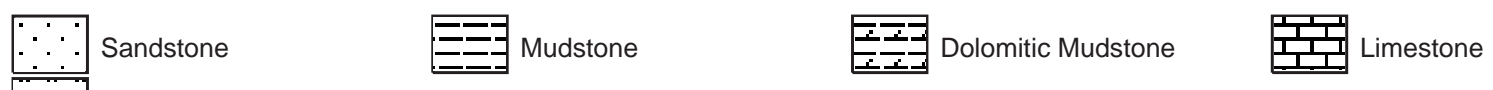

....... Siltstone

CONTACTS

mann Erosional

PHYSICAL STRUCTURES
- Ripple Drift Lamination/ Climbing Ripples
$\bar{\equiv}$ - Planar Lamination
$\therefore \quad$ - Graded Bedding
$\mathscr{6}$ - Soft Sediment Deformation
$\approx=$ - Wavy Laminations
im - Fractures

LITHOLOGIC ACCESSORIES
$\odot \odot$
Oolitic
Py - Pyrite
= - Dolomitic 


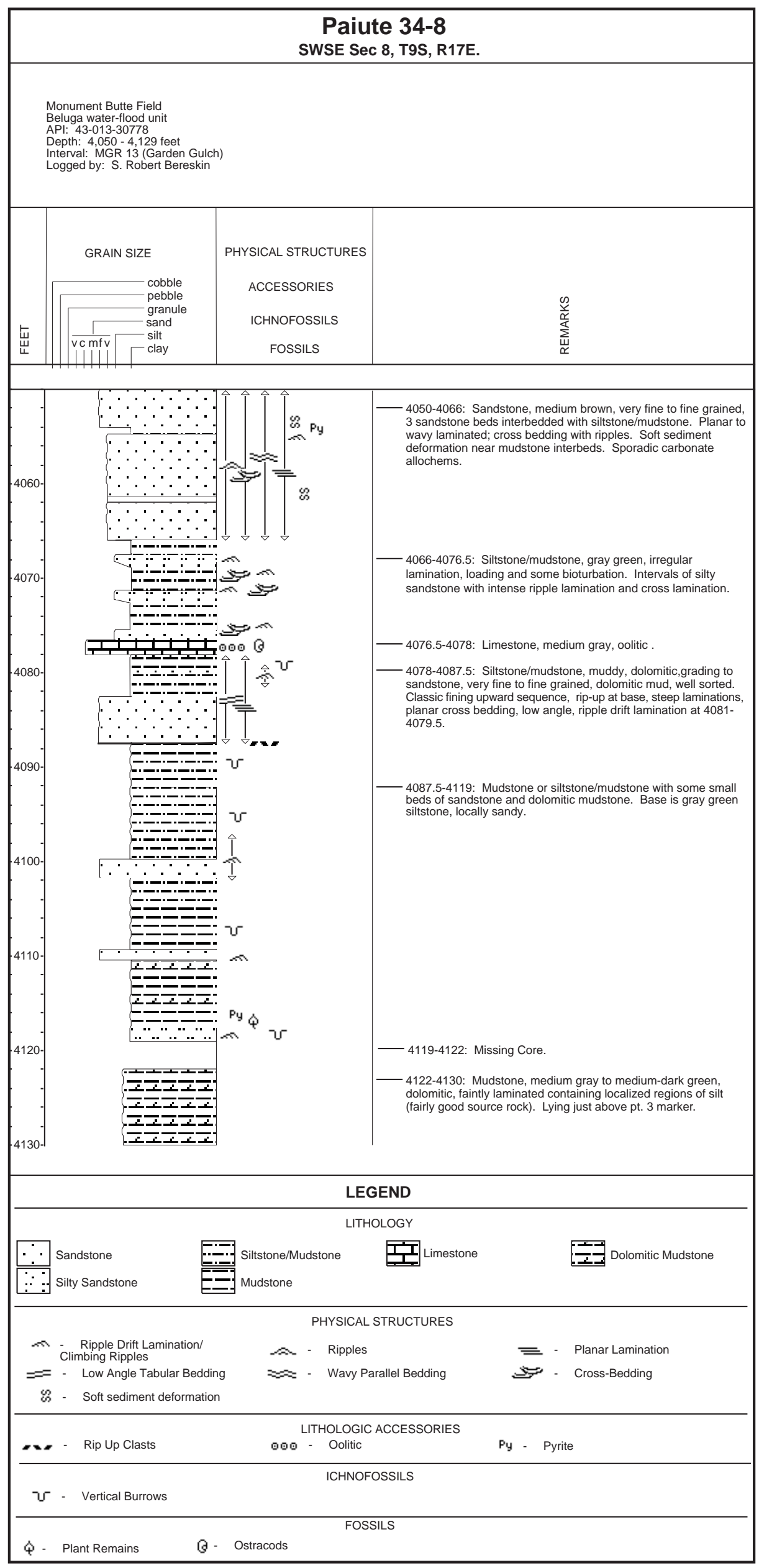




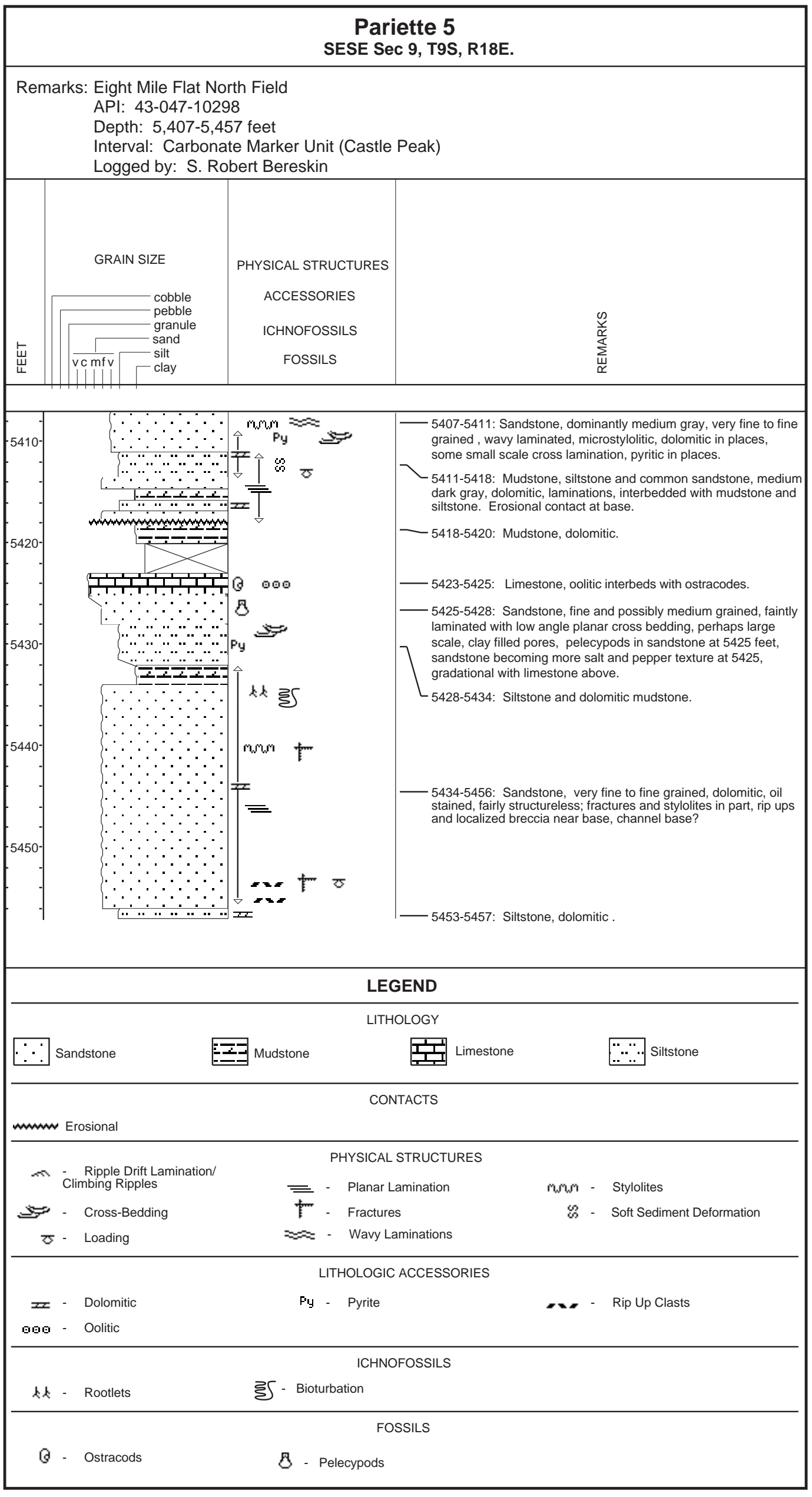




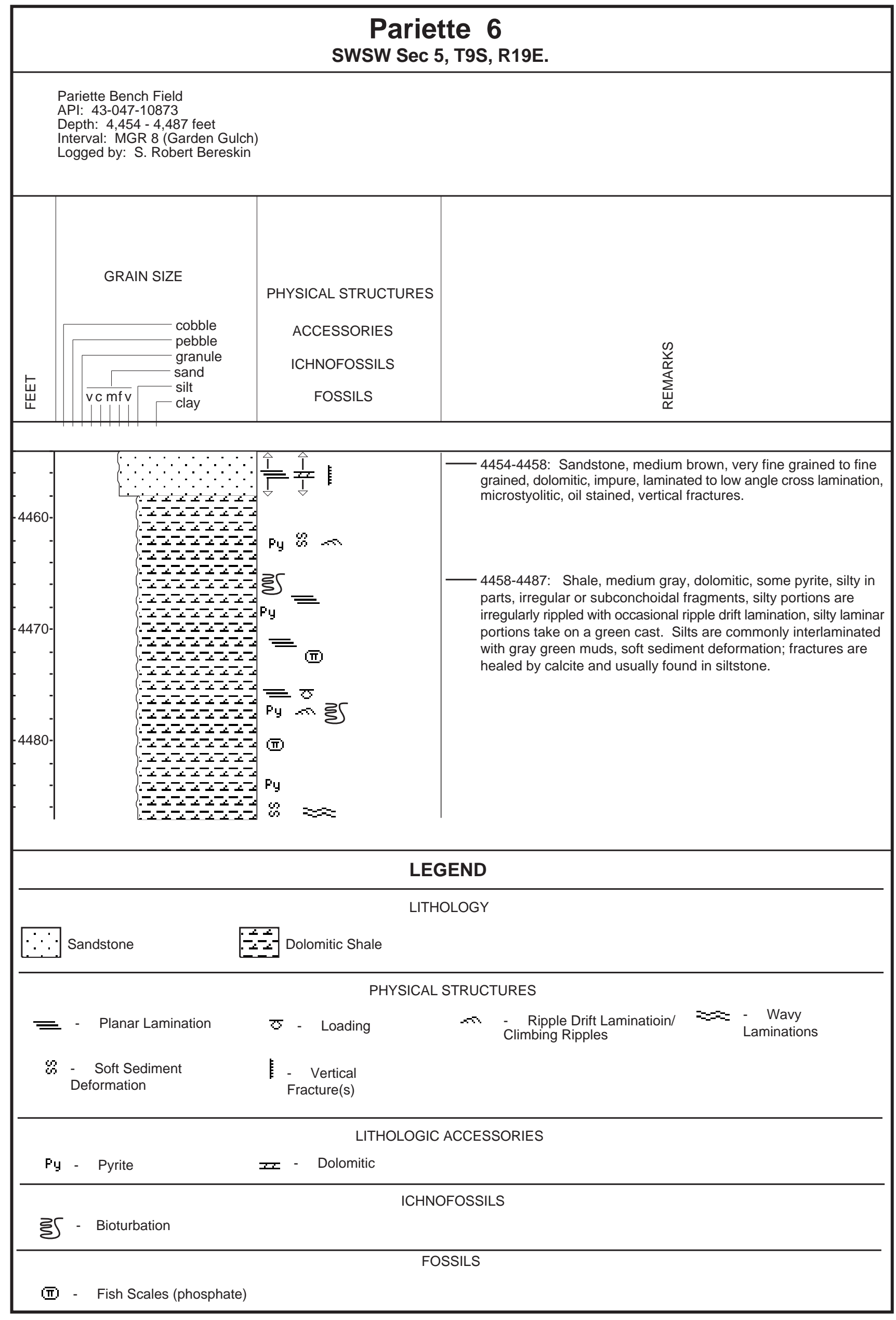




\section{Pariette 6 \\ SWSW Sec 5, T9S, R19E.}

Pariette Bench Field

API: 43-047-10873

Depth: $4,867-4,894$ feet

Interval: MGR 3 (lower Douglas Creek)

Logged by: S. Robert Bereskin

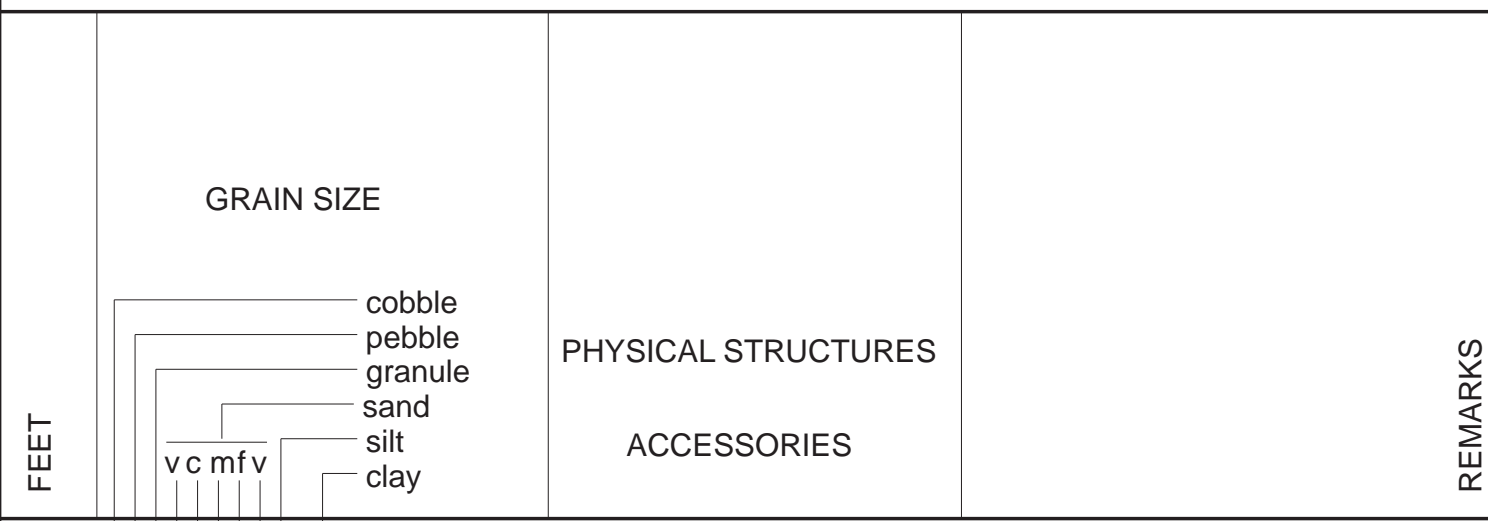

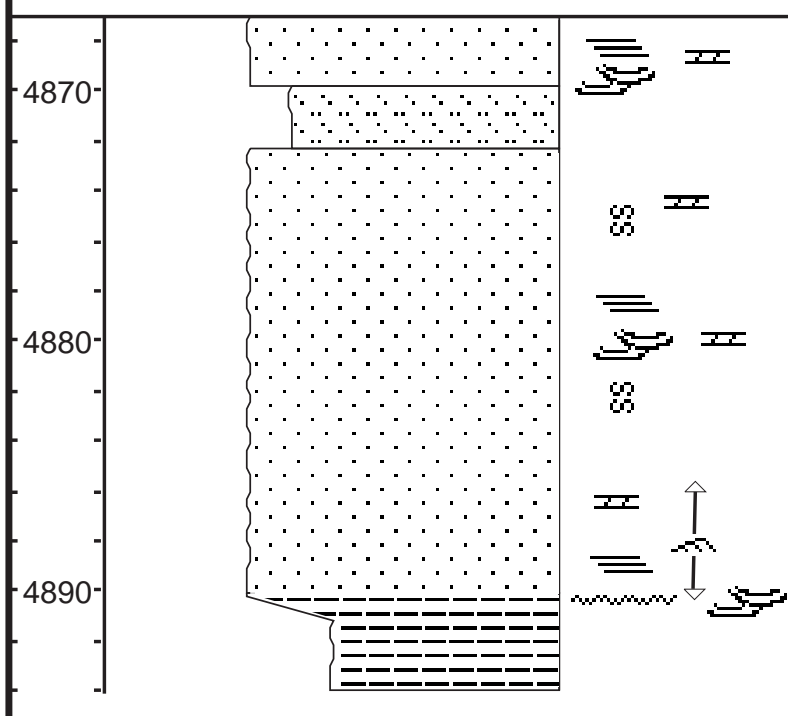

4867-4890: Sandstone, medium brown, very fine to fine grained, oil stained, laminated to low angle cross lamination, microstylolitic. More silt from 4870-4872 with some very fine grained sandstone, dolomitic in part, questionable erosional contact at 4875 (soft sediment deformation) and at 4890 feet. Silt to mud transition.

4890-4894: Mudstone, dark brown gray to medium gray.

\section{LEGEND}

\section{LITHOLOGY}

$\because \because$ Sandstone $\quad\left[\begin{array}{lll}\because \because & \ddots \\ \because & \ddots & \text { Silty Sand }\end{array}\right.$

\section{PHYSICAL STRUCTURES}

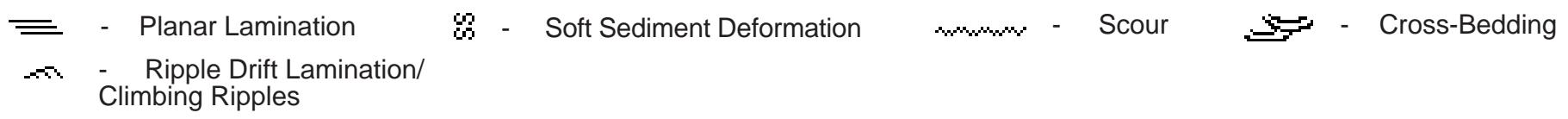




\section{Pariette 6 \\ SWSW Sec 5, T9S, R19E.}

Pariette Bench Field

API: 43-047-10873

Depth: 5,046 - 5,080 feet

Interval: MGR 3 (lower Douglas Creek)

Logged by: S. Robert Bereskin
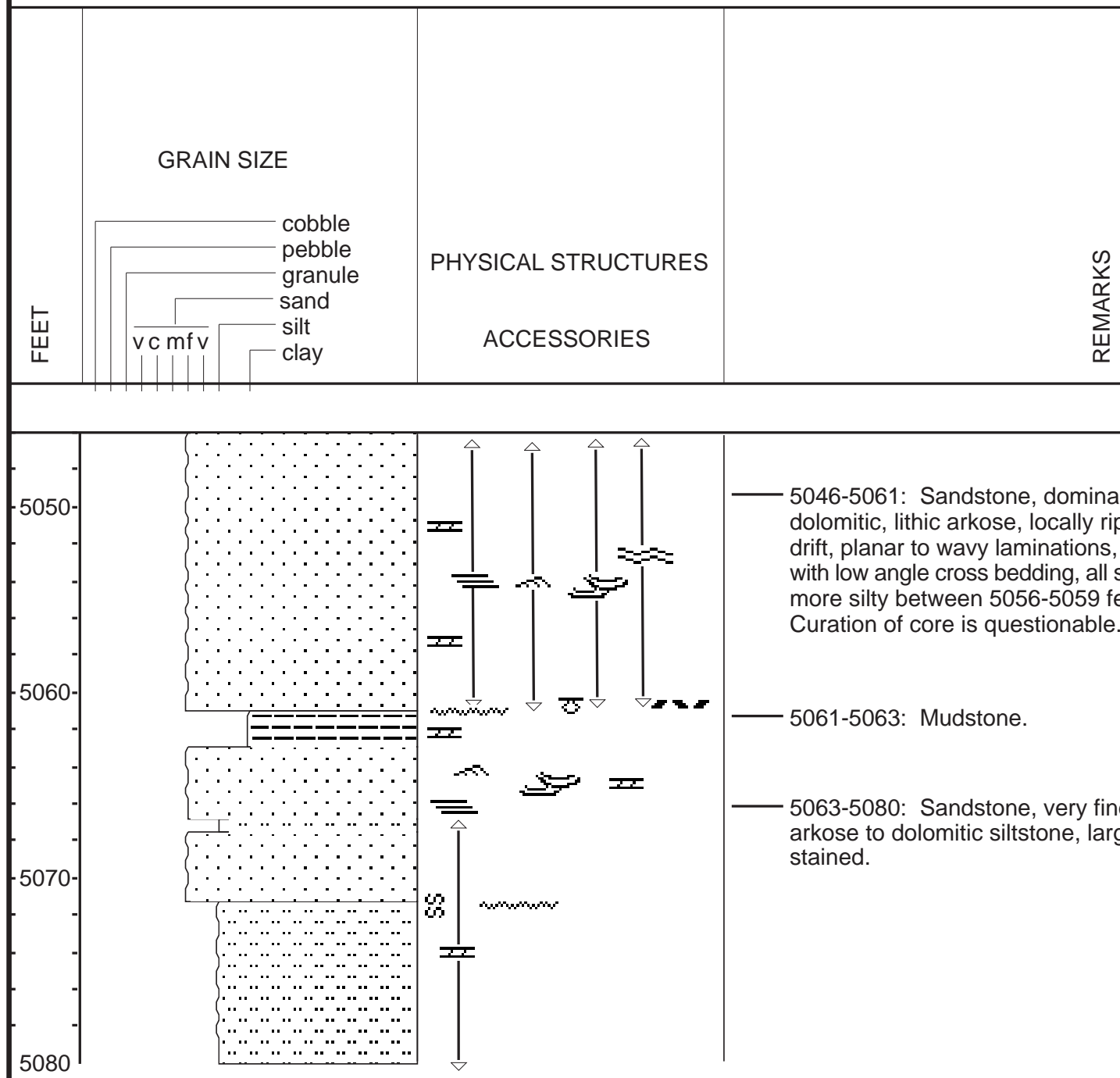

5046-5061: Sandstone, dominantely very fine to fine grained, dolomitic, lithic arkose, locally rippled and cross bedded, ripple drift, planar to wavy laminations, other portions contain lamination with low angle cross bedding, all sandstone is oil stained. Becomes more silty between 5056-5059 feet, channel lag at 5061 feet. Curation of core is questionable.

\section{LEGEND}

5061-5063: Mudstone.

5063-5080: Sandstone, very fine to fine grained, dolomitic lithic arkose to dolomitic siltstone, large slump fold at 5071 feet, oil stained.

\section{LITHOLOGY}

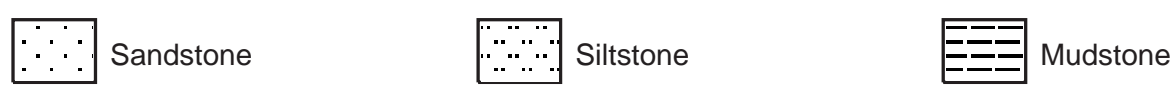

PHYSICAL STRUCTURES

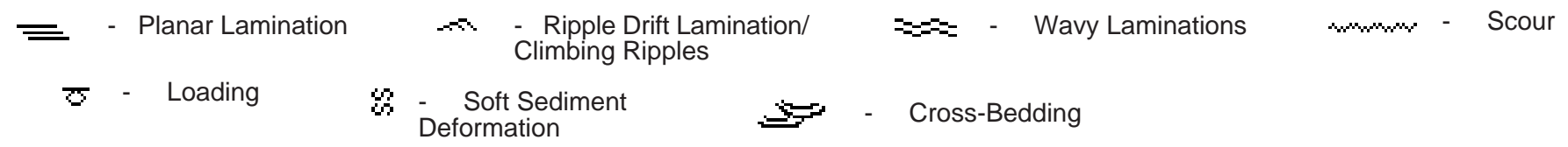

- $=$ - Rip Up Clasts 


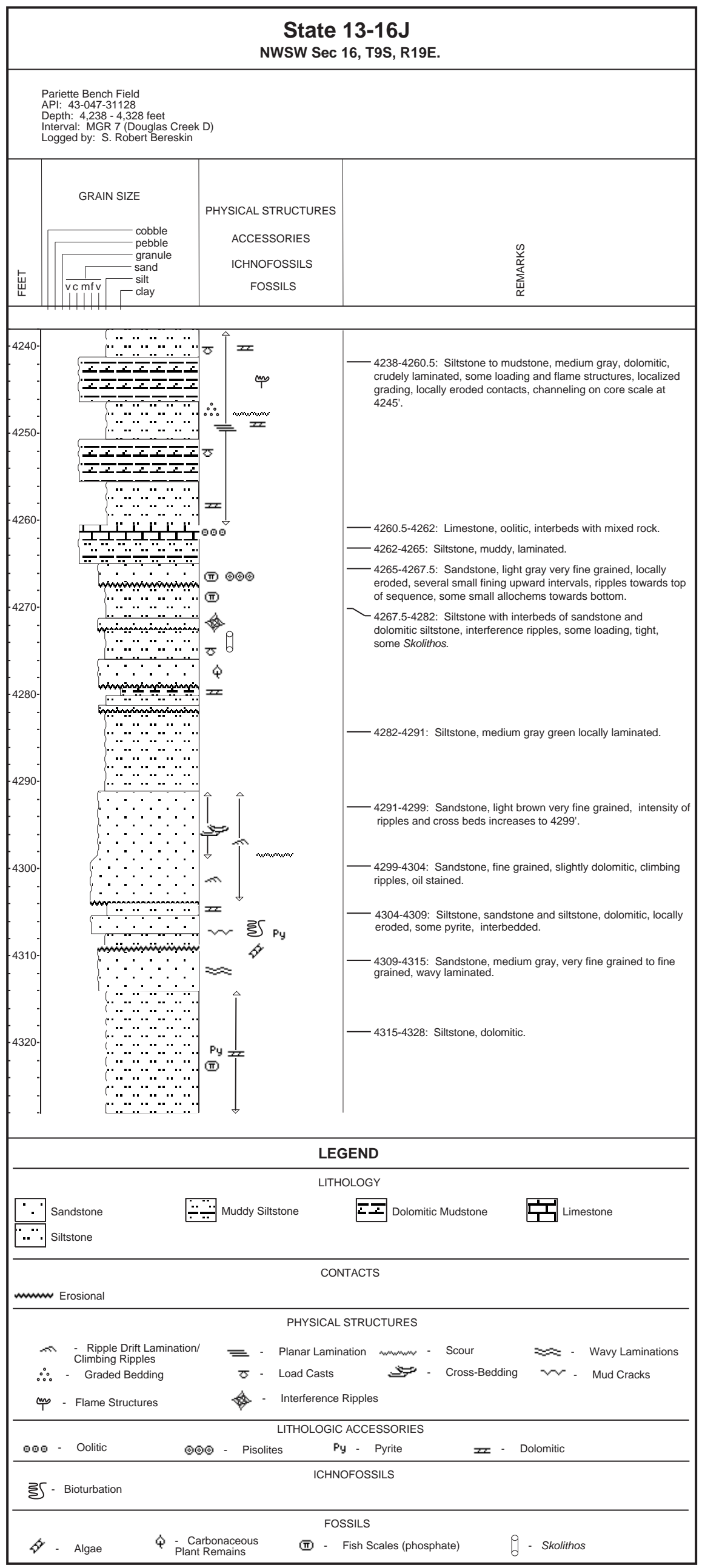




\section{State 13-16J}

NWSW Sec 16, T9S, R19E.

Pariette Bench Field

API: 43-047-31128

Depth: $5,350-5,385$ feet

Interval: LGR 3 (Uteland Butte Limestone)

Logged by: S. Robert Bereskin

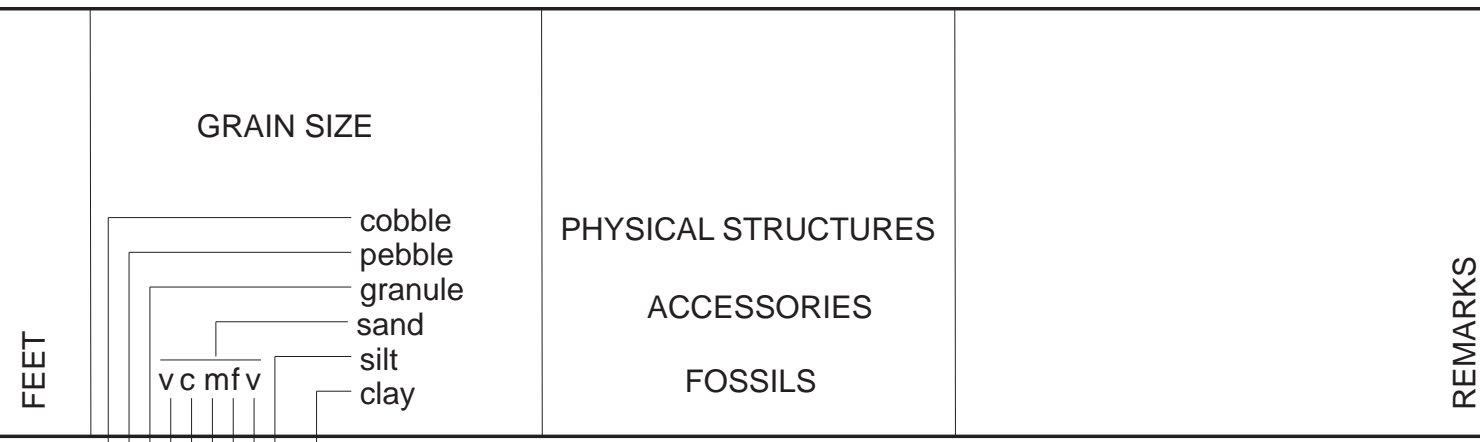

-

5350-5354: Mudstone, medium dark gray, calcareous .

5354-5362: Sandstone, light brown to brown gray, very fine to fine grained, impure, laminated, dolomitic, grading to rippled silty sandstone, with loading features. Fining upward sequence.

5362-5385: Mudstone, medium dark gray, calcareous (black shale facies?). Some very fine grained sandstone and mudstone interbeds, fish scales (phosphate), pyritic in part.

\section{LEGEND}

\section{LITHOLOGY}

$\because$ Sandstone Mudstone Siltstone

\section{PHYSICAL STRUCTURES} $\rightarrow \quad$ - Ripple Drift Lamination/ $\equiv \begin{gathered}\text { Planar } \\ \text { Climbing Ripples }\end{gathered}$

$\varangle \quad$ - Loading
PHYSICAL STRUCTURES

= Dolomitic Py - Pyrite

\section{FOSSILS}

$\Leftrightarrow-$ Molluscs $\quad$ (II) - Fish Scales (phosphate)




\section{State 6-32}

SENW Sec 32, T8S, R17E.

Monument Butte Field

Gilsonite water-flood unit

API: 43-013-30748

Depth: 5,042 - 5,052.8 feet

Interval: MGR 5 (Douglas Creek C)

Logged by: S. Robert Bereskin
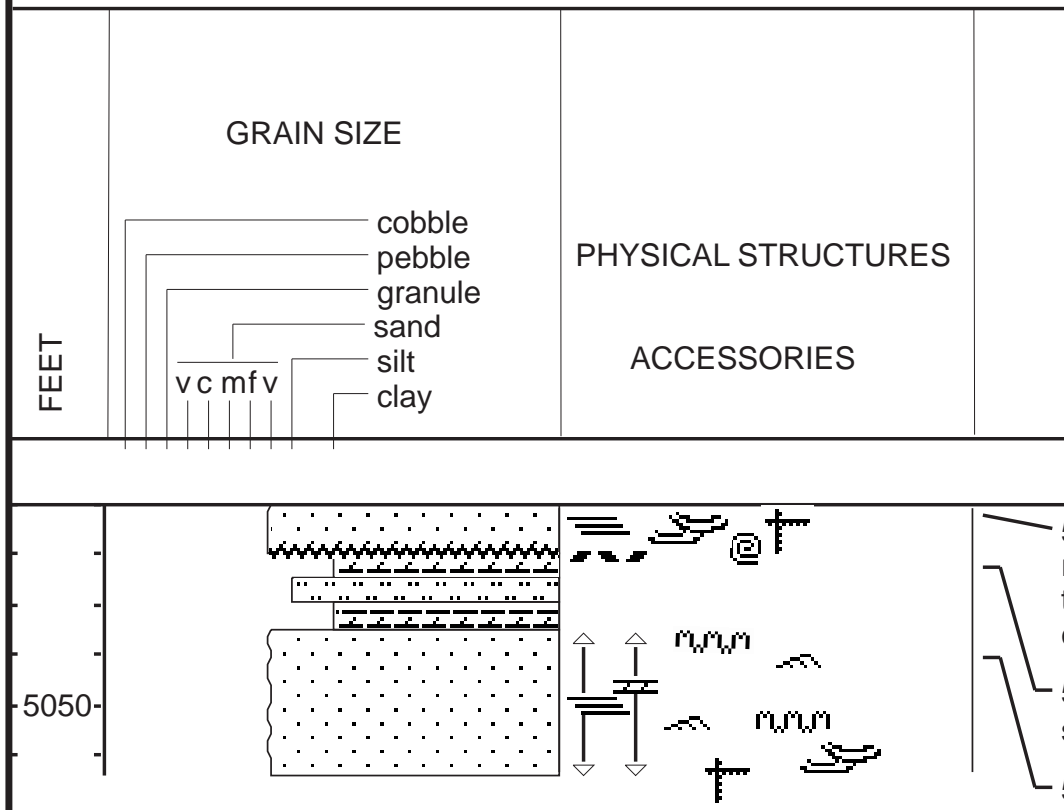

5042-5044: Sandstone, very fine to fine grained, parallel laminated reservoir, passes downward to chaotic zone of mixed tight very fine to fine grained sandstone with abundant dolomitic mud rip-ups, channel base at erosional contact, natural fractures calcite lined.

5044-5047: Mudstone, medium green gray, dolomitic, and siltstone, medium green gray .

5047-5052.8: Sandstone, very fine to fine grained, parallel lamination to ripple drift laminations, oil stained except at very top, dolomitic, microstylolitic in part, local rip up zone, possible natural fracture at base.

\section{LEGEND}

\section{LITHOLOGY}

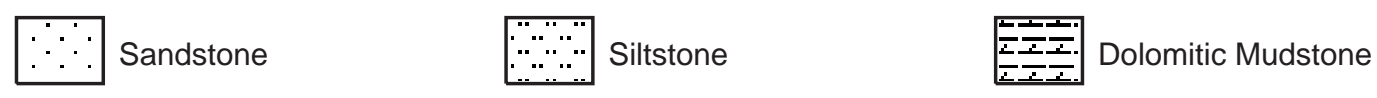

\section{CONTACTS}

myms Scoured

\section{PHYSICAL STRUCTURES}

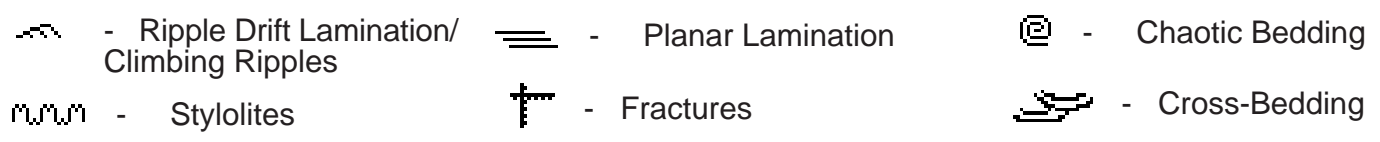

\section{LITHOLOGIC ACCESSORIES}

프 - Dolomitic

z- $\quad$ - Rip Up Clasts 


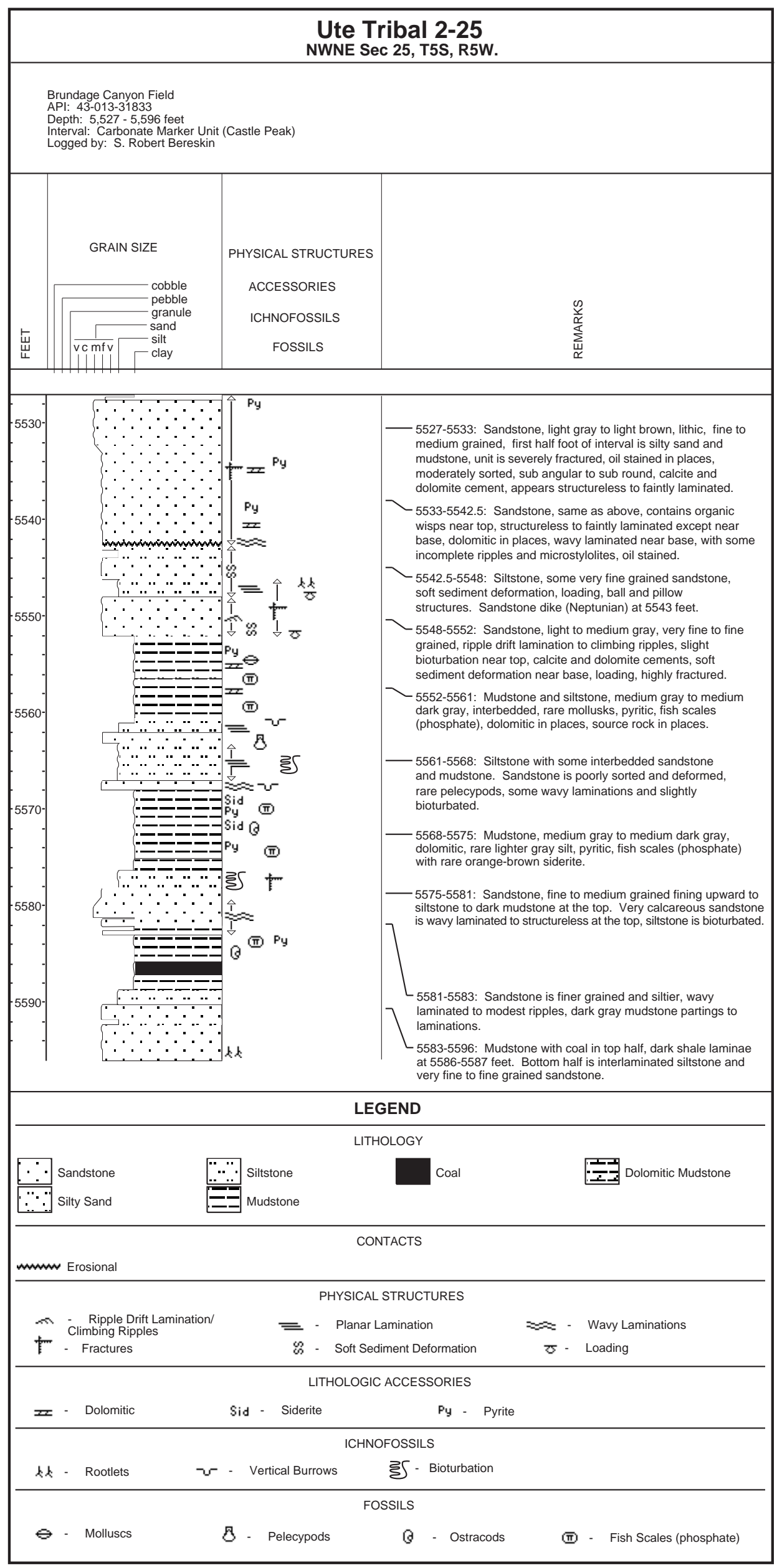




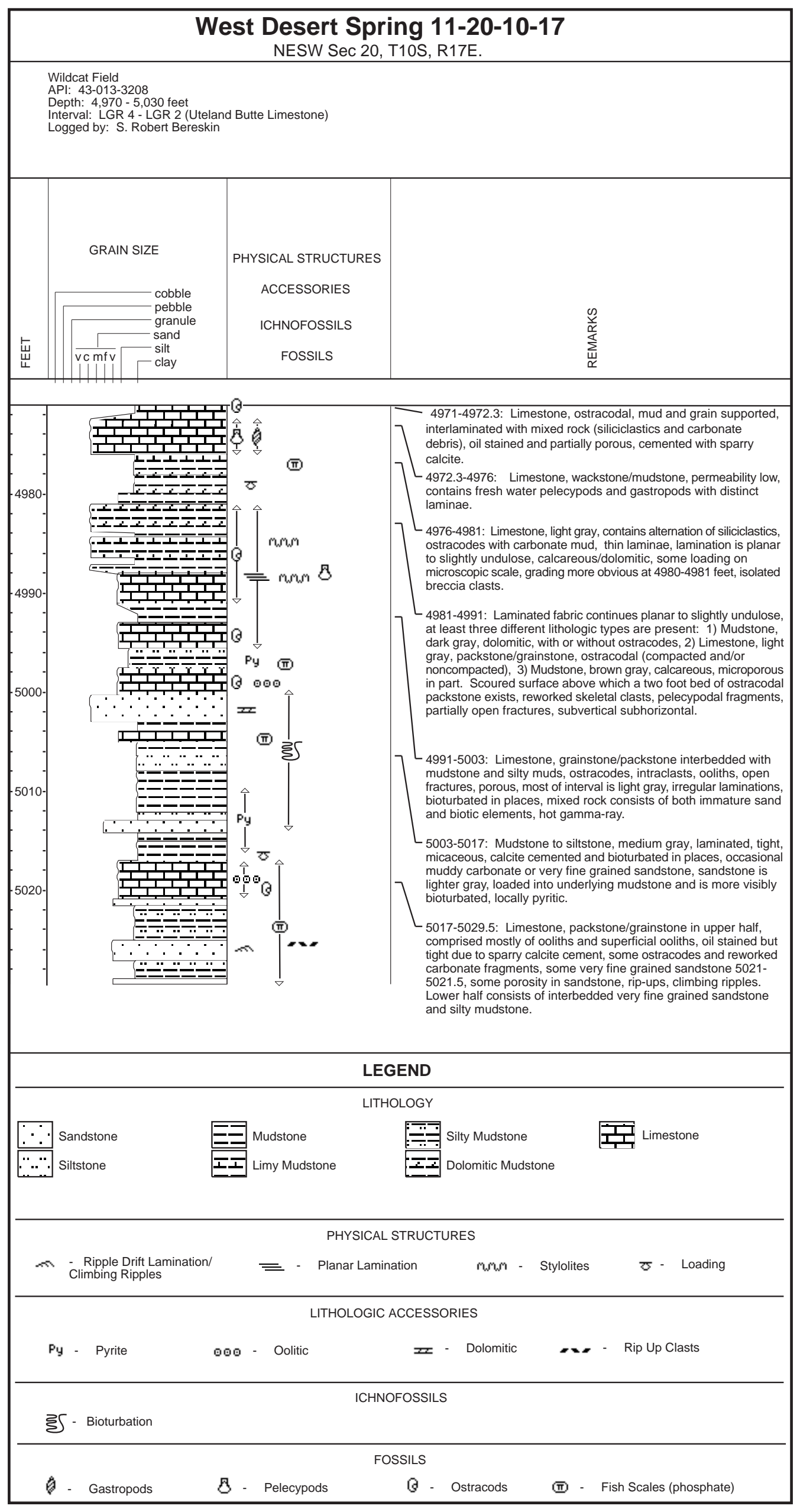




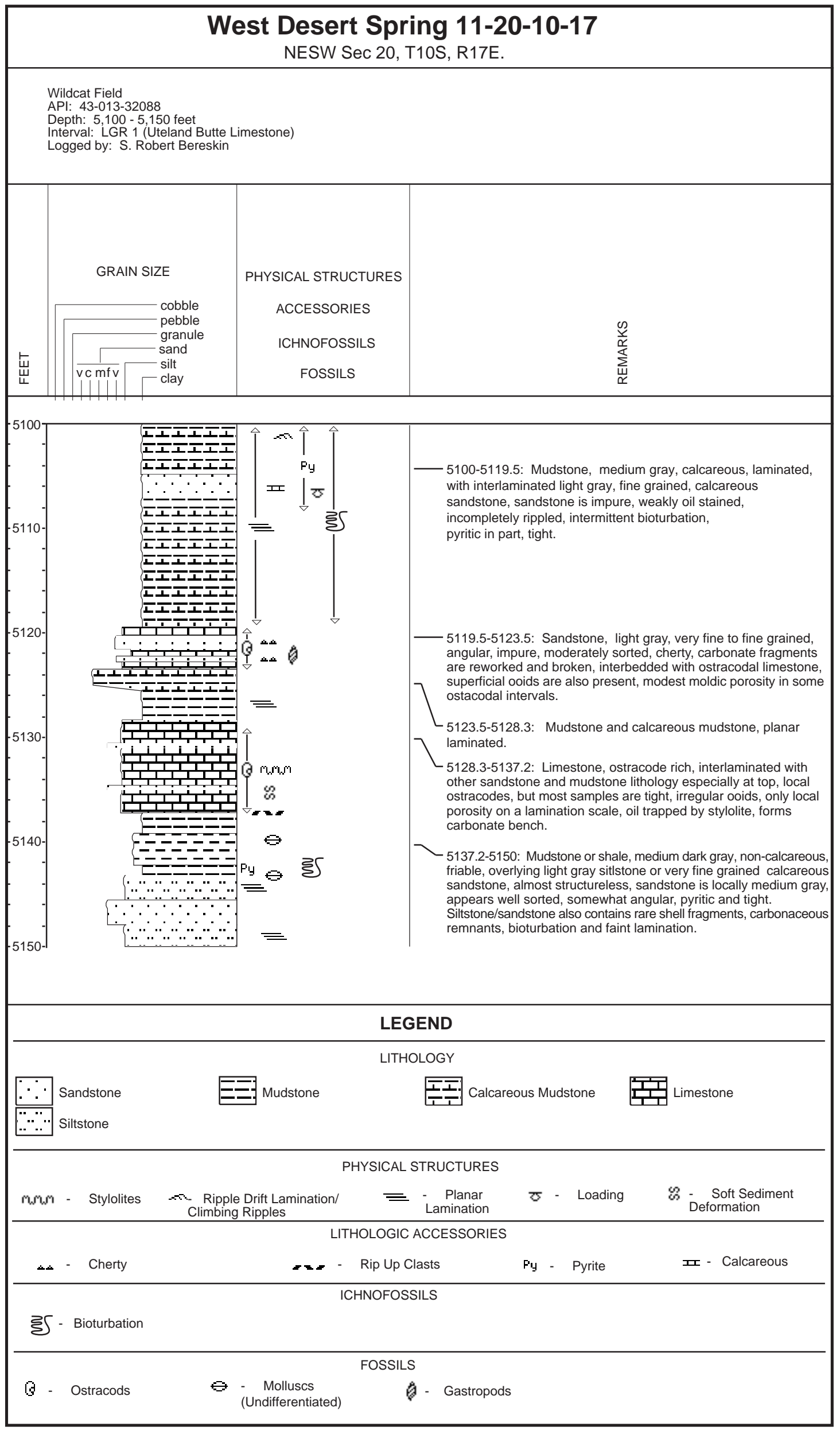




\section{West Monument 10-28 NWSE Sec 28, T8S, R16E.}

Monument Butte Field

API: 43-013-30856

Depth: 5,586 - 5,602 feet

Interval: MGR 3 (lower Douglas Creek)

Logged by: S. Robert Bereskin

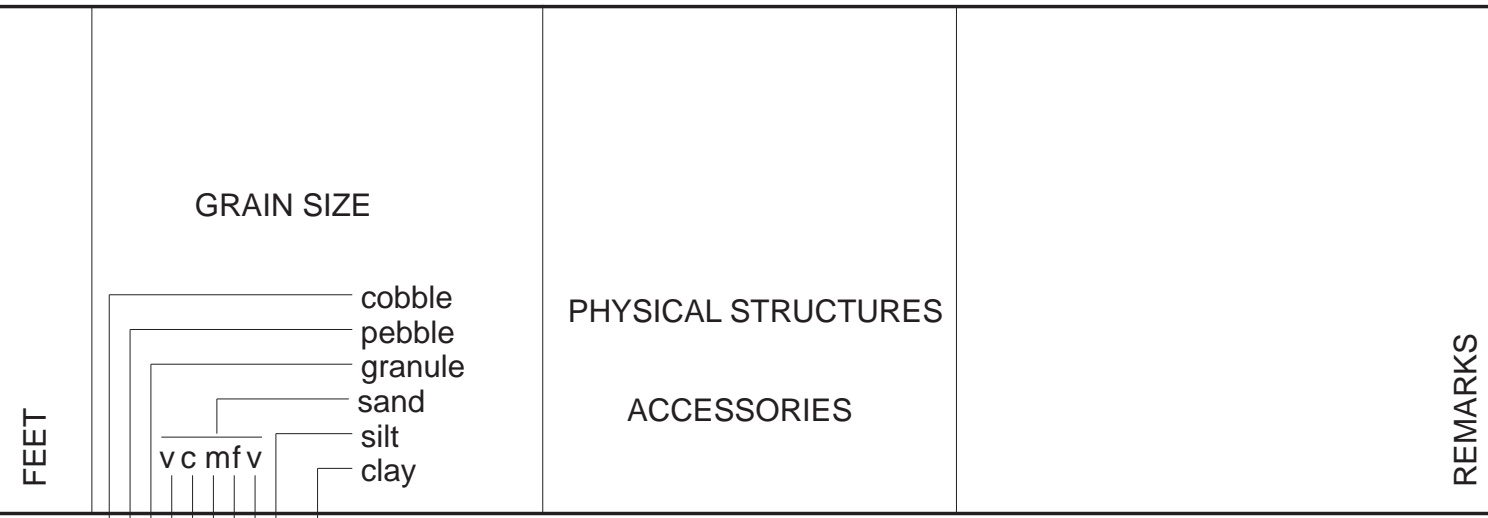

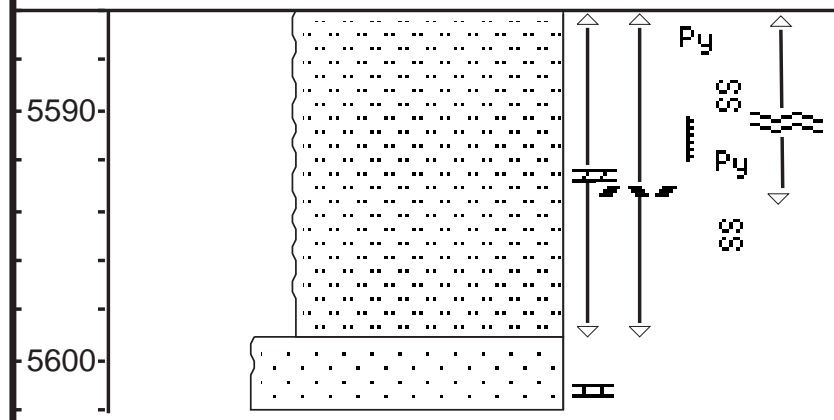

\section{LEGEND}

5599-5602: Sandstone, very fine grained, oil stained, localized siltstone in part, mudstone wisps, calcareous in part.

\section{LITHOLOGY}

\begin{tabular}{|c|c|c|}
\hline$\because \therefore$ & Sandstone & 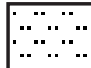 \\
\hline
\end{tabular}

PHYSICAL STRUCTURES

$\$$ - Vertical Fracture(s) $\quad \mathscr{G}-$ Soft sediment deformation $\quad=3-$ Wavy

LITHOLOGIC ACCESSORIES

프 - Calcareous $\quad$ Py - Dolomitic Pyrite $\quad$ - Rip Up Clasts

